\title{
Medidas de Protección Social para la Adopción de Dietas Sanas y Accesibles en América Latina y el Caribe
}

\section{Una revisión de la Literatura}

Patricia Biermayr-Jenzano, PhD 


\section{CONTENIDOS}

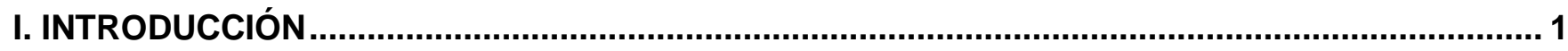

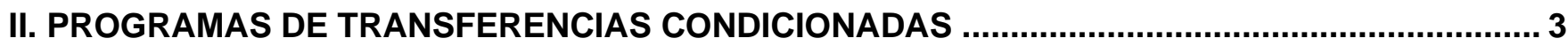

EVOLUCION DE LOS PROGRAMAS DE TRANSFERENCIAS CONDICIONADAS ........................ 3

MARCO DE IMPLEMENTACION DE LOS PROGRAMAS DE TRANSFERENCIA CONDICIONADA

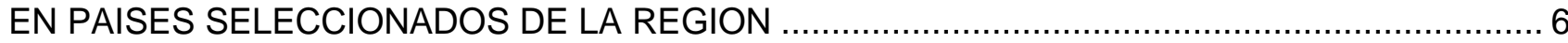

DESCRIPCION DE LOS PROGRAMAS DE TRANSFERENCIAS CONDICIONADAS ................... 8

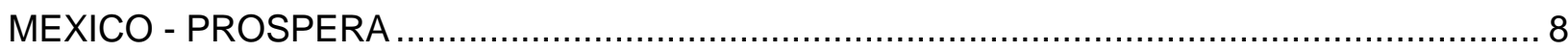

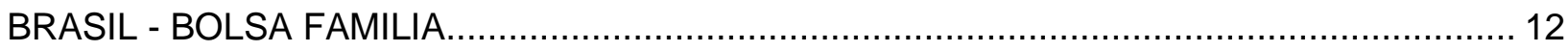

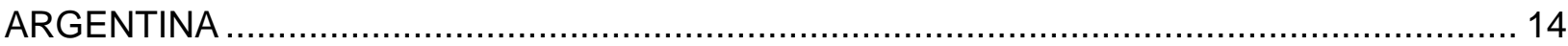

TARJETA ALIMENTARIA 2020 DEL PLAN ALIMENTAR............................................. 14

PROGRAMA DE ASIGNACIÓN UNIVERSAL POR HIJO (AUH) ...................................... 15

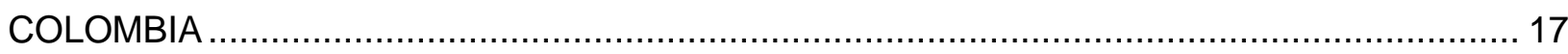

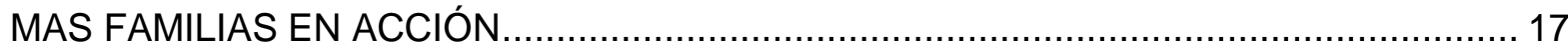

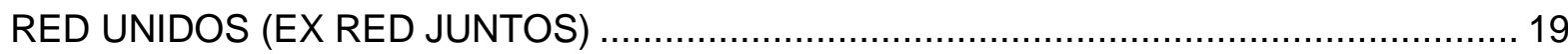

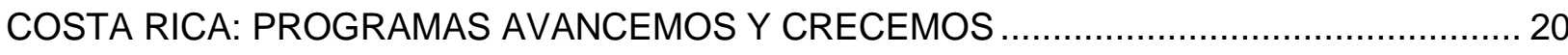

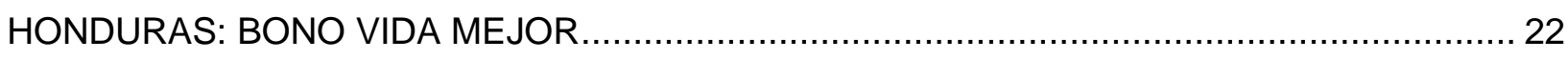

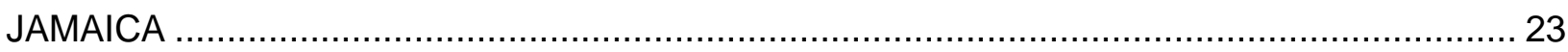

PROGRAMME OF ADVANCEMENT THROUGH HEALTH AND EDUCATION (PATH) .... 23

III. DESCRIPCION DE PROGRAMAS DE ALIMENTACION EN PAISES DE AMERICA LATINA ...... 25

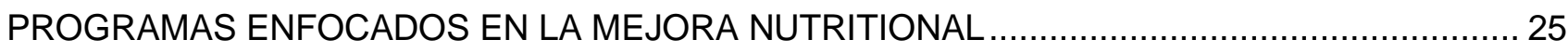

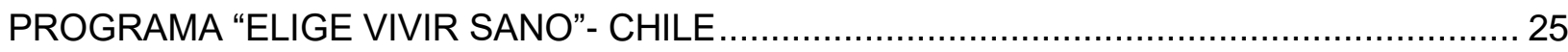

SABORES ANDANTES -PROGRAMAS INNOVATIVOS DE ALIMENTACION ADECUADA -

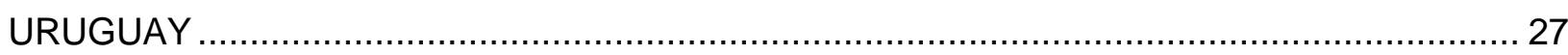

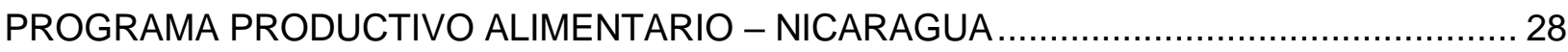

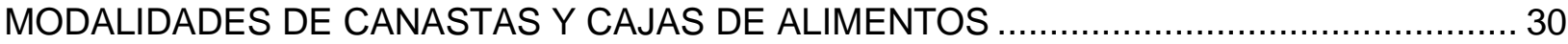

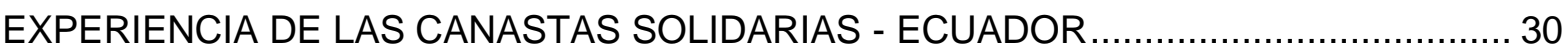

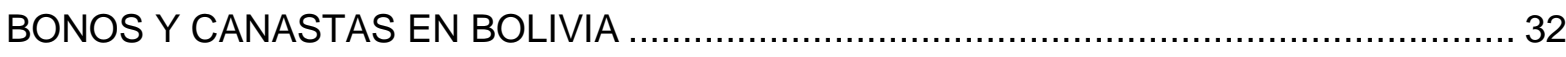

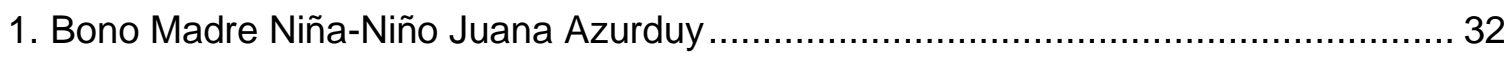


2. Canastas y Aportes de Asociaciones Locales......................................................... 33

CANASTAS ALIMENTARIAS PARA ADULTOS MAYORES - MEXICO …................................ 35

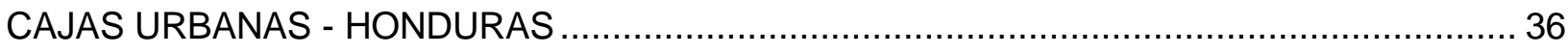

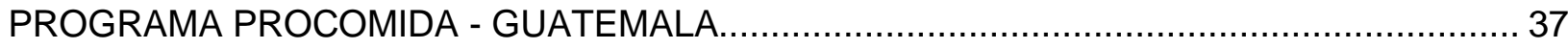

COMEDORES POPULARES “COCINANDO PARA LA SALUD” - PERÚ ................................. 38

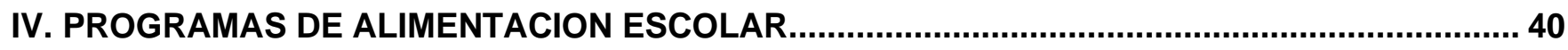

V. REFLEXIONES SOBRE PROGRAMAS DE PROTECCIÓN SOCIAL Y LA OFERTA DE ALIMENTOS SANOS Y VARIADOS EN LAC REGIÓN ........................................................... 51

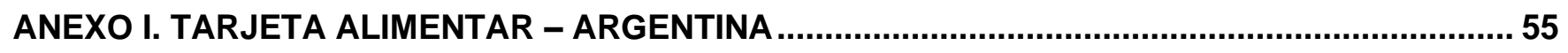

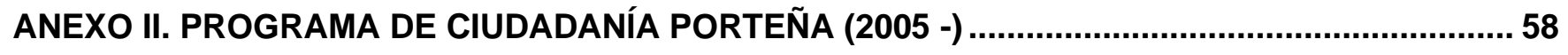

ANEXO III. DIMENSIONES Y LOGROS BÁSICOS de la red unidos - COLOMBIA ......................... 62

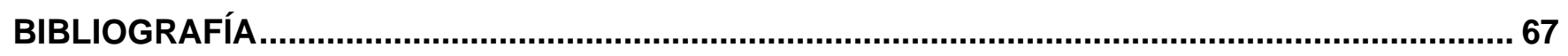

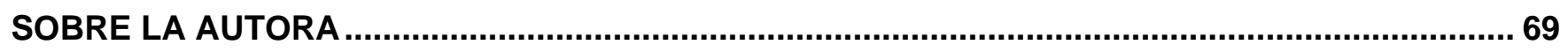

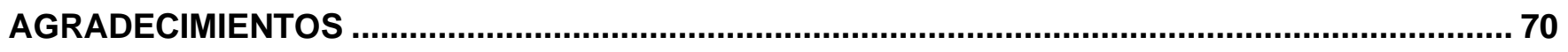

\section{GRÁFICOS}

Gráfico 1. Número de PTC en América Latina y el Caribe por año, Periodo 1996-2015 ................. 4

\section{CUADROS}

Cuadro 1. Programas de transferencias condicionadas en América Latina y el Caribe, según

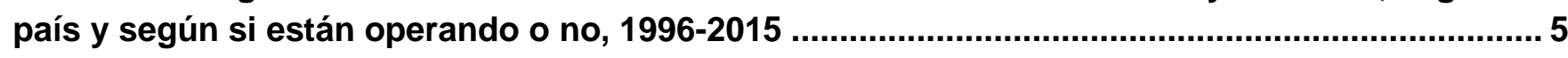

Cuadro 2. Programas de Transferencia Condicionada Concluidos .................................................... 6

Cuadro 3. Prospera. Programa de Inclusión Social (2014-2019) ..................................................... 11

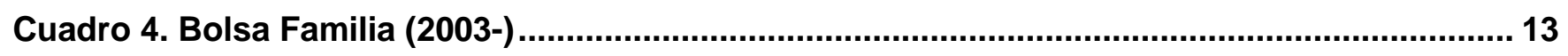

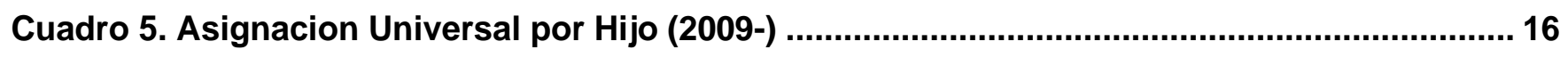

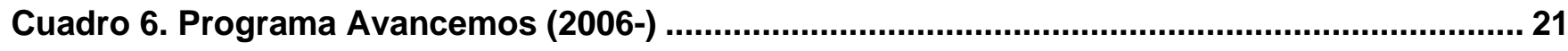

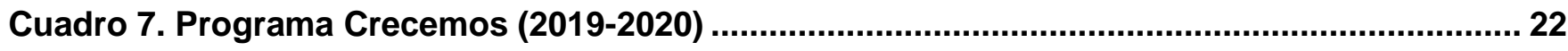

Cuadro 8. Programme of Advancement Through Health and Education (PATH) (2001-) .............. 24 
Cuadro 9. PROGRAMAS DE COMPLEMENTACION ALIMENTARIA ESCOLAR EN PAISES

SELECCIONADOS DE AMERICA LATINA.

\section{CAJAS}

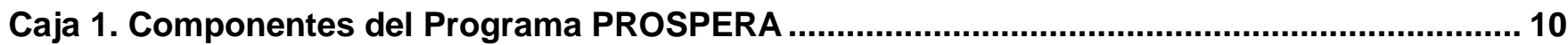

Caja 2. Detalle de Beneficios y pautas para acceder al programa Mas Familias en Acción (2001-). 


\section{INTRODUCCIÓN}

América Latina es el continente que se ha movilizado en forma consistente en cuanto al desarrollo, la adopción e implementación de estrategias de protección social que cubren aspectos de salud, nutrición, educación y trabajo entre otros factores de importancia básica para el desarrollo equitativo de la población de la región. La existencia de programas de transferencias condicionadas como así también de alimentación escolar o programas con metas específicas de alimentación dedicada a la niñez, la mujer lactante o personas de la tercera edad, tienen ya una profunda raigambre en la región con un reconocido impacto y en muchos casos se habla de estos programas en una segunda generación en determinados países (Adato \& Hoddinott 2010; Bastagli, et al 2018; Takahashi, 2017). Todos los países en la región han adoptado estrategias de apoyo a las poblaciones más vulnerables con mayor o menor éxito (Stampini \& Tornarolli, 2012), como parte de sus políticas de desarrollo integral. A pesar de la adopción e implementación de estas medidas, América Latina aun presenta un elevado porcentaje de su población con problemas de malnutrición (por desnutrición o sobrealimentación) lo cual hace que estos programas sean de una importancia central teniendo en cuenta además una variedad de modalidades como ser váuchers o bonos, tarjetas alimentarias y transferencias monetarias ( $\mathrm{Hi}$ drobo et al, 2014) como así también su implementación en espacios o lugares estratégicos (escuelas y comedores escolares, centros de salud, etc.) donde se reciben los servicios que de este modo facilitan su adopción.

Si bien América Latina y el Caribe ha mejorado los niveles de desarrollo socioeconómicos en las últimas dos décadas (Vásquez \& Uribe 2019) ${ }^{1}$, la inseguridad alimentaria en la región (2018-2019) afectaba a un 6.9\% de los hombres contra el $8.4 \%$ de las mujeres. Estos porcentajes implican aproximadamente 15 millones de hombres y 19 millones de mujeres que sufren de inseguridad alimentaria severa en todas sus formas. Durante el período 2016-2018 la prevalencia de la inseguridad alimentaria grave fue de $10 \%$ entre las mujeres adultas, mientras que para los hombres fue de 8,3\%. En tanto la prevalencia de la inseguridad alimentaria moderada 0 grave para las mujeres fue de $29,9 \%$ y para los hombres de $24,8 \%$. En términos absolutos, esto significa que 69,1 millones de mujeres adultas sufren de inseguridad alimentaria moderada o grave, en comparación con los 54,9 millones de hombres ${ }^{2}$. De acuerdo con la Organización Mundial de La Salud (OPS) alrededor del $58 \%$ de la población están afectadas además por el sobrepeso y un $23 \%$ sufren de obesidad. De este total, el $58 \%$ de hombres contra un $60.1 \%$ de las mujeres se ven afectadas por el sobrepeso y la obesidad. ${ }^{3}$ Con respecto a la niñez, se han establecido mejoras remarcables en desnutrición en las últimas décadas pasando de casi

\footnotetext{
${ }^{1}$ Vásquez Russi, Catalina María and Uribe Gómez, Mónica, Los estudios sobre los programas de transferencias monetarias condicionadas en América Latina: trayectorias, enfoques y perspectivas sobre la pobreza (Conditional Cash Transfer Programs in Latin America: Trajectories, Approaches and Perspectives on Poverty) (June 18, 2019). OPERA No. 25, Julio-Diciembre, 2019. Available at SSRN: https://ssrn.com/abstract=3406091

2 OPS/OMS Indicadores Básicos. Situación de la Salud en las Américas.2018.

http://iris.paho.org/xmlui/bitstream/handle/123456789/49511/IndicadoresBasicos2018 spa.pdf?sequence=2\&isAllowed=y\&ua=1 (SOFI 2019)

${ }^{3}$ FAO, IFAD, UNICEF, WFP and WHO. 2019. The State of Food Security and Nutrition in the World 2019. Safeguarding against economic slowdowns and downturns. Rome, FAO. http://www.fao.org/3/ca5162en/ca5162en.pdf
} 
14 millones de niños y niñas (WFP 2017) ${ }^{4}$ afectados por ese problema en la década de los '90 a menos de la mitad, unos 6.1 millones en 2015. Pero, por otra parte, existen estimaciones indicativas (FAO 2018) que establecen que en América Latina el sobrepeso afecta al 7,7\% de los niños y niñas; en el Caribe, al 7,2\% (aunque sería más alto el porcentaje sin contar Haití); y en Mesoamérica al 6,4\%. ${ }^{5}$ Estos valores superan el promedio mundial de $5.6 \% .{ }^{6}$

Este documento analiza las estrategias de protección social adoptadas en América Latina para hacer frente a las diferentes formas de malnutrición citadas (desnutrición, sobrepeso y obesidad) con énfasis en las siguientes modalidades: 1- Los programas de transferencias condicionadas (PTC); 2- los programas alimentarios incluyendo estrategias de bonos, canastas alimentarias o solidarias, cajas rurales o urbanas y 3 - los programas de alimentación escolar adoptados por los gobiernos de los países de la región para hacer frente a la desnutrición cualquiera fueren sus manifestaciones. Cada modalidad está discutida en una de las secciones siguientes. El documento no pretende hacer una revisión exhaustiva de dichos programas, sino que intenta establecer en qué medida los programas vigentes presentan enfoques con énfasis en la adopción de dietas sanas y variadas como un elemento importante en la prevención del sobrepeso y la obesidad a través de la adopción de las citadas estrategias de protección social que forman parte del menú de opciones accesible a través de distintas modalidades en los países.

\footnotetext{
${ }^{4}$ WFP. Nutrir el Futuro. (2017) Programas de Alimentación Escolar Sensibles a la Nutrición en América Latina y el Caribe Un Estudio de 16 Países https://docs.wfp.org/api/documents/WFP-0000071367/download/? ga=2.92193818.1462672604.1527517334307212363.1525721785

${ }^{5}$ FAO; PANORAMA 2018 pp. 11: http://www.fao.org/3/CA2127ES/CA2127ES.pdf

${ }^{6}$ FAO-OPS. 2018. Políticas y programas alimentarios para prevenir el Sobrepeso y la Obesidad. Lecciones aprendidas.
} 


\section{PROGRAMAS DE TRANSFERENCIAS CONDICIONADAS}

Los Programas de Transferencias Condicionadas (PTC) para América Latina y el Caribe, tienen como objetivo la contribución y apoyo para la superación de la pobreza, el acceso a la educación y la alimentación adecuada mediante la adopción de dietas sanas a lo largo de los últimos 20 años en la región. De acuerdo al estudio elaborado por Cecchini \& Atuesta (2017) que ofrece un detallado análisis de la extensa base de datos de programas de protección social no contributiva ${ }^{7}$ en América Latina y el Caribe de la Comisión Económica para América Latina y el Caribe (CEPAL), el mismo determina que la cobertura y la inversión de los PTC aumentó en forma considerable durante la década de los 2000, pasando por un período de estabilización luego de 2010, para luego mostrar caídas significativas entre 2014 y 2015. Esta sensible disminución correspondió directamente a bajas de cobertura en dos países, Ecuador y Guatemala durante dicho período. Esta evolución determina que los PTC cubrían un quinto de la población en 2015, alrededor de 132 millones de personas y 30 millones de hogares, con una inversión correspondiente al $0,33 \%$ del PIB regional, es decir 153 dólares per cápita (CEPAL). Posteriormente, desde el año 2016 se observa una subsiguiente baja de cobertura de todos estos programas a nivel regional.

Los PTC a través de su innovador modelo de gestión y mediante la utilización de programas tecnológicamente adecuados, han permitido avanzar sobre los mecanismos que alcanzan a las poblaciones necesitadas desde la política social. Así mismo se han introducido registros de destinatarios y de sistemas de gestión informática (Cecchini, 2013) que han facilitado el seguimiento y la evaluación de estos programas. Se considera que una de las principales contribuciones de los PTC está centrada en reorientar la protección social principalmente hacia la infancia y su desarrollo humano buscando disminuir la pobreza en el corto plazo por medio de las transferencias monetarias directas o el acceso a alimentos, permitiendo sostener niveles básicos de consumo, y en el largo plazo, a través de las mejoras en los niveles de salud y educación de niños y niñas de hogares en situación de pobreza.

\section{EVOLUCION DE LOS PROGRAMAS DE TRANSFERENCIAS CONDICIONADAS}

Actualmente, América Latina y el Caribe en toda la región cuenta con aproximadamente 30 PTC activos en unos 20 países (Cecchini \& Atuesta 2017). La modalidad de transferencias condicionadas presenta diversas formas de implementación además de una amplia cobertura geográfica como se puede ver en países como México (Progresa y Oportunidades) y Brasil (Bolsa Escola, Bolsa Familia) con cifras récord de personas cubiertas por dichos programas y por el otro lado programas de una extensión menor en número de personas cubiertas pero de igual magnitud e importancia en relación la población de cada país como ser los programas que se

\footnotetext{
7 "No contributivas" significa que se financian con ingresos generales de impuestos, mientras que los programas contributivos son en parte financiados con pagos o "contribuciones" de los beneficiarios.
} 
desarrollaron en Centroamérica y el Caribe como por ejemplo: Avancemos (Costa Rica); Mi Bono Seguro (Guatemala); Bono Vida Mejor (Honduras), Mas Familias en Acción (Colombia), Familias por la inclusión social (Argentina), etc. En el Gráfico No.1 se visualiza la progresión de los PCT en un período de 20 años y en el Cuadro No.1 se detallan los PTC en la región además de las fechas de operación de estos, en el Cuadro No.2 se provee una lista de PTC ya concluidos. Un aspecto de sumo interés, y que denota un cambio en la implementación de estos programas, se trata de la tendencia a enfatizar a través de estos el acceso y la selección de alimentos nutritivos y variados a modo de prevenir el incremento de patrones de sobrepeso y la obesidad.

Gráfico 1. Número de PTC en América Latina y el Caribe por año, Periodo 1996-2015

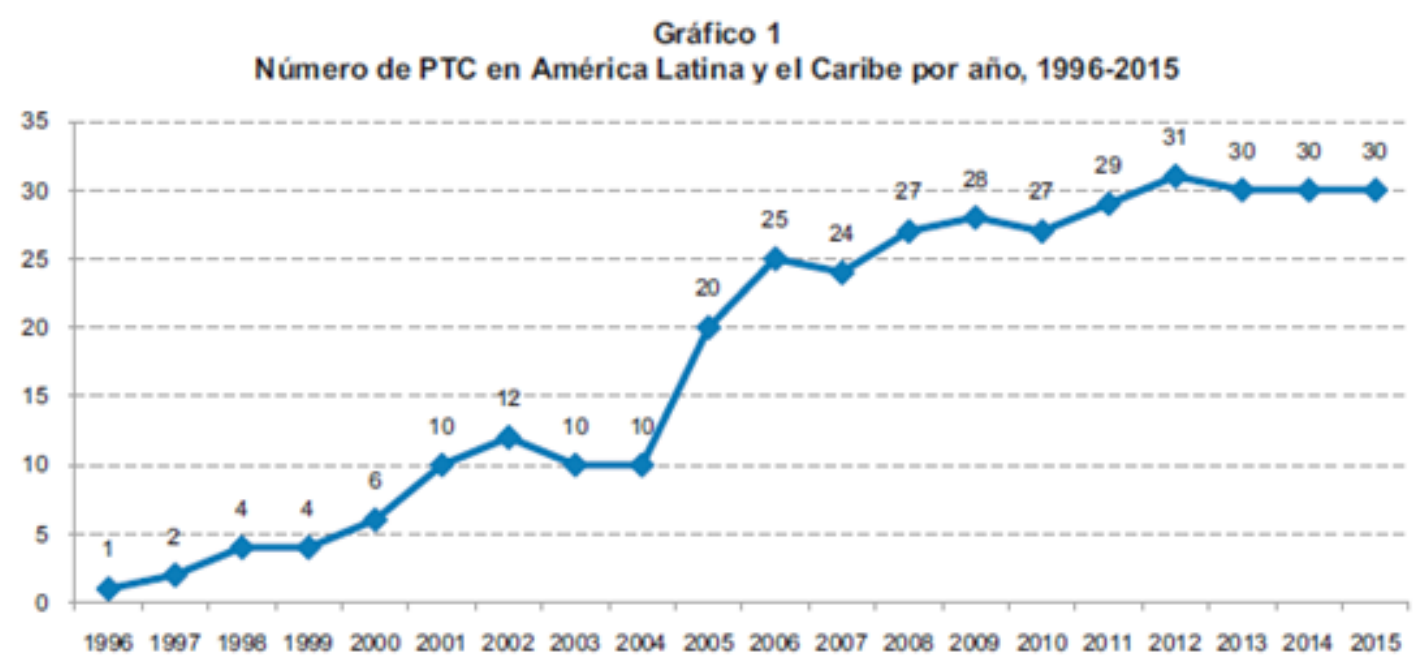

Fuente: Cecchini \& Atuesta, 2017. Los autores elaboran sobre la totalidad de programas de transferencia condicionada en cada año. CEPAL http://dds.CEPAL.org/bdptc/ . 
Cuadro 1. Programas de transferencias condicionadas en América Latina y el Caribe, según país y según si están operando o no, 1996-2015

\begin{tabular}{|c|c|c|}
\hline País & Nombre del programa & Año de inicio \\
\hline Argentina & $\begin{array}{l}\text { Asignación Universal por Hijo para Protección Social } \\
\text { Plan AlimentAR } \\
\text { Programa de Ciudadanía Porteña }\end{array}$ & $\begin{array}{l}2009 \\
2019 \\
2005\end{array}$ \\
\hline Belice & Building Opportunities for Our Social Transformation & 2011 \\
\hline $\begin{array}{l}\text { Bolivia } \\
\text { (Est. Plur, de) }\end{array}$ & $\begin{array}{l}\text { Bono Juancito Pinto } \\
\text { Bono Madre Niño-Niña Juana Azurduy }\end{array}$ & $\begin{array}{l}2006 \\
2009\end{array}$ \\
\hline Brasil & $\begin{array}{l}\text { Programa Bolsa Familia } \\
\text { Programa bolsa Verde } \\
\text { Programa de Erradicação do Trabalho Infantil }\end{array}$ & $\begin{array}{l}2003 \\
2011 \\
1996\end{array}$ \\
\hline Chile & $\begin{array}{l}\text { Chile Solidario/a } \\
\text { Subsistema de Seguridades y Oportunidades (Ingreso Ético Familiar) }\end{array}$ & $\begin{array}{l}2002 \\
2012\end{array}$ \\
\hline Colombia & $\begin{array}{l}\text { Más Familias en Acción } \\
\text { Red unidos }\end{array}$ & $\begin{array}{l}2001 \\
2007\end{array}$ \\
\hline Costa Rica & Avancemos & 2006 \\
\hline Ecuador & $\begin{array}{l}\text { Bono de Desarrollo Humano } \\
\text { Desnutrición Cero }\end{array}$ & $\begin{array}{l}2003 \\
2011\end{array}$ \\
\hline El Salvador & Programa de Apoyo a Comunidades Solidarias en El Salvador & 2005 \\
\hline Guatemala & Mi Bono Seguro & 2012 \\
\hline Haití & Ti Manman Cheri tou nef & 2012 \\
\hline Honduras & Bono Vida Mejor & 2010 \\
\hline Jamaica & Programme of Advancement through Health and Education & 2001 \\
\hline México & Prospera & 2014 \\
\hline Panamá & $\begin{array}{l}\text { Red de Oportunidades } \\
\text { Bonos Familiares para la Compra de Alimentos }\end{array}$ & $\begin{array}{l}2006 \\
2005\end{array}$ \\
\hline Paraguay & $\begin{array}{l}\text { Tekoporã } \\
\text { Abrazo }\end{array}$ & $\begin{array}{l}2005 \\
2005\end{array}$ \\
\hline Perú & Juntos & 2005 \\
\hline República Dominicana & Progresando con Solidaridad & 2012 \\
\hline Trinidad y Tobago & Targeted Conditional Cash Transfer Program & 2006 \\
\hline Uruguay & $\begin{array}{l}\text { Asignaciones Familiares - Plan de Equidad } \\
\text { Tarjeta Uruguay Social }\end{array}$ & $\begin{array}{l}2008 \\
2006\end{array}$ \\
\hline
\end{tabular}

Fuente: Base de datos de programas de protección social no contributiva en América Latina y el Caribe de la CEPAL, Programas de transferencias condicionadas ${ }^{8}$ [en línea]

\footnotetext{
${ }^{8} \mathrm{http}: / / \mathrm{dds} . c e p a l . o r g / b d p t c /$.
} 
A partir de 2012, el principal programa en Chile es el Subsistema de Seguridades y Oportunidades (Ingreso Ético Familiar), sin embargo, a la fecha aún quedan familias que ingresaron al Chile Solidario y siguen participando en ese programa.

\section{Cuadro 2. Programas de Transferencia Condicionada Concluidos}

\begin{tabular}{|c|c|c|}
\hline País & Nombre del programa & Período de Actividad \\
\hline Argentina & $\begin{array}{l}\text { Familias por la Inclusión Social } \\
\text { Plan de Jefas y Jefes de Hogar Desempleados }\end{array}$ & $\begin{array}{l}2005-2010 \\
2002-2005\end{array}$ \\
\hline Brasil & $\begin{array}{l}\text { Programa Bolsa Alimentação } \\
\text { Bolsa Escola } \\
\text { Cartão Alimentação }\end{array}$ & $\begin{array}{l}2001-2003 \\
2001-2003 \\
2003-2003\end{array}$ \\
\hline Colombia & Subsidios Condicionados a la Asistencia Escolar & $2005-2012$ \\
\hline Costa Rica & Superémonos & $2000-2002$ \\
\hline Ecuador & Bono Solidario & 1998-2003 \\
\hline Guatemala & $\begin{array}{l}\text { Mi Familia Progresa } \\
\text { Protección y Desarrollo de la Niñez y Adolescencia Tra- } \\
\text { bajadora }\end{array}$ & $\begin{array}{l}2008-2011 \\
2007-2008\end{array}$ \\
\hline Honduras & Programa de Asignación Familiar & 1998-2009 \\
\hline México & Oportunidades (ex Progresa) & $1997-2014$ \\
\hline Nicaragua & $\begin{array}{l}\text { Red de Protección Social } \\
\text { Sistema de Atención a Crisis }\end{array}$ & $\begin{array}{l}2000-2006 \\
2005-2006\end{array}$ \\
\hline República Dominicana & Programa Solidaridad & $2005-2012$ \\
\hline Uruguay & Plan de Atención Nacional a la Emergencia Social & $2005-2007$ \\
\hline
\end{tabular}

Fuente: Base de datos de programas de protección social no contributiva en América Latina y el Caribe de la CEPAL, Programas de transferencias condicionadas ${ }^{9}$

\section{MARCO DE IMPLEMENTACION DE LOS PROGRAMAS DE TRANSFERENCIA CONDICIONADA EN PAISES SELECCIONADOS DE LA REGION}

La implementación de programas de transferencia condicionadas (PTC) en América Latina se remonta a la década de los 70', particularmente en Brasil a partir de 1975 se crearon distintos programas y si bien compartían similares metas para poblacionales necesitadas, los mismos

\footnotetext{
${ }^{9}$ http://dds.cepal.org/bdptc/
} 
diferían en aspectos tales como la selección de productos y la proporción o monto de las transferencias. Posteriormente ya en 1996 se lanza el Programa de Erradicación del Trabajo Infantil (PETI) y en 1999 el Programa de Garantía de Renta Mínima. En 2001 se creó el PTC Bolsa Escola, cuya administración estaba a cargo del Ministerio de Educación. Brasil presenta una serie de programas en forma consistente poniendo en marcha además sucesivamente los programas Bolsa Alimentação, Cartão Alimentação y Auxilio-Gás los cuales aportaron experiencias positivas en la mayoría de los casos, pero con una alta superposición de acciones y un elevado nivel de segmentación. Para corregir esta situación en 2003 se crea Bolsa Familia que corresponde a la unificación de los diversos programas de transferencia de ingresos sectoriales y locales. Bolsa Familia constituye el PTC más grande en operación en toda la región (Cecchini y Martínez, 2011) ${ }^{10}$.

Si bien Brasil fue pionero en la implementación de programas de transferencias, el primer PTC de alcance nacional en América Latina y el Caribe fue PROGRESA que fue puesto en marcha en México en el año 1997. Este programa debido a su amplia cobertura, la inclusión de aspectos de educación, salud y alimentación lo convierten en un referente trascendental en la región. El programa experimentó cambios en la cobertura e inclusive en su denominación a través del tiempo -los que se detallan a continuación- y está hoy aún vigente desde 2014 bajo el nombre PROSPERA. Actualmente, PROSPERA posibilita la coordinación y la oferta de programas sociales en especial aquellos relacionados con el fomento productivo, generación de ingresos, bienestar económico y la inclusión financiera y laboral.

En Centroamérica la puesta en marcha de dichos programas es notoria desde el año 2000 con el lanzamiento de Superémonos en Costa Rica y la Red de Protección Social en Nicaragua, mientras que, en el Caribe, particularmente en Jamaica se puso en marcha el Programme of Advancement through Health and Education. En Colombia en el año 2001 se inician las operaciones del programa Familias en Acción, hoy este programa ya está en una fase de nueva ejecución bajo el nombre Más Familias en Acción.

Una extensa revisión de la literatura sobre los PTC realizada en IFPRI establece que estos programas (Adato \& Hoddinott 2010), inicialmente se enfocaban en la provisión de váuchers o alimentos, teniendo en cuenta una variedad de resguardos para asegurar que dichos beneficios fueran empleados específicamente en la alimentación. Actualmente, la descripción de los PTC presenta en algunos casos una tendencia a la adopción de alimentos nutritivos y variados, de acceso local de preferencia (para evitar transporte y movilizar la economía local) y también para promover y facilitar una alimentación accesible y adecuada en cuanto al valor calórico y de nutrientes para evitar crecientes problemas a nivel de la región de sobrepeso y obesidad. Se presentan a continuación una compilación actualizada de los PTC más significativos de corriente funcionamiento y operación en la región, en cuanto a su accionar, tipo de cobertura, operacionalización y montos de ayuda ofrecida a la población beneficiaria.

\footnotetext{
${ }^{10}$ Cecchini, S. y R. Martínez (2011), - Protección social inclusiva en América Latina: una mirada integral, un enfoque de derechosll, Libros de la CEPAL, No. 111 (LC/G.2488-P CEPAL), Santiago de Chile, Comisión Económica para América Latina y el Caribe (CEPAL)
} 


\section{DESCRIPCION DE LOS PROGRAMAS DE TRANSFERENCIAS CONDICIONADAS ${ }^{11}$}

Los Programas de Transferencias Condicionadas vigentes en la región prestan especial atención a la ejecución de medidas que enfatizan no solo estrategias de apoyo monetario a poblaciones de bajos ingresos sino también las guías con respecto a la alimentación sana y variada que conforman el menú de opciones de dichos programas para beneficiar a distintos sectores de la población rural y urbana de bajos recursos. Es de destacar que si bien la gran mayoría de estos programas dirigen un particular apoyo al acceso de productos destinados a la alimentación del publico carenciado, no existe la determinación especifica o una guía estandardizada o de referencia a alimentos nutritivos y variados en detalle, sino que en general se abren las opciones a las compras locales (mercados y ferias) para así mismo estimular la economía local.

Si bien el tema de dietas saludables es un aspecto que se menciona en la mayoría de estos programas, la operacionalización y acceso a los mismos para que las familias compren productos saludables, en oportunidades no es tan clara. Además, la gran mayoría de los registros, controles o mecanismo de seguimiento para asegurar que se compren productos saludables se centran en prohibiciones sobre la adquisición de licor o cigarrillos con los váuchers o transferencias monetarias, pero por lo general no hay descripción exacta o sugerida como ser guías que indiquen aquellos alimentos que ayudan a mantener una dieta saludable o el valor calórico de los mismos.

Esta revisión de la literatura presenta una descripción de los Programas de Transferencias Condicionadas en operación en: Argentina, Brasil, Colombia, Costa Rica, Jamaica, Honduras y México. Cuando se adoptan medidas y descripciones específicas sobre alimentación o referencia a desnutrición (por falta o exceso) estos aspectos se detallan en cada uno de los programas. Se incluye, además, cuando esta información es accesible, aspectos sobre la operacionalización del sistema y sus controles.

\section{MEXICO - PROSPERA}

México presenta la evolución de uno de los programas más antiguos y de una extensa cobertura en la región. El gobierno de México comenzó la implementación del Programa de Transferencia Condicionada PROGRESA entre 1997-2001, el cual evoluciono con mejoras y paso luego a llamarse OPORTUNIDADES durante el periodo 2001-2014, para lanzar posteriormente PROSPERA (2014-) o Programa de Desarrollo Humano.

El programa PROGRESA inició su operación en 1997 principalmente en zonas rurales de alta marginación, cubriendo aspectos de Educación, Salud y Alimentación. PROGRESA consistía en aportar transferencias monetarias condicionadas a los hogares estableciendo que los mismos debían cumplir una serie de requisitos en particular: (a) la asistencia a la escuela de

\footnotetext{
${ }^{11}$ El detalle de los programas descriptos está referenciado en la base de datos de "Programas de protección social no contributiva en América Latina y el Caribe": https://dds.cepal.org/bpsnc/ptc
} 
los niños beneficiarios en edad escolar, (b) realizar visitas regulares a las clínicas de salud y (c) la asistencia de las personas titulares del Programa (mujeres) a una serie de talleres de educación sobre alimentación y medidas de salud preventiva entre otros temas. En el año 2001 el Programa es renombrado, pasando a llamarse, OPORTUNIDADES y luego de 17 años de existencia, fue reconocido como un programa social valioso y ejemplar a nivel internacional. La nueva etapa obedeció a un mejoramiento en las prestaciones y a una expansión de su cobertura. En 2014, el Programa se transformó en PROSPERA o Programa de Inclusión Social, cuyo cambio de nombre lleva implícita la necesidad de convertirse en un programa no sólo de transferencias condicionadas sino también que tiende a adoptar importantes bases de inclusión social. Actualmente, el Programa atiende a más de 6 millones de hogares beneficiarios en todo el país.

PROSPRERA continua la modalidad de cobertura nacional de los programas precedentes y su accionar extiende apoyos monetarios sujetos a un incremento cada seis meses de acuerdo con el Índice Nacional de Precios de la Canasta Básica que adopta el Banco de México. La Coordinación Nacional de Prospera Programa de Inclusión Social está a cargo de Secretaría de Desarrollo Social (SEDESOL) como organismo responsable y el organismo ejecutor es la Coordinación Nacional de Prospera que es a su vez también el ente que mantiene un padrón de beneficiarios. Las principales fuentes de financiamiento son el Gobierno de México y el Banco Mundial. La cobertura o estimación del número de personas en hogares perceptores alcanza un récord de 31.245 .838 aproximadamente un $24,13 \%$ de la población (2018). 


\section{Caja 1. Componentes del Programa PROSPERA}

PROSPERA presenta componentes bien definidos ${ }^{12}$ de alimentación, salud y educación -al igual que su antecesor PROGRESA- además de varias líneas de acción ${ }^{13}$ (de inclusión social, productiva, laboral y financiera) como ser:

1- Fomentar la inversión en capital humano de los miembros en edad escolar de las familias más pobres mediante transferencias de efectivo condicionadas a la asistencia regular a la escuela. El programa otorga becas para niñas (os) y jóvenes menores de 18 años inscritos entre tercero de primaria y tercero de preparatoria, becas a jóvenes menores de 23 años con necesidades educativas especiales, además apoyo para acceder a transporte, la adquisición de útiles escolares, incentivos monetarios para apoyar la educación media superior. Posteriormente en 2016 , el programa comienza a ofrecer becas de educación superior en instituciones públicas.

2- Promover el mejoramiento de la salud para las familias pobres mediante la modalidad de transferencias condicionadas en efectivo además de la asistencia a centros de salud. El programa permite el acceso a un paquete básico de salud proporcionando suplementos alimenticios a niños (as) menores de cinco años, también a mujeres embarazadas y en periodo de lactancia. Se incluyen estrategias de educación en referencia al autocuidado de la salud, la prevención de enfermedades y particularmente un énfasis en aspectos de nutrición. Mas recientemente, estos beneficios básicos se han ampliado en consecuencia de la adopción del Seguro Popular Universal para la población atendida bajo la modalidad de PROSPERA con mayores oportunidades de atención relacionadas directamente a aspectos de la salud.

3- Mejorar las condiciones alimentarias de las familias en condición de pobreza, por medio de transferencias monetarias de periodicidad mensual para incentivar el consumo de alimentos en cantidad, calidad nutricional y diversidad adecuada. Se establecen transferencias adicionales para la cobertura de niños (as) hasta los 9 años de edad y también para personas de la tercera edad de 70 años en adelante.

4-Facilita también la posibilidad de vincular a los integrantes de las familias beneficiarias con proyectos de producción, oportunidades laborales además del acceso a servicios financieros.

Fuente: PROSPERA, Teruel, Arenas y Flores. 2014. Gobierno de México.

Si bien PROSPERA es un programa emblemático de un alcance y duración no alcanzada por otros en la región, en los últimos periodos de su implementación ha recibido ciertas críticas que se enfocan en una insuficiente atención con respecto a el empoderamiento económico de las mujeres y niñas (ILO 2017). Este programa presenta una buena cobertura para la niñez con índices que implican notables mejoras para este grupo etario, ayudando de este modo a romper con la pobreza intergeneracional. Aun así, el programa establece que se realizan apoyos de inclusión financiera y laboral, además de aspectos de educación, alimentación y salud dirigidos a la población bajo pobreza extrema. Pero el programa no presenta opciones de empleo u otras formas de apoyo laboral (como ser entrenamiento) y tampoco opciones de acceder a estructuras de apoyo como las guarderías que permiten a las mujeres participantes eventualmente salir del ámbito de cobertura del programa una vez que han encontrado empleo o mejorado su situación perpetuando de esta manera una dependencia con el mismo.

\footnotetext{
12 Graciela Teruel; Erika Arenas y Karla Renata Flores. Coordinación Nacional de PROSPERA Programa de Inclusión Social y la Universidad Iberoamericana, A.C. México. 2014. www.gob.mx/PROSPERA

${ }^{13}$ PROPERA. ACUERDO por el que se emiten las Reglas de Operación de PROSPERA Programa de Inclusión Social, para el ejercicio fiscal 2015. DOF: 30/12/2014

http://dof.gob.mx/nota detalle.php\%3Fcodigo\%3D5377725\%26fecha\%3D30/12/2014\&print=true
} 
Cuadro 3. Prospera. Programa de Inclusión Social (2014-2019)

Características

Año

2018

Presupuesto

MXN\$

82.729.888.797

USD\$

4.298.920.183

\%PIB / GDP

$0,35 \%$

\section{Cobertura de personas}

Estimación del número de personas en hogares perceptores

31.245 .838

\% Población

$24,13 \%$

Fuente: CEPAL.org y elaboración propia

Para asegurar el consumo de "alimentos saludables" en cantidad, calidad nutricional y diversidad adecuada, la operacionalización de PROSPERA consta de 14 componentes, de los cuales solo cuatro componentes ${ }^{14}$ tratan el tema de alimentación saludable, en su mayoría desde el punto de vista de la corresponsabilidad y sin especificar una lista de alimentos adecuados, diversos y de cierta calidad nutricional. Los cuatro componentes establecen los siguiente:

COMPONENTE 1: APOYO ALIMENTARIO: Para todas las familias del Programa. Las familias de este componente pueden ser parte de los esquemas de apoyos con y sin corresponsabilidad. Alimentación: Destinar apoyos correspondientes a alimentación del hogar y consumir suplementos nutricionales. Las familias beneficiarias cuentan con los beneficios del Programa de Abasto Social de Leche, pudiendo adquirir productos lácteos a un bajo costo y de alto valor nutricional.

COMPONENTE 4: SUPLEMENTOS ALIMENTICIOS: Destinado a niños/as de 4 a 23 meses, niños/as entre 2 y 5 años con problemas de desnutrición y mujeres embarazadas/en lactancia (hasta por 1 año). Descripción: Suplemento nutricional de consumo diario presentado en dos versiones -Nutrisano- y -Nutrivida- que aporta hasta el 100\% de los micronutrientes diarios requeridos, y el $20 \%$ promedio de las necesidades calóricas diarias. Son elaborados en 3 sabores diferentes. A través de la Estrategia Integral de Atención a la Nutrición (EsIAN), se entregan cada dos meses nuevos suplementos alimenticios para combatir la desnutrición de la población beneficiaria.

COMPONENTE 9: APOYO ALIMENTARIO -vivir mejor-: Para todas las familias del Programa. Alimentación: Destinar apoyos correspondientes a alimentación del hogar y consumir suplementos nutricionales.

\footnotetext{
${ }^{14}$ Fuente: CEPAL 14 Componentes de PROSPERA https://dds.cepal.org/bpsnc/programa?id=92
} 
COMPONENTE 10: APOYO INFANTIL -vivir mejor-: Destinado a hijos/as entre 0 y 9 años. Las familias de este componente pueden ser parte de los esquemas de apoyos con y sin corresponsabilidades. Alimentación: Destinar apoyos correspondientes a alimentación del hogar y consumir suplementos nutricionales

\section{BRASIL - BOLSA FAMILIA}

Brasil presenta el PTC de mayor cobertura en toda la región, Bolsa Familia ${ }^{15}$. Como se explicó con anterioridad, Bolsa Familia se originó en parte por la fusión de Bolsa Escola con una cobertura para escolares 6-15 años pertenecientes a familias pobres y Bolsa Alimentación que presentaba una cobertura destinada a familias en extrema pobreza con niños/niñas entre 0-6 años y también a mujeres embarazadas. Desde 2003 a la fecha el programa se constituye como el programa más emblemático en Sudamérica dada su extensión y su ejecución se basa en tres líneas principales que incluyen: 1- Transferencias monetarias como suplemento de ingresos y paliativo inmediato para el alivio a la pobreza; 2- Acceso a derechos e inclusión social mediante la mejora de aquellas condiciones que permitan a las familias salir del ciclo de la pobreza y 3- la articulación con otros programas o acciones de apoyo a las familias en condición de pobreza extrema.

Los programas que se desarrollaron y articularon paralelamente a Bolsa Familia incluyen el Programa de Erradicación del Trabajo Infantil (PETI) aun en ejecución, el Programa Tarjeta de Alimentación de una cobertura federal a través de transferencias de ingresos relacionados a la seguridad alimentaria y el Programa Bolsa Verde (2011-2018) que inicialmente cubría con exclusividad la Región de la Amazonia Legal (9 estados) para luego en 2012 comenzar su expansión al resto del país. El Programa Bolsa Verde, fue destinado principalmente a aquellas familias en extrema pobreza que desarrollaran actividades de conservación ambiental y de recursos naturales favoreciendo a aquellas de estrato rural principalmente. ${ }^{16}$

Bolsa Familia presenta una gestión descentralizada lo cual implica que los estados, el Distrito Federal y los municipios están involucrados en su ejecución mientras que el ente responsable a nivel federal es el Ministerio de Ciudadanía, El Ministerio de Desenvolvimiento Social e Combate a Fome (MDS), la Secretaría Nacional de Renda de Ciudadanía (SENARC) y el Conselho Gestor do Programa Bolsa Familia (CGPBF). El financiamiento de Bolsa Familia, que en 2019 fue de casi 8,5 Billones de dólares presentando una cobertura de 57.229.083 personas pertenecientes a los hogares receptores de este beneficio. Bolsa Familia es financiado por el Gobierno Federal de Brasil y el Banco Mundial.

El programa Bolsa Familia presenta una serie de ocho componentes o lineamientos de implementación que incluyen alimentación y el acceso a suplementos nutricionales y minerales como

\footnotetext{
${ }^{15}$ Fuente: Base de datos de programas de protección social no contributiva en América Latina y el Caribe. CEPAL Brasil: https://dds.cepal.org/bpsnc/ptc

${ }^{16}$ El programa Bolsa Verde es parte del plan estratégico "Brasil sin Miseria" oficialmente reconocido como "Programa de Apoyo a la Conservación Ambiental" cuyo objetivo es fomentar la conservación, mediante el cuidado y el uso sostenible de los ecosistemas ambientales. El organismo responsable de su ejecución es el Ministerio de Medio Ambiente, con el financiamiento del Tesoro Nacional de Brasil.
} 
un importante componente para la mejora alimentaria y nutricional de las familias beneficiarias. De acuerdo con la CEPAL los ocho componentes de Bolsa Familia son:

“1. Bono Básico, 2. Bono variable, 3. Bono variable adolescente, 4. Bono variable embarazadas, 5. Bono variable niños lactantes (corresponsabilidades: Cumplimiento del calendario de vacunaciones de los niños/as y los controles nutricionales peso y talla al día). 6. Bono para la Superación de la Extrema Pobreza, 7. Programa de Atención Integral a la Familia (PAIF) y finalmente 8. Brasil Carinhoso: destinado a niños/as entre 0 y 6 años en familias en situación de extrema pobreza por medio de entrega de dinero y de suplemento nutricional (Hierro y vitamina A). ${ }^{17}$ “

Cuadro 4. Bolsa Familia (2003-)

2018

29.974.727.387

8.203.656.284

57.075 .896

$26,82 \%$

2019

33.070.493.349

8.420.579.220

\section{Cobertura personas}

Estimación del número de personas que viven en hogares perceptores

\% Población

Fuente: CEPAL y elaboración propia

Con respecto a la "alimentación saludable" de los 8 componentes ${ }^{18}$ citados por el programa, solo dos tratan el tema de alimentación y son el componente 5 desde el punto de vista de la corresponsabilidad y el componente 8, desde la forma de transferencia, ninguno de estos componentes especifica una lista de alimentos adecuados, diversos y de calidad nutricional:

COMPONENTE 5: BONO VARIABLE NIÑOS LACTANTES. Se enfatiza el cumplimiento del calendario de vacunaciones de los niños/as y los controles nutricionales (peso y talla) al día. Además, se otorga un pago a las familias con ingresos mensuales de hasta $R \$ 178.00$ por persona y que tienen hijos de entre 0 y 6 meses en su composición, para fortalecer la alimentación del bebé, incluso en los casos en que el bebé no vive con la madre. Son seis entregas al mes. Para que el beneficio sea concedido, el niño debe tener sus datos incluidos en el Registro Único hasta el sexto mes de vida. El beneficio variable vinculado a nutrición es de $\mathrm{R} \$ 41^{19}$.

\footnotetext{
${ }^{17}$ Fuente de datos CEPAL.org Brasil https://dds.cepal.org/bpsnc/ptc

${ }^{18}$ Los Componentes de Bolsa Familia (8) se detallan en https://dds.cepal.org/bpsnc/programa?id=6

${ }^{19}$ Fuente: Bolsa Familia http://mds.gov.br/assuntos/bolsa-familia/o-que-e/beneficios/beneficios cuya fecha de publicación es 01/07/2015.
} 
COMPONENTE 8: BRASIL CARINHOSO: Destinado a niños/as entre 0 y 6 años en familias en situación de extrema pobreza, la transferencia se realiza a través de entrega de dinero y de suplemento nutricional (Hierro y vitamina $A$ ).

\section{ARGENTINA}

\section{TARJETA ALIMENTARIA 2020 DEL PLAN ALIMENTAR.}

La Tarjeta Alimentaria forma parte del Plan Argentina Contra el Hambre (Plan AlimentAR), que fue puesto en marcha en diciembre de 2019. Este programa apoya el fortalecimiento de las acciones que lleva adelante la promoción y mejora del acceso a la canasta básica de alimentos ${ }^{20}$.

El programa AlimentAR está destinado en principio a cubrir a madres y padres de niños de entre 0 y 6 años, embarazadas a partir del tercer mes, y discapacitados, que no pueden alcanzar la canasta alimentaria básica y que reciben la Asignación Universal por Hijo (AUH). También se prevé una ayuda excepcional para jubilados, pensionados y titulares de la AUH mediante un bono de $\$ 2000$ y otro bono de $\$ 5000^{21}$. La tarjeta alimentaria funciona en forma similar a cualquier tarjeta de débito bancaria pero solo puede ser utilizada para comprar alimentos y no para extraer dinero en efectivo. Operativamente se trata de una tarjeta emitida por el Banco de la Nación Argentina (BNA). La tarjeta se recarga todos los meses (el tercer viernes del mes) acreditando el monto de $\$ 4000$ para familias con 1 hijo y $\$ 6000$ para familias con 2 o más hijos. Se prevé en un futuro ampliar la cobertura a más personas como quienes cobran la jubilación mínima, pensionados, y otros sectores con necesidades alimentarias no cubiertas ${ }^{22}$.

La Administración Nacional de la Seguridad Social (ANSES) es el organismo que notifica al titular que está en condiciones de retirar su tarjeta por el banco que determine cada provincia y estas notificaciones se realizan vía telefónica o por SMS. La tarjeta permite comprar alimentos sanos y nutritivos por la totalidad del monto asignado, solo está habilitada para comprar alimentos y no admite la posibilidad de adquirir otros productos o bebidas alcohólicas. También se provee de una serie de guías o consejos que determinan una alimentación sana para referirse a la buena calidad de los alimentos que se pueden adquirir por este medio. Esta modalidad de transferencia condicionada no permite que ningún comercio retenga la tarjeta o cobre algún tipo de comisión. Este es un programa de cobertura nacional disponible en la mayoría de las ciudades y provincias de la Argentina a partir de marzo 2020. Es interesante que este nuevo programa de transferencias no reemplaza otros programas ya existentes como la Asistencia Universal por Hijo (AUH), ni es excluyente con otros programas locales urbanos como el de la Ciudadanía Porteña que está en vigencia desde 2005. Se calcula que la Tarjeta AlimentAR inicialmente alcanzara unos dos millones de niños a nivel país. El programa prevé una inversión anual de por lo menos 60 mil millones de pesos, monto que se ajustara a las necesidades con-

\footnotetext{
20 https://www.argentina.gob.ar/argentinacontraelhambre

${ }^{21}$ Valores en Pesos Argentinos

${ }^{22}$ https://www.ayudatramites.com/tarjeta-alimentaria-2020-del-plan-alimentar
} 
cretas de su implementación. En Febrero de 2020, el Estado Argentino otorgó el 70\% de un total de 1.4 millones de tarjetas estipuladas de emisión global en el plan. El $60 \%$ de las compras de la Tarjeta Alimentar están destinadas a la adquisición de alimentos como los productos lácteos, carnes, frutas y verduras por parte de los usuarios. En cuanto a la implementación del programa, lamentablemente no se mencionan mecanismos de control o monitoreo en forma explícita para asegurar la adquisición de estos alimentos, pero se detallan una serie de recomendaciones y consejos sobre la elección de dietas sanas en forma exhaustiva ${ }^{23}$ (Ver Anexo No.1). Este programa se ha ejecutado en la provincia de Buenos Aires (conurbano bonaerense) y las provincias de Santa Fe, Entre Ríos, Tucumán, Chaco, Santa Cruz mientras que las provincias de Jujuy y Mendoza comenzaran la implementación del programa en forma subsiguiente y de allí en más otras localidades durante el corriente año.

A continuación, se detalla el Programa de Asignación Universal por Hijo (AUH), también de carácter nacional, pero al mismo tiempo existen programas más localizados como el Programa de Ciudadanía Porteña que se implementa en la Ciudad Autónoma de Buenos Aires (CABA) y que está en vigencia desde 2005. Las características y el alcance de la implementación de este programa más local se describen en el ANEXO No.2

\section{PROGRAMA DE ASIGNACIÓN UNIVERSAL POR HIJO (AUH) ${ }^{24}$}

El programa de Asignación Universal por Hijo $(\mathrm{AUH})^{25}$, es un programa de cobertura de carácter nacional que tiene comienzo en el año 2009 hasta la fecha con el objetivo de mejorar la calidad de vida y el acceso a la educación de niños, niñas y adolescentes, a través de transferencias de ingresos con énfasis en garantizar el derecho a la protección social ${ }^{26}$. Esta es una asignación mensual por hasta 5 hijos menores de 18 años. Pueden acceder a este beneficio tanto padres o madres (aunque existe preferencia de otorgamiento a las madres) que cobran mensualmente y deben presentar una vez al año el documento de identidad de cada hijo/a. Del monto total de dicho beneficio el $80 \%$ se otorga mensualmente y el $20 \%$ restante en forma anual con la presentación de la Libreta de Asignación Universal que acredita que se han cumplido con las condicionalidades de educación y salud. En referencia a educación, se controla la asistencia escolar de los niños y niñas entre 5 a 18 años. En cuando a salud, existen dos grupos meta, los niños/niñas menores de 5 años quienes deben cumplir con el esquema de vacunación y controles de salud. El segundo grupo lo constituyen los menores entre 5 a 18 años que igualmente deben mantener un esquema de vacunación completo y además estar inscriptos en el programa SUMAR de Salud Pública ${ }^{27}$ que hace énfasis en la gestión sanitaria y en la

\footnotetext{
${ }^{23}$ En la página web https://www.argentina.gob.ar/argentinacontraelhambre/preguntasfrecuentes\#12 el programa AlimentAR sugiere una completa lista de alimentos saludables.

${ }^{24}$ Ministerio de Economía y Finanzas Publicas. Secretaria de Política Económica. Nota Técnica No.23 Asignación Universal por Hijo en la Argentina. Nota Técnica Perteneciente al Informe Económico No. 70. Cuarto Trimestre. 2009. Argentina. https://www.economia.gob.ar/peconomica/informe/notas tecnicas/23\%20NOTA\%20TECNICA\%20Empleo\%20e\%20Ingresos\%20inf\%2070.pdf

${ }^{25}$ Asignación Universal por hijo para Protección Social 2009 https://dds.cepal.org/bpsnc/programa?id=162

${ }^{26}$ ANSES https://www.anses.gob.ar/asignacion-universal-por-hijo

${ }^{27}$ EI Programa SUMAR es de alcance nacional a través del Ministerio de Salud de la Nación y brinda cobertura a la población materno-infantil, niños/as y adolescentes de 6 a 19 años y a las mujeres y hombres hasta los 64 años. http://www.msal.gob.ar/sumar/index.php/institucional/programa-sumar-mas-salud-publica
} 
mejora de la calidad de atención de la salud. Las condicionalidades de salud deben ser acreditadas por un profesional matriculado.

La forma de acceso a los beneficios del Programa AUH es por medio de una tarjeta de débito. Los montos otorgados son los mismos para todo el país con una variación única para la llamada Zona 1 para quienes residen en las provincias de La Pampa, Chubut, Neuquén, Río Negro, Santa Cruz, Tierra del Fuego, Antártida e Islas del Atlántico Sur y el Partido de Patagones (provincia de Buenos Aires). ${ }^{28}$ Desde mayo del 2011, se incrementó la cobertura de este programa con la inclusión de la Asignación Universal por Embarazo con intención de contribuir a la disminución de la mortalidad infantil en menores de 1 año y a mejorar la calidad del proceso de embarazo, parto y puerperio. En 2015 se suma además a este programa, la Ayuda Escolar Anual (AEA), cuya modalidad está destinada a la cobertura de cada hijo/a en edad escolar. El Organismo responsable de la distribución, así como de la selección de posibles integrantes es la Administración Nacional de la Seguridad Social (ANSES). Existe además una previsión para los extranjeros residentes en el territorio argentino que pueden optar a los beneficios de la Asignación Universal por Hijo (AUH) acreditando un mínimo de tres años de residencia definitiva en el país.

A pesar del énfasis del Programa AUH en cuando a la salud y las ramificaciones con otros programas, no hay referencias explicitas en cuanto a una alimentación adecuada, ni al consumo de dietas saludables en su articulación con los entes de salud, ya sea a través del desarrollo central del programa o en alguno de sus componentes.

Cuadro 5. Asignación Universal por Hijo (2009-)

\section{Presupuesto}

ARS\$

USD\$
2018

89.696 .700 .000

3.192.622.410

$0,62 \%$

\%PIB / GDP

3.994 .424

$8,97 \%$

Hombres

Mujeres

Fuente CEPAL ${ }^{29}$, Elaboración propia

\footnotetext{
${ }^{28}$ Los valores generales (expresados en pesos) son para todo el país, con una variación en la Zona 1. Vigencia: desde 01/09/2019 al 31/12/2019.

${ }^{29}$ https://dds.cepal.org/bpsnc/ptc
} 
Es importante mencionar que fuera de estos programas vigentes, también se pusieron en marcha programas de carácter oficial que ya han cumplido su ciclo como ser el programa: Jefas y Jefes de Hogar Desocupados (2002-2005). Este PTC de cobertura nacional incluyo la unificación de programas de empleo de emergencia y fue creado en el contexto de la crisis económica política y social que vivió la Argentina a fines de 2001. El mismo se destinó a familias con jefes/as de hogar desocupados/as con hijos/as de hasta 18 años, discapacitados o mujeres embarazadas. Al cierre de este programa se adoptó una segunda etapa bajo el título Familias por la Inclusión Social (2005-2010) con un énfasis en particular sobre la promoción y participación social y la reformulación del componente Ingreso de Desarrollo Humano (IDH) del Programa de Atención a Grupos Vulnerables (PAGV) (1996). Ninguno de estos dos programas hacía mención explícita en particular a requisitos para lograr una alimentación sana o la adquisición de determinados productos saludables y/o variados como parte de la oferta de Transferencia condicionada. Este elemento, el conocimiento y la prescripción de una alimentación sana, se ofrece a través de las consultas clínicas obligatorias a la que están sujetos quienes hayan accedido a estos programas de protección social.

\section{COLOMBIA}

Colombia presenta actualmente la ejecución de 2 programas de amplia cobertura: 1- Mas Familias en Acción (Ex Familias en Acción) y 2- Red Unidos (Ex Red Juntos).

\section{MAS FAMILIAS EN ACCIÓN}

Este programa de transferencias condicionadas (PTC) está en funcionamiento desde 2001 y es la nueva fase de un programa titulado: Familias en Acción. El programa cubre las necesidades de unos 2.7 millones de familias que reciben beneficios asociados con la asistencia escolar y los controles de salud. El programa cuenta con dos componentes: Bono de nutrición: Para hijos/as menores de 6 años y Bono de Educación: Para hijos/as de entre 4 y 18 años. Descripción de Servicios ver cuadro No.7.

La población meta de este programa son las familias en situación de pobreza y que además presentan un alto nivel de vulnerabilidad de acuerdo con la caracterización realizada por el Sistema de Selección de Beneficiarios para Programas Sociales (SISBEN) ${ }^{30}$, las familias en condición de desplazamiento por la violencia interna o indígenas con hijos/as menores de 18 años que son consideradas en un Nivel \#1. Dicho nivel determina que estas familias presentan condiciones de pobreza más aguda. El programa es de cobertura nacional. El diseño y la planificación de este incluye la información pertinente al Registro Único de Victimas (RUV) y también datos provistos por el Censo indígena. Las fuentes de financiamiento son el Gobierno de Colombia, el Banco Mundial (BM) y el Banco Interamericano de Desarrollo (BID). La modalidad de acceso al beneficio es una tarjeta de débito con la cual luego del enrolamiento y el cumplimiento de los requisitos (asegurar la participación escolar, la revisión médica, etc.) por parte de

\footnotetext{
${ }^{30}$ El Sistema de Selección de Beneficiarios para Programas Sociales (SISBEN) es una herramienta, conformada por un conjunto de reglas, normas y procedimientos para obtener información socioeconómica confiable y actualizada de grupos específicos en todos los departamentos, distritos y municipios del país. Gobierno de Colombia. http://www.piedras-tolima.gov.co/
} 
las familias, se acredita un fondo único como primer pago y luego en forma recurrente cada dos meses. Los retiros de los cajeros no sufren deducción monetaria si se circunscriben a dos retiros por mes. Esta modalidad del Programa Mas Familias en Acción ha expandido el empleo de este beneficio haciendo uso de las redes bancarias aun en zonas rurales (banco Agrario) ${ }^{31}$. Es interesante destacar que a pesar de que el programa se basa en dos intervenciones concretas o bonos y siendo uno de ellos explícitamente el "Bono de Nutrición", no existen detalles o guías de los alimentos recomendables o accesibles a través de estos bonos. No se describen seguimientos de salud relacionadas con la buena alimentación o dietas sanas fuera del cumplimiento de citas médicas en el caso de los menores de 6 años.

\section{Caja 2. Detalle de Beneficios y pautas para acceder al programa Mas Familias en Ac- ción (2001-).}

\section{Este programa apoya a las familias pobres y pobres extremas a través de la entrega condicionada de in-} centivos de salud y educación

El incentivo de salud se entrega uno (1) por cada familia por todos los niños y niñas menores de 6 años de edad. Este incentivo se entrega cada dos meses ( 6 veces al año) hasta el día antes que el niño o niña cumpla los 6 años, siempre y cuando asistan oportunamente a las citas de valoración integral en salud para la primera infancia en la respectiva IPS.

El incentivo de educación se entrega de manera individual, a tres (3) niños, niñas o adolescentes de la familia, entre 4 y 18 años de edad que estén en el sistema escolar. El incentivo se entrega cada dos meses, menos en el período de vacaciones de fin de año escolar, es decir, cinco veces al año, siempre y cuando la familia cumpla con dos compromisos: los niños, niñas y adolescentes deben asistir como mínimo al $80 \%$ de las clases programadas y no pueden perder más de dos años escolares. En el caso que uno de los participantes tenga 18 o 19 años de edad debe estar cursando mínimo $10^{\circ}$ grado, y si tiene 20 años grado $11^{\circ}$.

Familias en Acción entrega tres incentivos en educación independientemente de la edad, grado o condición del participante:

- Entre los grados $1^{\circ}$ y $11^{\circ}$ lo reciben máximo tres (3) niños, niñas o adolescentes por familia. En Bogotá, a quienes cursen grados de $6^{\circ}$ a $11^{\circ}$ únicamente.

- A los niños, niñas y adolescentes con discapacidad que estudian y están identificados por el Ministerio de Salud y Protección Social. (Este incentivo es adicional a los 3 incentivos de educación que puede recibir una familia)

- A los niños o niñas entre los 4 y 6 años de edad que estén en transición o grado cero.

Fuente: Descripción tomada de Prosperidad Social, Gobierno de Colombia ${ }^{32}$

Desde el año 2006 el programa Más Familias en Acción facilita la participación de las familias en la llamada Red Unidos (Ex Red Juntos), que es una estrategia de intervención integral y

\footnotetext{
${ }^{31}$ Mas Familias en Acción. Como se accede al beneficio, Banco Agrario https://www.bancoagrario.gov.co/SAC/Paginas/ComoAccederSubsidio.aspx

${ }^{32}$ Fuente: Fuente Prosperidad Social https://www.prosperidadsocial.gov.co/que/fam/famacc/Paginas
} 
coordinada que provee acompañamiento familiar y comunitario a las familias. Inicialmente la cobertura era de ámbito rural y para urbanizaciones no mayores de 100. 000 habitantes. Además, a partir del año 2007 se incluyen en la cobertura la totalidad de los grandes y medianos centros urbanos de Colombia donde la asistencia, el acceso y la atención de los servicios de salud y educación de la población vulnerable son diferentes y de costo más elevado por lo que se procedió a modificar el monto de subsidios recibidos. En el año 2008 se extendió un apoyo adicional a las familias mediante su vinculación a cuentas bancarias (bancarización) de modo que las mismas tenían acceso al sistema financiero y en el año 2011 se focalizaron los beneficios aún más como así también las transferencias, los aspectos de acceso a la educación y la regulación de acceso y salida del programa. Estos aspectos se rigen por la ley 1.532 (2012) que propone una revisión anual de los montos de las asignaciones de acuerdo con el Índice de Precios al Consumidor (IPC).

\section{RED UNIDOS (EX RED JUNTOS)}

La Red Unidos (para la Superación de la Pobreza Extrema) ${ }^{33}$ es una Estrategia Nacional de intervención integral y coordinada, para lograr contribuir al mejoramiento de la calidad de vida de las familias objeto de su intervención, su acumulación de capital social y humano para que de ese modo se pueda lograr la reducción de los niveles de pobreza y pobreza extrema en el país. Red Unidos está liderada por la Agencia Nacional para la Superación de la Pobreza Extrema (ANSPE) del Gobierno de Colombia y brinda un acompañamiento en forma permanente a las familias que califican (pobreza extrema, desplazamiento, indígenas, etc.) por medio de la articulación de recursos y la posibilidad de formar parte de programas sociales del Estado Colombiano:

"La estrategia de intervención de la Red está basada en contribuir a que las familias beneficiarias alcancen los 45 Logros Básicos ${ }^{34}$ (Ver Anexo No 3) de las 9 Dimensiones de Desarrollo Humano (Ingresos y trabajo, Habitabilidad, Bancarización y Ahorro, Nutrición, Dinámica Familiar, Salud, Identificación, Acceso a la Justicia, Educación) que son aspectos del bienestar de las familias, definidas como áreas de intervención por UNIDOS, a fin de contrarrestar las trampas de pobreza existentes entre las familias más vulnerables. "35

Dentro de las 9 dimensiones del desarrollo, el aspecto de "Nutrición" establece que todos los miembros de la familia deben contar con una alimentación adecuada y buenos hábitos en el manejo de alimentos, considerando los siguientes logros:

\footnotetext{
33 Gobierno de Colombia https://www.dnp.gov.co/programas/desarrollo-social/pol\%C3\%ADticas-sociales-transversales/Paginas/red-unidos-para-superacion-de-la-pobreza-extrema.aspx

${ }^{34}$ Los Logros Básicos Familiares constituyen el conjunto de condiciones mínimas deseables que una familia en pobreza extrema debe alcanzar para superar su situación. Con base en esto, la Red estructura el acompañamiento familiar y comunitario, y gestiona la oferta de programas y servicios sociales hacia ellas.

${ }^{35}$ Red Unidos para la Superación de la Pobreza. Gob. De Colombia https://www.dnp.gov.co/programas/desarrollo-social
} 
1. La familia practica hábitos saludables en la manipulación y preparación de alimentos.

2. La familia consume alimentos variados y de manera saludable.

3. Los adolescentes y adultos, de ambos sexos, conocen los métodos de planificación familiar.

4. Los niños menores de seis meses reciben al menos cuatro de los seis meses recomendados de lactancia materna exclusiva.

Fuera de dicha mención sobre alimentos "variados y saludables" no hay referencias detalladas o guías que presenten información para acceder esta alimentación sana o sobre el establecimiento de mecanismos que sirvan de guía a quienes se benefician de la participación en este programa.

Este programa, cuya implementación inició en el 2007, tiene como meta la vinculación de 1.5 millones de familias a la Red las cuales fueran identificadas según el Sistema de Identificación de Beneficiarios de Programas del Estado (SISBEN 2), o en situación de desplazamiento y se hubieran inscrito en el Registro Único de Población Desplazada (RUPD). Algo innovativo de este programa es que se trabaja con las familias y en base a sus falencias, la Red Unidos, establece una estructura para el acompañamiento familiar y comunitario, además gestiona la oferta de programas y servicios sociales hacia las familias evitando superposiciones y ajustando sus carencias a la existencia de oportunidades ofrecidas por el programa y sus redes.

La Red Unidos se implementa a partir de las siguientes líneas de trabajo: 1) Acompañamiento Familiar y Comunitario, 2) Oferta y Acceso Preferente, 3) Fortalecimiento Institucional y 4) Ingreso para la Prosperidad Social. Las familias pueden gozar de los beneficios del programa por un periodo de 5 años y los destinatarios son los jefes (padre o madre) de familia perteneciente al programa Red-Unidos cuya edad este comprendida entre los 18-35 años y que además tengan una educación mínima del 5to grado o el 11 vo grado como máximo y que además no estén vinculados al sector formal (desocupados). La entrega de este beneficio es el pago efectivo mediante una modalidad bimestral que se otorga mediante los compromisos establecidos por el programa: 1) Estudiar hasta alcanzar un grado de formación técnica; 2) Participar activamente en las actividades de servicio social; 3) Cumplir con los logros de la Red Unidos; y finalmente 4) Ahorrar. ${ }^{36}$ El programa Mas Familias en Acción es parte de la Red Unidos y quienes califican bajo el primero, pueden acceder a coberturas ofrecidas a través de los programas de la Red.

\section{COSTA RICA: PROGRAMAS AVANCEMOS Y CRECEMOS}

Este país presenta actualmente en ejecución dos programas de transferencia condicionada cuya fuente de financiamiento es el gobierno de Costa Rica, estos son: 1- AVANCEMOS (2006) y 2- CRECEMOS (2019-). EL primero, Avancemos, promueve el acceso y permanencia en el sistema de educación secundaria de personas estudiantes a partir de los once años, en situación de pobreza, a través de una transferencia monetaria condicionada que complementa el ingreso familiar. El programa está dirigido concretamente a familias con adolescentes y jóvenes

\footnotetext{
${ }^{36}$ Red Unidos https://dds.cepal.org/bpsnc/programa?id=34
} 
entre 12 y 25 años que tienen dificultades para mantener a sus hijos en el sistema educativo por causas económicas. La recertificación es cada dos años y medio y solo se cancela la transferencia si la persona abandona el sistema educativo. Este programa presenta una coordinación estratégica de organismos que comparten la responsabilidad de su implementación en particular el Viceministerio de Vivienda y Desarrollo Social y el Instituto Mixto de Ayuda Social (IMAS) como responsable del registro de usuarios.

Con respecto al Programa Crecemos, este programa busca promover la permanencia de niños y niñas de familias en condición de pobreza o extrema pobreza en el sistema educativo formal en los ciclos de primera infancia y primaria. Las familias beneficiarias incluyen aquellas en situación de pobreza o pobreza extrema con niños y niñas que asistan a centros del Ministerio de Educación Pública en los ciclos de preescolar o primaria. Este Programa a su vez consolida el apoyo prestado previamente por becas preescolares y de enseñanza primaria del Fondo Nacional de Becas (FONABE) que desde julio de 2019 pasaron automáticamente a ser usuarios de Crecemos.

A partir de 2020 el organismo responsable de la ejecución de Crecemos es la Dirección de Asignaciones Familiares del Ministerio de Trabajo y Seguridad Social (DESAF) y el Instituto Mixto de Ayuda Social (IMAS), en conjunto con el Ministerio de Educación Pública (MEP) y el financiamiento: Fondo de Desarrollo Social y Asignaciones Familiares (FODESAF). Es importante establecer que, si bien estos dos programas de ejecución corriente no establecen aportes de alimentación, acceso a dietas sanas o comedores escolares, los mismos son la evolución del Programa SUPEREMONOS ejecutado entre el año 2000-2002. Este programa presentó un marcado énfasis en la prevención de la deserción escolar en educación primaria a cambio de un bono alimenticio o cupones de alimentos de una periodicidad mensual de entrega a la madre para asistir a niños/as de 6 a 18 años en su atención escolar. De este modo se promovía el acceso y la permanencia de niños y jóvenes carenciados en el sistema educacional. En otras palabras, este programa no ha tenido como objetivo el promover dietas saludables, sino simplemente evitar/reducir la deserción escolar, usando alimentos como incentivos. Este programa se ejecutó a través del Instituto Mixto de Ayuda Social (IMAS) con fuentes de financiamiento del Banco Interamericano de Desarrollo (BID) y el Fondo Nacional de Desarrollo Social. $^{37}$

Cuadro 6. Programa Avancemos (2006-)

Programa Avancemos

Presupuesto

CRC\$

USD\$
2018

70.115 .924 .889

121.523.859

$0,20 \%$

\%PIB / GDP

${ }^{37}$ https://dds.cepal.org/bpsnc/programa?id=35 Base de datos CEPAL, programas Costa Rica. 
Fuente CEPAL ${ }^{38}$; Elaboración de la autora

Cuadro 7. Programa Crecemos (2019-2020)

\begin{tabular}{lc} 
Presupuesto & 2020 \\
\hline CRC\$ & 50.000 .000 .000 \\
USD\$ & 87.473 .758
\end{tabular}

Fuente $\mathrm{CEPAL}^{39}$; Elaboración de la autora

\section{HONDURAS: BONO VIDA MEJOR}

El propósito del Bono Vida Mejor, que es la continuación del Programa Bono 10.000 Educación, Salud y Nutrición ${ }^{40}$, es contribuir con la ruptura del ciclo intergeneracional de la pobreza a través de la creación de oportunidades, desarrollo de capacidades y competencias en la educación, la salud y en particular de la nutrición de las familias en extrema pobreza en Honduras. Este programa de alcance nacional busca promover estrategias y acciones intersectoriales (salud-nutrición) mediante la coordinación con otros programas sociales relacionados con empleo, ingreso y ahorro familiar. El programa se lleva a cabo desde el año 2010.

El Programa cuenta con cuatro subcomponentes: 1) Bono de nutrición, 2) Bono de salud, 3) Bono educación y 4) Apoyo básico. No se detallan características de los componentes de las dietas. Cabe destacar que la operacionalización del Bono de nutrición se centra en la adopción de una alimentación que contenga micronutrientes a través de la oferta de servicios a la población participante por parte de la Secretaría de Salud. El Bono permite acceder a dietas y alimentos ricos en micronutrientes destinados a los niños y niñas de 0 a 5 años, a mujeres embarazadas y también a aquellas que se encuentran dentro de los 40 días del puerperio ${ }^{41}$.

El modo de operación requiere la inscripción de niños/as y mujeres embarazadas o en periodo de lactancia en una Unidad de Salud para la realización de controles. La periodicidad de entrega es del orden trimestral y el pago se realiza a través del Banco de Honduras. El método de

\footnotetext{
$38 \mathrm{https}: / /$ dds.cepal.org/bpsnc/ptc

$39 \mathrm{https} / / / d d s . c e p a l . o r g / b p s n c / p t c$

40 Este Programa se llamó Bono 10.000 porque otorgaba un apoyo de 10.000 Lempiras por hogar durante un periodo de un año para solventar e invertir en la educación y alimentación de aquellas familias que calificaban para acceder a este subsidio. https://dds.cepal.org/bpsnc/programa?id=37

${ }^{41}$ Se denomina puerperio al periodo que va desde el momento posterior al parto hasta los 35-40 días posteriores, este periodo que es el tiempo que necesita el organismo de la madre para recuperar en forma progresiva las condiciones que presentaba antes del inicio del embarazo.
} 
aplicación de este programa incluye una zonificación geográfica, la inscripción a través del Registro Único de Beneficiarios (RUB), también la participación comunitaria mediante los Comités Escolares Comunitarios (CEC) y la inclusión únicamente de hogares que cumplen con criterios de selección del programa.

Este programa se apoya en la información provista por medio del censo poblacional y las encuestas de hogares para identificar las zonas geográficas con mayor incidencia de pobreza además de la ficha única de caracterización socioeconómica del citado Registro Único de Beneficiarios (RUB) para localizar los hogares en condición de necesidad extrema. El organismo responsable es la Secretaría de Estado en el Despacho Presidencial y el organismo ejecutor el Programa Asignación Familiar (PRAF), por medio de los Ministerios de Salud y Educación. ${ }^{42}$ Las principales fuentes de financiamiento para la ejecución de este programa son el Gobierno de Honduras, el Banco Interamericano de Desarrollo (BID), el Banco Mundial (BM) y el Banco Centroamericano de Integración Económica (BCIE).

Si bien el Bono Vida Mejor ya cuenta con una década, el accionar del mismo se cimenta en la existencia de previos programas de transferencia condicionada como ser el Programa de Asignación Familiar o PRAF (1990-2009) y dos programas apoyados por el Banco Interamericano de Desarrollo durante periodos subsiguientes, el PRAF/BID Fase II (1998-2005) ${ }^{43}$ y PRAF/BID Fase III (2006-2009). PRAF II incorporó un diseño experimental que permitió diversas evaluaciones de impacto llevadas a cabo por el Instituto Internacional de Investigación de Políticas Alimentarias (IFPRI), convirtiéndose en uno de los principales referentes de este tipo de programas. Todos estos programas cubrían las necesidades de familias en situación de extrema pobreza con hijos menores de 6 años en riesgo de desnutrición quienes accedían a suplementos nutricionales. En el caso del PRAF/BID la cobertura se extendió hasta los 12 años y/o mujeres embarazadas o dando lactancia. EI Programa PRAF/BID III, presentaba una cobertura regional cubriendo los departamentos de Intibucá, La Paz, Lempira y Santa Bárbara. Además, constaba de dos modalidades: una de intervención inicial en que se otorgan transferencias monetarias (Bono de nutrición) sin condiciones, pero con promoción de la demanda por servicios de educación y salud y una segunda intervención de carácter integral en que se otorgaban además un bono de salud y otro de educación, sujetos a condicionalidades.

\section{JAMAICA}

\section{PROGRAMME OF ADVANCEMENT THROUGH HEALTH AND EDUCATION (PATH)}

Este programa de transferencias condicionadas se encuentra vigente desde 2001 y se creó con énfasis al apoyo de grupos vulnerables mediante la racionalización de tres programas de transferencias de ingresos previamente existentes: Food Stamp, Outdoor Poor Relief y Public Assistance. En el año 2008 se agregó también una transferencia educativa, además de un bono adicional para los estudiantes que terminen la secundaria y se inscriban en la educación superior.

\footnotetext{
${ }^{42}$ El marco legal de este programa es el Decreto Ejecutivo PCM-010 (2010); Decreto Ejecutivo PCM-024 (2010); Acuerdo Ejecutivo No.022-DP-2013; Acuerdo Eject. No. SEDIS -003-2015; Acuerdo Ministerial No.072-SEDIS-2015.

${ }^{43}$ El programa se desarrolló de manera paralela al programa PRAF establecido en 1990 y ejecutado con fondos nacionales, que no verificaba condicionalidades. Una de sus mayores innovaciones fue incluir transferencias a la oferta según la cantidad de población atendida
} 
El acceso a este programa es por medio de tarjetas magnéticas que permiten acceso a nuevos fondos cada dos meses. La población meta son familias en situación de pobreza con niños/as menores de 17 años, adultos mayores de 60 años, discapacitados/as, mujeres embarazadas 0 dando lactancia y/o adultos pobres sin empleo (entre 18 y 64 años). El programa presenta una cobertura nacional y además de las transferencias provee acceso gratuito a almuerzos escolares (comedores locales) y también a servicios de salud. Al presente este programa consta de cuatro componentes: 1) Bono de salud, 2) Bono de educación, 3) Bono de educación postsecundaria y 4) Beneficio base. La recertificación para acceder a este programa se realiza cada 4 años por medio de un instrumento de selección: Sistema de Identificación de Beneficiarios (Beneficiary Identification System - BIS). Actualmente el programa cubre más de 360, 000 personas o un $12.41 \%$ de la población ${ }^{44}$. Es interesante destacar que, si bien el programa PATH evoluciona del programa de Food Stamps y actualmente articula un Bono de Salud, no se hace referencia detalladas en cuanto a la alimentación o dietas saludables en el desarrollo central del programa ni en sus componentes.

Cuadro 8. Programme of Advancement Through Health and Education (PATH) (2001-)

\begin{tabular}{|c|c|}
\hline Características & 2018 \\
\hline \multicolumn{2}{|l|}{ Presupuesto } \\
\hline JMD\$ & 7.918.264.000 \\
\hline USD\$ & 61.443 .087 \\
\hline \%PIB / GDP & $0,39 \%$ \\
\hline \multicolumn{2}{|l|}{ Cobertura personas } \\
\hline Efectiva & 360.000 \\
\hline \% Población & $12,42 \%$ \\
\hline
\end{tabular}

Fuente CEPAL. ${ }^{45}$; Elaboración propia

\footnotetext{
${ }^{44}$ Base de datos de programas de protección social no contributiva en América Latina y el Caribe. CEPAL, País: Jamaica https://dds.cepal.org/bpsnc/ptc?pais=im

${ }^{45}$ https://dds.cepal.org/bpsnc/ptc
} 


\section{DESCRIPCION DE PROGRAMAS DE ALIMENTACION EN PAISES DE AMERICA LATINA}

Una segunda modalidad de programas de protección social incluye una vasta cartera de programas "de alimentación" modelados de acuerdo con las necesidades específicas de los países de la región. Estos programas, adquieren características particulares y a veces son parte complementaria de los PTC para reforzar necesidades concretas de públicos diversos que califican bajo esta modalidad de apoyo.

A continuación, se describen una serie de programas en países seleccionados que presentan ciertas opciones de cobertura y oferta alimentaria para una variada gama de públicos, desde la temprana edad -niños y niñas de 0 a 5 años, adolescentes y jóvenes, mujeres gestantes y personas de la tercera edad. No todos los programas cubren la totalidad de las citadas categorías, algunos se circunscriben a la ejecución a nivel nacional y otros se enfocan en una cobertura para el público rural o urbano. Los programas descriptos en este documento incluyen: "Sistema Elige Vivir Sano" de vigencia en Chile; el Sistema Alimentario Sostenible para una Alimentación Saludable y la estrategia de "Sabores y Saberes" en Uruguay; una variedad de programas de "Canastas Solidarias" en Ecuador; las Canastas Alimentarias para Adultos Mayores en México, las Cajas Urbanas de Honduras, el Bono Madre Niña-Niño Juana Azurduy en Bolivia; el Programa Productivo Alimentario en Nicaragua, el Programa PROCOMIDA en Guatemala y los Comedores Populares en Perú. Estos programas de protección social también movilizan la economía a nivel local mediante la compra de productos en sus áreas de influencia. A continuación, se describen los citados programas con sus distintas modalidades de implementación y ejecución en varios países de América Latina.

\section{PROGRAMAS ENFOCADOS EN LA MEJORA NUTRITIONAL}

\section{PROGRAMA “ELIGE VIVIR SANO"- CHILE}

El Programa Elige Vivir Sano (EVS) ${ }^{46}$, es una política pública impulsada por el Gobierno de Chile, que tiene por objeto promover hábitos y estilos de vida saludables para mejorar la calidad de vida y el bienestar de las personas. El programa rescata y se enfoca en los miembros de la sociedad más vulnerables con mayor riesgo de malnutrición e inseguridad alimentaria. La coordinación del Sistema Elige Vivir Sano, está a cargo del Ministerio de Desarrollo Social y Familia.

${ }^{46}$ Información Ministerio Secretaria General de Gobierno, Chile. Nueva Agenda Social. Graciela Godoy http://eligevivirsano.gob,cl/ y https://msgg.gob.cl/wp/2018/05/09/conoce-en-que-consiste-el-nuevo-sistema-elige-vivir-sano/ 
Con la sanción de la Ley 20670, en mayo de 2013, se creó la Secretaría "Sistema Elige Vivir Sano". Esta iniciativa establece que todos los órganos de la Administración del Estado que tengan una relación con la promoción de hábitos de vida saludables deberán incorporar en sus políticas, planes, o programas, componentes que apunten a "informar, educar y fomentar la prevención de los factores y conductas de riesgo asociadas a las enfermedades no transmisibles, derivadas de hábitos y estilos de vida no saludables." Presenta además un enfoque sistémico y social con una estrategia de equidad señalando que se debe contribuir a disminuir obstáculos para que las personas más vulnerables tengan acceso a factores de protección. La estrategia del Programa Elige Vivir Sano (EVS) propone también una serie de importantes medidas para hacer frente al sobrepeso y la obesidad y adopta además una estrategia de género para su implementación.

El Programa EVS propone cuatro pilares importantes y establece que todas las políticas que impulsen los Ministerios deben ir enfocadas en los mismos:

- Alimentación Saludable: promoción de la educación en aquellos hábitos alimentarios tendientes a mejorar la nutrición integral y la disminución del sobrepeso.

- Actividad Física: actividades que fomenten el ejercicio y la actividad física como elementos fundamentales de la salud y el bienestar.

- Vida en Familia: espacios tendientes a fortalecer las familias y que facilitan el desarrollo de actividades dirigidas al esparcimiento y al ejercicio de disciplinas lúdicas o deportivas.

- Vida al Aire Libre: promoción de los beneficios que tiene la realización de acciones en las cuales exista contacto con la naturaleza.

El Programa EVS promueve opciones de proactividad y de cuidado para que las personas puedan optar por decisiones saludables y así incorporarlas en forma efectiva a las prácticas diarias. El sistema EVS está diseñado para toda la población con una cobertura a nivel nacional. EVS se apoya en la difusión de información específica en cuanto al desarrollo de hábitos y prácticas que corresponden a una vida sana. Existen también medidas suplementarias y la Ley №20.545 que modifica las normas de protección a la maternidad incorporando el permiso postnatal parental en tres áreas temáticas a) la extensión del postnatal; b) el permiso postnatal parental; y c) la extensión de cobertura a mujeres no incluidas en el régimen de subsidio por incapacidad laboral.

Un importante aspecto que el programa EVS incluye, es el énfasis en el ejercicio físico mediante la creación de Centros Deportivos EVS que son espacios donde las mujeres puedan desarrollar estas actividades en lugares abiertos (parques) sintiéndose seguras (física y socialmente), todo esto unido al llamado Plan de mejoramiento urbano y la Estrategia de Cero Obesidad 2030. El sistema EVS se desarrolla en los 29 Servicios de Salud de 284 comunas del país, con un total de 71.800 cupos. Este programa presenta una gran fluidez y la adaptación a las necesidades de la población, a partir de Abril 2020 se adopta también la iniciativa "Pedidos Sanos" que permite realizar compras (frutas y verduras) en ferias libres de forma virtual con la 
ventaja de que la entrega a domicilio ${ }^{47}$ es totalmente gratuita (solo el envío). Este servicio ha comenzado su funcionamiento en unas 6 ferias de las comunas de Herrera, Martin Rozas, Esperanza, Coquimbo, 10 de Julio y San Camilo.

\section{SABORES ANDANTES -PROGRAMAS INNOVATIVOS DE ALIMENTACION ADECUADA - URUGUAY}

Uruguay presenta una interesante serie de medidas y la formación de líneas de base bajo el marco del Sistema Alimentario Sostenible para una Alimentación Saludable. Este marco está formado por decretos, leyes y acciones directas que tienen como objetivo la reducción de la obesidad. Dentro de las medidas se incluye la Ley Marco de Alimentación Adecuada; la ley 19.140 de Alimentación Saludable en Centros Educativos; el Plan Nacional de Agroecología; el Decreto de Etiquetado Frontal de advertencias nutricionales; las compras públicas a la agricultura Familiar; guías de actividad física y alimentarias entre otras medidas.

Las guías alimentarias son importantes dado que impulsan un marco de alimentación adecuada convirtiéndose en una herramienta educativa con perspectiva de género ${ }^{48}$. En ese marco se introducen acciones de revaloración de la "cocina" y de la comida, con la participación de hombres y mujeres fomentando habilidades culinarias para ambos, creando redes de intercambio y valorando la comida autóctona mediante recetarios inclusivos y variados. La cocina se incluye al trabajo local territorial y además se realizan encuentros, reuniones y sesiones culinarias (encuentros de cocina) con públicos diversos de todas las edades: padres, madres, adultos mayores, niños-niñas y adolescentes para crear y compartir una cocina inclusiva y saludable. Este enfoque establece que la enseñanza culinaria no tiene límites de edad y las sesiones de cocina se realizan en establecimientos educacionales de la primera edad donde se aprenden aspectos básicos que facilitan el conocimiento y la exposición a una dieta saludable, considerándose una inversión social estratégica. Este programa está centrado en aspectos educativos y no otorga beneficios de pagos por alimentos ni tampoco transferencias condicionadas. Otro programa de interés llevado a cabo por el Ministerio de Desarrollo Social (MIDES) se basa en los "encuentros de cocina", los programas de "Sabores Andantes" desarrollados mediante cocinas móviles y un énfasis en las compras de productos a la agricultura familiar adoptando la idea primordial de que "la alimentación adecuada es un derecho y de nosotros depende consagrarlo." Mediante la implementación de este programa se busca explorar el "vinculo" existente entre la alimentación, la comida y la creatividad, mediante la preparación de comidas y alimentos ${ }^{49}$

\footnotetext{
${ }^{47}$ Elige Vivir Sano, Municipalidad de Santiago lanza Pedidos Sanos. http://eligevivirsano.gob.cl/noticias/elige-vivir-sano-municipalidad-de-santiago-y-pedidosya-lanzan-pedidos-sanos-iniciativa-que-llevara-productos-de-ferias-libres-a-domicilio/

${ }^{48}$ La equidad de género se consolidó como una política de estado en Uruguay a través del Plan Nacional de Igualdad de Oportunidades y de Derechos regulado desde el Instituto Nacional de la Mujer; la Ley 19,685 (2018) sobre la promoción del desarrollo con equidad de género y la creación del Sistema Nacional Integrado de Cuidados, además de otras leyes que atienden problemas como la violencia de género y la falta de autonomía económica de las mujeres. https://www.gub.uy/ministerio-desarrollo-social/comunicacion/publicaciones/sabores-andantes-encuentros-cocina

${ }^{49}$ Sabores Andantes. Gobierno de Uruguay. 2019. Este libro comparte y redescubre la preparación de comidas sanas y las presenta como actividades familiares, comunitarias y de entretenimiento, facilitando aprender y optar por opciones sanas, teniendo en cuenta sabores, aromas y texturas para incentivar la creatividad culinaria.
} 


\section{PROGRAMA PRODUCTIVO ALIMENTARIO - NICARAGUA}

El Programa Productivo de Alimentario de Nicaragua ${ }^{50}$ está vigente desde el año 2007 y es de cobertura nacional con énfasis en el área rural. El programa otorga un Bono Productivo Alimentario (BPA $)^{51}$ que permite el fortalecimiento de la producción de alimentos de autoconsumo en las familias rurales nicaragüenses. Una interesante variante de este programa es que permite la comercialización de los excedentes en el mercado local e incentiva de este modo la expansión de las cadenas de producción primarias y también en el orden agroindustrial, cuyo objetivo es dar un valor agregado a los productos básicos en la unidades rurales productivas o granjas. Este bono ofrecido por el programa brinda también acceso a herramientas para mejorar la eficiencia del trabajo rural, semillas, insumos, etc. El apoyo ofrecido tiene una perspectiva a mediano y largo plazo y además su objetivo es contribuir al desarrollo económico del país a través de: un suministro interno de alimentos, ahorro de divisas, valor acordado para productos locales y nacionales y también pretende lograr el crecimiento de las exportaciones ${ }^{52}$. Este programa elige a las mujeres de la unidad familiar como beneficiarias directas quienes deben dar seguimiento a chequeos prenatales en caso de embarazo y también asegurar la asistencia de los niños y niñas a controles médicos regulares asegurando también su participación en programas escolares. Además, las mujeres deben poseer la titularidad de la tierra de predios entre 1 a 10 manzanas. Las transferencias del Bono son "en especie" adjudicadas directamente a las beneficiarias con la finalidad de apoyar el empleo independiente en el ámbito comercial de estas familias productoras.

Existe una clasificación de las familias cubiertas por el Bono la cual está dada por la extensión de tierra que poseen además de la característica de la explotación. Así el programa provee de tres tipos de bono: a) Bono de Asentamiento que está destinado a familias con extensiones de tierra entre 1-10 manzanas dedicadas a la explotación pecuaria; b) Bono Típico que es otorgado a familias con áreas menores a una manzana que producen aves de corral y vegetales; $y$ c) Bonos de Patio incluyendo familias urbanas con huertos-patio de al menos de $1 / 4$ de manzana también dedicadas a criar pequeños animales (aves y otros animales de granja).

El organismo responsable de la ejecución es el Ministerio de Economía Familiar, Comunitaria, Cooperativa y Asociativa bajo el Plan Nacional de Desarrollo Humano. Se estima que la asignación del Bono Productivo cubre unas 51.146 familias (2016) de los departamentos de Boaco, Alto Coco, Carazo, Chinandega, Chontales, Estelí, Granada, Jinotega, León, Madriz, Managua, Masaya, Matagalpa, Minas, Nueva Segovia, Rio San Juan, Rivas y Zelaya con una estimación de gastos estimados en el orden del $0.12 \%$ del PIB (2016). El mecanismo de apoyo consiste en la entrega de productos proveedores de proteínas y en ciertos casos herramientas en un valor de hasta US \$1000 anuales por hogar, esto incluye también bienes, capacitación, más gastos

\footnotetext{
${ }^{50}$ Ministerio de Agricultura Familiar y Comunitaria, Bono Productivo Alimentario: https://www.economiafamiliar.gob.ni/bono-productivo-alimentario/

${ }^{51}$ Programa Productivo Alimentario, Nicaragua. Social Protection.org. https://www.socialprotection.org/discover/programmes/programa-productivo-alimentario-food-productive-programme

${ }^{52}$ ECLAC n.d. "Food Productive Programme (Programa Productivo Alimentario)". Economic Commission for Latin America and the Caribbean, Non-contributory Social Protection Programmes Database website. https://dds.cepal.org/bpsnc/programme?id=76 . Accessed 23 January 2019.
} 
de ejecución del programa. Los bienes entregados a los hogares son animales, semillas y alimentos vegetales para animales, árboles alimenticios, material para establos, gallineros y biodigestores para producir gas con excrementos de animales. Otra ventaja del programa es que a través de sus redes se organizan cursos de capacitación sobre: economía de los agricultores, prácticas agrícolas para mejorar la producción, cultura empresarial, sanidad animal, higiene ambiental, asociatividad y autogestión, crédito, comercio, etc.

Si bien el primer objetivo es fortalecer la producción de alimentos de autoconsumo en las familias rurales nicaragüenses, el programa cuenta con una segunda etapa de comercialización de los excedentes en el mercado nacional apoyando la formación de cadenas productivas mediante el valor agregado a los bienes producidos en las unidades de producción (embutidos, jaleas, procesamiento de alimentos, etc.), todo esto con una nueva visión de ahorro y de un eficiente manejo del capital. La estrategia de implementación del programa consiste en la producción de las especies vegetales y la reproducción de las especies animales en tres etapas bien definidas:

a. Comienza con la entrega de semillas, vegetales y animales además de una capacitación técnica y social que incluye temáticas productivas, de comercialización, pero también temas como ser higiene, autoestima e igualdad de género para mujeres productoras. El primer nivel de créditos para emprender es de 10 mil córdobas como máximo,

b. La segunda etapa promueve la formación de núcleos de beneficiarias lo cual facilita el acceso a créditos y capacitación financiera. En este segundo nivel los créditos se incrementan entre 10 mil a 60 mil córdobas.

c. La tercera etapa promueve la creación y planificación de negocios y estrategias financieras accesible a las familias participantes.

Se estima que la inversión de este programa en 2017 fue de aproximadamente de 340 millones de córdobas o aproximadamente 10 millones de dólares. Entre el 2007 y el 2016 se han entregado casi 200 mil bonos productivos con una inversión de más de 3 mil millones de córdobas. Otorgados a unos 2 mil núcleos productivos organizados y más de 700 cooperativas a nivel país. El financiamiento del Programa del Bono Productivo Nicaragüense se realiza a través de diversas fuentes de financiamientos nacionales como el Tesoro Nacional y FONDEAGRO, y también por contribuciones del Fondo Internacional de Desarrollo Agrícola (FIDA), el Banco Interamericano de Desarrollo (BID), la FAO y las agencias de desarrollo de Austria y Taiwán. 


\section{MODALIDADES DE CANASTAS Y CAJAS DE ALIMENTOS}

Las llamadas "Canastas" son programas de compras de alimentos frescos llevados a cabo por grupos de familias, ONGs, cooperativas y en oportunidades cuentan también con la participación de los gobiernos locales. Si bien las canastas se han constituido en una opción de acceso a alimentos variados a valores accesibles, estos programas por lo general no son de orden nacional. En oportunidades las ofertas de las canastas se suplementan también con cupones ${ }^{53}$ (PMA 2014) para adquirir productos alimentarios únicamente. La diferencia de estos cupones con los PTC es que las canastas permiten directamente el acceso a ciertos alimentos bajo la responsabilidad de los consumidores. El funcionamiento es por medio de compras en cantidades importantes para la provisión de lotes de alimentos que incluyen por lo general elementos que forman parte de la canasta básica establecida en el país. Un aspecto de importancia singular es que esta modalidad de distribución de alimentos establece un vínculo directo entre los agricultores y los consumidores beneficiarios que reciben dichos alimentos.

Algunas de estas intervenciones están íntimamente ligadas a la agricultura ecológica (eco agricultura) y a los principios de soberanía alimentaria que han sido adoptado en países de la región (Collin, 2014; Hidalgo, et al 2013). Quienes se benefician de estos paquetes, cajas o canastas se hallan en situación de inseguridad alimentaria o pobreza, pero no necesariamente en situación de pobreza extrema. El acceso a las canastas o cajas por lo general es de ciclo mensual o bimensual, aunque pueden presentarse con mayor frecuencia aportando provisiones que ayudan a cubrir necesidades concretas de alimentación de una familia mediante la provisión de productos que incluyen verduras y frutas frescas, legumbres, maíz y granos, productos lácteos como garantía de la oferta de alimentos saludables. Muchos de estos programas son organizados a nivel local por las municipalidades o por los estados provinciales, pero se apoyan en la relación existente con productores locales y de circuitos cortos para una movilización constante de productos frescos que cubran los requerimientos de los individuos o familias destinatarias.

Entre los casos más emblemáticos puede mencionarse las canastas de circulación en Ecuador. El caso de las Canastas Solidarias de la Red de Quito y en la Provincia de Pichincha (Lara \& Donoso, 2018) dejan ver que las canastas cubren ámbitos urbanos o periurbanos con una distribución regular que presenta una coordinación entre quienes produces, quienes consumen y también instituciones involucradas a nivel gubernamental y del ámbito del sector privado.

\section{EXPERIENCIA DE LAS CANASTAS SOLIDARIAS - ECUADOR}

En Ecuador el programa de las canastas solidarias comenzó en el año 1987 en la Provincia de Riobamba con un número de 25 familias apoyadas por una entidad eclesiásticas con el fin de dar la opción de una adquisición o comprar de alimentos en mayor escala para luego dividir estos alimentos entre un grupo de familias. En el año 2008, había más de mil familias beneficiarias en Quito las que accedían a los alimentos mediante las canastas en forma continua. Los grupos o familias presentan autonomía de compra y también ejercen decisión en cuanto a la

\footnotetext{
${ }^{53}$ Los cupones pueden ser emitidos por organizaciones como el Programa Mundial de la Alimentación (PMA) que emite estos cupones o váuchers durante situaciones de crisis o también por medio de entes gubernamentales locales. PMA. 2014. Manual sobre transferencias de efectivo y cupones. SEGUNDA EDICIÓN. Roma. Italia https://docs.wfp.org/api/documents/WFP$\underline{0000015440 / \text { download/ }}$
} 
selección de alimentos que adquieren, es decir que cada comunidad que opera bajo la modalidad de canastas tiene una dinámica propia (Howe, 2008). Algo singular en el Ecuador, es que las canastas se han adoptado como una herramienta que apoya la soberanía alimentaria del país. Este programa de canastas se ha extendido en distintas regiones del Ecuador, alcanzando una alta representación en regiones y ciudades como Otavalo, Guayaquil, Santo Domingo, Ibarra, Machala y Cuenca. Se considera una "canasta comunitaria" a una organización popular urbana de consumidores, por lo general cada una de ellas está conformada por grupos de 15 a 400 familias (Garcés \& Kirwan, 2009). Las mismas han aumentado en el ámbito del país organizándose en grupos de más de 1500 consumidores y con alrededor de 600 granjas agroecológicas a cargo de familias de agricultores además de contar en ocasiones con el apoyo de varias organizaciones del sector privado (Kirwan, 2008).

La más conocida en Ecuador es la "Red de Canastas de Quito" que hoy se ha unido a la campaña nacional "Come Sano, Seguro y Soberano" para mejorar la oferta alimenticia ya que los programas se complementan y apoyan mutuamente. Las canastas que conforman la Red de Quito incluyen: La Merced (Alcantarilla), El Carmen, Nina Pacha, San Carlos y San José de Chilibulo. Además, como bajo esta modalidad los alimentos se adquieren en gran cantidad como compras al mayoreo esto facilita la participación de organizaciones de gran envergadura por lo que bajan los costos de los productos. La implementación de estos programas apoyan la soberanía alimentaria local, lo cual se relaciona directamente con la legislación nacional en referencia al "derecho a la alimentación" establecido por medio de la Constitución de Ecuador ${ }^{54}$ en su artículo 13 donde se detalla que las personas y los grupos (colectividades) tienen derecho al acceso "seguro y permanente a alimentos sanos, suficientes y nutritivos, preferentemente producidos a nivel local y en correspondencia con sus diversas identidades y tradiciones culturales."

Estos programas son manejados localmente y presentan varias opciones administrativas como ser a través de acuerdos de los gobiernos locales (alcaldías, municipalidades) con cooperativas o grupos de la sociedad civil (grupos organizados por iglesias, etc.) y se consideran como una opción alternativa de provisión de alimentos, cuyo accionar reafirma el derecho a la autosuficiencia de alimentos sanos. A lo largo del tiempo mediante el empleo de esta modalidad, los usuarios o grupos de familias no solo compran en conjunto, sino que también pueden gozar de otras actividades coordinadas y así reciben educación nutricional para mejorar la alimentación de sus familias a través de campañas de capacitación que incluyen también clases de nutrición, de cocina, visita a granjas entre otras oportunidades para sus participantes. Otro elemento de interés es que esta modalidad expandida en todo el país cuenta con una Red Nacional de Canastas Comunitarias y Solidarias del Ecuador que se reúnen anualmente en desde 2004 en el Encuentro Nacional, Red, Tierra y Canasta. Además, dado su continuidad de implementación,

\footnotetext{
${ }^{54}$ FAO. Constitución de Ecuador. FAOLEX Data base. 2008. http://www.fao.org/faolex/results/details/en/c/LEX-FAOC127389/ EI Estado ecuatoriano promoverá la soberanía alimentaria (art. 13). En tema de soberanía alimentaria, véase el Capítulo tercero del Título VI sobre el Régimen de desarrollo. La soberanía alimentaria constituye un objetivo estratégico y una obligación del Estado para garantizar que las personas, comunidades, pueblos y nacionalidades alcancen la autosuficiencia de alimentos sanos y culturalmente apropiados de forma permanente (art. 281)
} 
utilización y presencia se ha logrado desarrollar y crear una base de datos de contactos (organizaciones, localidades, productos, etc.) para mejorar no solo la nutrición de las familias sino también los ingresos de agricultores en el país (Howe, 2008). ${ }^{55}$

Otra localidad de interés donde se desarrollan programas de canastas es la provincia de Pichincha. Estas canastas al igual que la Red de Quito, se conforma por grupos de familias en zonas periurbanas, la compra se realiza en cantidades para luego ser igualmente divididas por las familias locales. El Gobierno Autónomo de la Provincia de Pichincha desarrolla este proyecto ofreciendo una alternativa a las necesidades alimenticias de un sector de bajos ingresos de su población. Las familias de productores por un lado y las familias de consumidores por el otro logran evitar los costos de intermediación que aquejan a otras localidades con la intervención y el apoyo del gobierno local. Esto demuestra una planificación estratégica y sostenible para quienes participan de modo que se mejora la posición económica de productores y consumidores involucrados (Lara \& Donoso, 2018). El costo de una canasta implementada por el Gobierno de Pichincha es de US\$10-15. Las canastas son repartidas a aquellos hogares que forman parte del Comité de Compras y de este modo acceden a una amplia gama de productos. El contenido de las mismas varía según la disponibilidad estacional y se mide por unidad, atado, ciento, kilo, quintal o libra, cada canasta puede contener entre 10 y hasta 20 productos, la entrega puede ser semanal, quincenal o mensual. Los componentes podrían ser: papas, cebolla blanca, yuca, pimiento, pepinos, zanahorias, rábano, remolacha, lechuga (criolla, mixta o romana), acelga, col, cilantro, perejil, tomate de árbol, tomate, ají, también frutilla, plátano, aguacate y una variedad de granos como grano seco, grano tierno, frejol seco, frejol tierno, habas, hierbas, y limón. Entre los productos procesados se menciona el yogurt, queso y una diversidad de carnes (Cárdenas et al, 2014) ${ }^{56}$ llegando en oportunidades a una oferta total de casi 68 productos diferentes. Las Canastas de Quito y de la Provincia de Pichincha son modelo de planeación estratégica manejadas eficientemente y de manera sostenible en conjunción con el Gobierno Provincial y todos los involucrados desde la producción al consumo.

\section{BONOS Y CANASTAS EN BOLIVIA}

\section{Bono Madre Niña-Niño Juana Azurduy}

Bolivia presenta una interesante combinación de la oferta de bonos y la suplementación por el empleo de la modalidad de canastas. En el año 2009 se creó por Decreto No. 0066 el Bono Madre Niña-Niño Juana Azurduy, también llamado Subsidio Prenatal para La Vida. Este subsidio fue diseñado para ofrecer cobertura a las mujeres embrazadas entre el $5^{\circ}$ y el $9^{\circ}$ mes de gestación y niños menores de dos años que no puedan acceder a seguros de salud con el fin de reducir la desnutrición crónica y los niveles de mortalidad materna e infantil. Este bono

\footnotetext{
${ }^{55}$ Howe, Caitlin. Las Canastas Solidarias: Construyendo una comercialización directa con los productores. Primavera 2008. Pomona College. https://digitalcollections.sit.edu/cgi/viewcontent.cgi?article=1015\&context=isp collection

${ }^{56}$ Cárdenas, Angeline, Eduadro Conrrado, Gabriela Guato. 2014.Evaluación y Expansión del Proyecto Canastas Solidarias del Gobierno Autónomo descentralizado de la Provincia de Pichincha (GAPP) en la Parroquia de Chillogallo. Tesis de Grado. Quito. Ecuador. Pp.18
} 
ofrece, además de los beneficios normales de las transferencias condicionadas incluye un suplemento de alimentos mediante el acceso a Canastas alimentarias ${ }^{57}$. El público de mujeres beneficiarias debe estar inscritas formalmente en el Programa Bono Juana Azurduy. El organismo responsable es el Ministerio de Salud, pero quien lo ejecuta es el de Salud y Servicio de Desarrollo de las Empresas Públicas Productivas. El financiamiento viene en parte de los recursos internos del Tesoro General de la Nación, del Banco Mundial, y del Banco Interamericano de Desarrollo. ${ }^{58}$ Los requisitos establecidos para el acceso a beneficios son semejantes a los de otros programas con énfasis en controles prenatales y un control integral de la salud de los niños/niñas. Un aspecto de interés es que este programa va más allá del apoyo económico normal y apoya el espaciamiento de los embarazos, por lo cual es un prerrequisito que las madres gestantes que son parte del programa no tengan otros hijos/hijas menores de dos años. Esta información se comparte mediante instrucciones y presentaciones durante el proceso de inscripción que ponen en conocimiento a las madres que ellas deben esperar dos años al menos entre sus embarazos. ${ }^{59}$ Además para facilitar el flujo de información y ante la situación actual, el Ministerio de Salud creó una aplicación móvil para que las mujeres pueden manejar sus bonos. ${ }^{60}$ La forma de entrega de beneficios es en especie, es decir que son canastas concretas de alimentos divididas en cuatro paquetes comenzando su entrega en los últimos cuatro meses del embarazo. El equivalente de cada canasta suma unos Bs. 300 ofreciéndose alimentos de alto valor nutricional como ser cereales, frutas secas, productos procesados como barras energéticas, productos lácteos y carnes entre otras cosas. El bono y las canastas son accesibles en zonas urbanas y rurales por igual a quienes se inscriben y completen los requisitos. Además, en áreas rurales las canastas se suelen suplementar principalmente con trigo, quinoa, y frutas. ${ }^{61}$ Las mujeres que están inscritas en el bono, pueden recibir estas canastas ${ }^{62}$ en primer lugar luego del control médico de corresponsabilidades que tiene lugar entre el 4 y 5 mes de gestación; el segundo paquete al mes siguiente luego del control con un médico comunitario asociado al sistema; el tercer y cuarto paquete ocurre entre el 6 y 9 mes de gestación completando así una serie de seguimientos y controles requeridos por el programa.

\section{Canastas y Aportes de Asociaciones Locales}

En Bolivia también se han desarrollado programas de alimentos que se denominan "Canastas Solidarias y Saludables" como una innovación en el tema de la comercialización de productos exclusivamente orgánicos sin la aplicación de agroquímicos de ningún tipo. Estos programas son más localizados a nivel de departamento y los mismos son coordinados por una combinación de asociaciones o grupos de productores y compradores incluyendo ONGs, entidades de

\footnotetext{
57 Bono Madre Niña-Niño Juana Azurduy (2009-) https://dds.cepal.org/bpsnc/programa?id=5

${ }^{58}$ CEPAL, Bono Madre Niña-Niño Juana Azurduy, Base de datos de pragramas de protección social no contributiva, https://dds.cepal.org/bpsnc/programa?id=5

${ }^{59}$ Estado Plurinacional de Bolivia, Requisitos de inscripcion al Bono Juana Azurduy, https://www.bja.gob.bo/index.php/el-bono/requisitos-para-inscribirse

${ }^{60}$ Estado Plurinacional de Bolivia, Bono Juana Azurduy, https://www.bja.gob.bo/

${ }^{61}$ Estado Plurinacional de Bolivia, Qué es el Subsidio Universal Prenatal, Bono Juana Azurduy, https://www.bja.gob.bo/index.php/el-subsidio/que-es-el-subsidio-universal-prenatal

62 Estado Plurinacional de Bolivia, Quienes acceden al Subsidio Universal Prenatal, Bono Juana Azurduy, https://www.bja.gob.bo/index.php/el-subsidio/quienes-acceden-al-subsidio
} 
gobierno local y en oportunidades con apoyo internacional. Este es el caso de la Asociación Agroecología y Fe en Cochabamba que centra su acción en las localidades de Tacopaya, Sipe, Cochabamba, Arbieto y también en el Norte de Potosí, Anzaldo y Totora. Es de sumo interés destacar que estas localidades incluyen un extenso número de familias pertenecientes a grupos originarios como Quechua en Sipe Sipe y Cochabamba y Aymara en Tacopaya y Arque.

Este emprendimiento es apoyado por entidades parroquiales locales al igual que por la agencia de cooperación internacional MISEREOR, que es la Obra Social de la Iglesia Católica de Alemania $^{63}$. La modalidad es semejante a la citada en el Ecuador y es llevada a cabo por familias de pequeños agricultores, que a su vez reciben el apoyo de otras instituciones que se enfocan en la a agricultura sostenible local. De este modo también se estrecha la conexión entre los productores agrícolas y los consumidores. Este tipo de programa o emprendimiento adopta una serie de principios como son la: organización local, solidaridad y cooperación reciproca, la buena calidad de productos cultivados por familias campesinas que apoyan la "economía para la vida" y que favorece la producción sustentable y a la economía local. Las "canastas solidarias y saludables", se realizan en forma mensual y entre los meses de mayo a septiembre realizándose el aprovisionamiento cada dos meses para reiniciar la modalidad mensual a partir del mes de noviembre. La organización del abastecimiento es por medio de compras comunitarias por parte de las familias y las ventas directas por los productores coordinados por la organización de base. Los productos que se comercializan incluyen hortalizas, tubérculos, granos, frutales, cebolla, papa, tomate, zanahoria, acelga, repollo, también carnes, miel, quesillo y productos transformados. Una canasta media tiene un costo de aproximadamente US\$14 (100 pesos Bolivianos).

Los grupos comunitarios suelen coordinar las compras mediante listas de pedidos por anticipado de las familias compradoras y los productores facilitando la compra directa. En este caso, como existe la relación institucional de Agroecología y Fe, también se realizan actividades educativas en forma periódica como la planificación de alimentos (menús nutricionales) y además incluyen la visita a parcelas de agricultores que proveen los productos. Si bien no existen estadísticas concretas del alcance y el funcionamiento de estas canastas las mismas se han llevado a cabo en forma continua por unos 15 años y se manejan con una consigna que reconoce la alimentación saludable en todo el país: "Te vendemos productos orgánicos y te regalamos salud."

\footnotetext{
${ }^{63}$ La Asociación Agroecología y Fe http://asociacionagroecologiayfe.com/ es apoyada por MISEREOR que es la mayor organización de ayuda católica de Alemania. MISEREOR, trabaja para ayudar a combatir la pobreza, independientemente de su denominación. En Cochabamba, la Asociación Agroecología y Fe cuenta con una plataforma de apoyo a https://cambioclimatico.org.bo/contenido/agroecologia-y-fe-en-cochabamba/
} 


\section{CANASTAS ALIMENTARIAS PARA ADULTOS MAYORES - MEXICO}

México también ha adoptado el sistema de canastas alimentarias para lograr la cobertura de su población a nivel nacional con carencias o de bajos ingresos. Uno de estos programas se enfoca exclusivamente en las personas de la tercera edad. El Programa Desarrollo Social Familias Fuertes Apoyo a Personas Adultas Mayores ${ }^{64}$ contribuye a disminuir aspectos de carencias de alimentos para aquellas personas de 60 años de edad en adelante con la entrega de canastas alimentarias y servicios para apoyar sus necesidades básicas y contribuir a su bienestar. El Programa, desarrollado por la Secretaria de Desarrollo Social y el Consejo Estatal de la Mujer y Bienestar Social (CEMyBS) se halla actualmente en ejecución y tiende a cubrir los 125 municipios del Estado de México ${ }^{65}$, este es un programa estadual. El apoyo que brinda este programa es "en especie" con la modalidad de canastas alimentarias de frecuencia de hasta diez entregas durante el ejercicio fiscal anual teniendo en cuenta aspectos de disponibilidad de productos y la cobertura correspondiente en base a la disponibilidad presupuestal del ente estatal. No existe una determinación detallada de los productos que componen las canastas o los aspectos nutritivos de las mismas. Los beneficios se otorgan a través de las llamadas "Ferias de Bienestar" donde se llevan a cabo chequeos médicos con módulos de atención y unidades móviles con citas programadas con antelación ${ }^{66}$. Las Ferias de Bienestar proporcionan un conjunto de servicios a cargo de profesionales que brindan asesoría y atención en materia legal, psicológica, de trabajo social y gerontología desde entes de los gobiernos estatales y también municipales. El apoyo a la atención integral es completamente gratuito mediante la gestión de servicios desde las instancias públicas o también privadas gestionadas por el Gobierno del Estado de México.

Existen una serie de criterios para calificar en el programa lo cual incluye: 1- Requisito de edad, es decir tener 60 años de edad cumplidos; 2- Presentar condición de pobreza y carencia de acceso a la alimentación; 3- Vivir en forma permanente en el Estado de México; 4- No tener doble cobertura o ser beneficiario de programas similares de orden social ya sea federal, estatal o municipal y también mediante otros programas de transferencias monetarias o en especie. Quienes gocen de este beneficio deben presentar una muestra de identificación ${ }^{67}$, su Clave Única de Registro de Población (CURP) y también poseer domicilio en el Estado de México. Existe además un criterio de selección que incluye y da prioridad a obtener este beneficio a personas adultas mayores que hayan sido víctimas de delincuencia y también a quienes tiene a su cargo hijas e hijos menores de edad de mujeres que perdieron su libertad por resolución judicial; y también aquellas personas de nacionalidad mexicana que experimenten repatriación a México.

\footnotetext{
${ }^{64}$ Programa de Desarrollo Social Familias Fuertes Apoyo a Personas Adultas Mayores http://cemybs.edomex.gob.mx/canasta alimentaria 6069

${ }^{65}$ El Estado de México, es una de las treinta y dos entidades federativas que conforman los Estados Unidos Mexicanos, su capital es la ciudad de Toluca de Lerdo que es además la ciudad más poblada del estado con más de quince millones de habitantes.

${ }^{66}$ Objetivos de las Ferias de Bienestar http://cemybs.edomex.gob.mx/sites/cemybs.edomex.gob.mx/files/files/Ferias\%202019.pdf

${ }^{67}$ Aviso de Privacidad para el programa de desarrollo social; Familias Fuertes Apoyo a Personas Adultas Mayores

Revisión Número 01 Fecha de aprobación 12 de septiembre de 2019. http://cemybs.edomex.gob.mx/sites/cemybs.edomex.gob.mx/files/files/1\%20AVISO\%20ADULTOS\%20MAYORES-FINAL.pdf
} 
Este programa en particular presenta un interesante enfoque de género ya que esta insertado en Consejo Estatal de la Mujer y Bienestar Social (CEMyBS) y da prioridades a público vulnerable adoptando una atención integral que incluye la alimentación sana en especies.

\section{CAJAS URBANAS (2009-2011) - HONDURAS}

Las Ilamadas "Cajas Urbanas" de Honduras, parten de un proyecto piloto entre $\mathrm{FAO}^{68}$ y por la Alcaldía Municipal del Distrito Central de Tegucigalpa ofreciendo un interesante ejemplo de cobertura social y alimentaria que tuvo como principal objetivo el fortalecimiento de la agricultura urbana y periurbana (APU) a modo de contribuir a la seguridad alimentaria y nutricional de poblaciones en estado de pobreza. El modelo se centró en una visión que incluye la financiación comunitaria principalmente liderada por mujeres hondureñas. El programa APU se desarrolló en el Distrito Central (Tegucigalpa y Comayagüela y alrededores), fue conocido como "el proyecto de los huertos" y entre sus metas incluyo el consumo de hortalizas en una cantidad igual o mayor a los $110 \mathrm{gr}$ per cápita por individuo con una frecuencia diaria ${ }^{69}$, mediante la instalación y permanencia de huertos comunales y/o familiares (FAO 2013). La participación en esta modalidad de "Cajas" podía ser en forma individual o comunitaria, destinándose un porcentaje de los ingresos de las ventas de los productos a la formación de un pequeño capital "semilla" de este modo el proyecto cubrió no solo aspectos de nutrición y alimentación sino de enfoque productivo y de comercialización.

Durante el período de ejecución 2009-2011 se lograron establecer 1.075 huertos familiares o de "traspatio" con un $88 \%$ de participación femenina de las cuales el $53 \%$ estaban entre los 20 y los 39 años; el $41 \%$ entre los 40 y los 59 y el $5 \%$ eran mayores de 60 años $^{70}$. En el Distrito Central de Honduras (Tegucigalpa y Comayagüela), viven aproximadamente más de 1.126.534 personas y el $91 \%$ de esta población vive en áreas urbanas y periurbanas (FAO-INE, 2012). En este contexto se crearon unas 10 Cajas en 10 Colonias, entre ellas Monte de los Olivos, Los Pinos, Nueva Suyapa y Villa Nueva y además en las zonas periurbanas del Departamento de Francisco Morazán.

La modalidad de las Cajas Urbanas adopto el perfil de las llamadas Cajas Rurales que fue llevado a cabo con anterioridad y fue inicialmente una estrategia promovida por el Programa Especial de Seguridad Alimentaria (PESA) ${ }^{71}$. Las Cajas urbanas adoptaron un importante componente de género enfocado en la participación y el empoderamiento de mujeres y principalmente

\footnotetext{
${ }^{68}$ Proyecto piloto de FAO para el fortalecimiento de la agricultura urbana y periurbana (APU) y de la seguridad alimentaria en el Distrito Central (Tegucigalpa y Comayagüela y alrededores)"

${ }^{69}$ Las Cajas Urbanas: Una experiencia de financiación comunitaria liderada por mujeres. Cristina Rentería Garita Karla Andino y Alberto Pantoja. Proyecto piloto para el fortalecimiento de la agricultura urbana y periurbana (APU) y de la seguridad alimentaria en el Distrito Central (Tegucigalpa, Comayagüela y alrededores), Honduras. FAO, Santiago, Chile, 2013, pp 4.

${ }^{70} \mathrm{FAO}, 2013$. "Las Cajas Urbanas: Una experiencia de financiación comunitaria liderada por mujeres" http://www.fao.org/3/i3286s/i3286s.pdf

${ }^{71}$ Este fue un Proyecto piloto para el fortalecimiento de la agricultura urbana y periurbana (APU) y de la seguridad alimentaria en el Distrito Central (Tegucigalpa y Comayagüela y alrededores), FAO.
} 
madres solteras que conformaron el $71 \%$ del público participante en este programa. Algunos de los beneficios de estas Cajas no solo incluyen la alimentación adecuada, sino que se promovieron aspectos como el acceso a prestamos comunitarios, dinero en efectivo con bajas tasas de interés para emergencias y/o emprendimiento de negocios, apoyo en situaciones de necesidad alimentaria, etc. Estos programas proponen alternativas como la generación de ingresos con apoyo de capacitaciones enfocadas en la oferta de préstamos; el establecimiento de montos mínimos de ahorro obligatorio y también la integración al mercado laboral. Finalmente, el modelo de las Cajas Urbanas ofrece la posibilidad de una integración que puede ser modelo replicable en otros contextos semejantes de la Región con miras a la complementariedad nutricional y económica del público meta.

\section{PROGRAMA PROCOMIDA - GUATEMALA}

PROCOMIDA, fue un programa de asistencia a la seguridad alimentaria, la salud materno-infantil de mujeres embarazadas o lactantes y de la alimentación para niños/as de 0 - 24 meses en situación de inseguridad alimentaria aguda en la zona norte de Guatemala. El programa fue llevado a cabo durante el período 2009-2014 y fue implementado con apoyo de la Agencia de Desarrollo de Estados Unidos (USAID), la oficina local de la ONG Mercy Corps y el gobierno Departamental. Los Departamentos cubiertos por este programa incluyeron, Alta Verapaz, el Petén y el Quiche. El programa ofrecía una serie de beneficios que incluyeron transferencias alimentarias para disminuir la inseguridad alimentaria local, atención de los problemas de desnutrición mediante la provisión de raciones nutritivas, las que se componían de una mezcla de maíz y soya, arroz en bolsas, frijoles pintos y aceite vegetal. La estrategia de implementación también incluyó el desarrollo de la capacidad para que las madres y personal de cuidado pudieran adoptar prácticas más saludables y también propiciar un cambio de actitud positivo en cuanto a la salud. PROCOMIDA fue llevado a cabo con la participación del personal de establecimientos de salud del gobierno mediante el empleo de estructuras comunitarias organizadas para mejorar la prestación de servicios técnicos y culturalmente apropiados. De este modo también se abordaron otros aspectos referentes también a la atención médica para la población del área geográfica de implementación.

Como todo programa de asistencia alimentaria, el mismo se enfocó en obtener una mejora del orden nutricional mediante la distribución de raciones como un incentivo para lograr la participación de los hogares pobres. Otros beneficios incluyeron la organización a nivel local mediante la formación de grupos de madres; la enseñanza de prácticas saludables reforzadas a través de visitas domiciliarias, la distribución de raciones y el establecimiento de fondos comunitarios de emergencia para facilitar el transporte a los servicios de salud, de este modo se buscó reducir la vulnerabilidad de los hogares participantes.

Si bien el programa logró una mejora sustancial para evitar el retraso del crecimiento (stunting) en el norte de Guatemala, el mismo en forma no intensional enfatizó el consumo de alimentos altos en calorías llevando a un excesivo aumento de peso principalmente para las mujeres en 
el postparto. Una reciente evaluación del IFPRI (Leroy et al 2019) estableció que no es fácil determinar exactamente el nivel de ganancia de peso dado que el $47 \%$ de las mujeres participantes sufrían de sobrepeso u obesidad pre-embarazo, lo cual es un factor de suma importancia para lograr la pérdida de peso post-embarazo. Si bien el programa tomó en cuenta la calidad de la ingesta, las raciones alimentarias facilitaron a que las mujeres incrementaran la ingestión de alimentos ricos en calorías. El estudio concluyó que el programa facilitó el aumento de peso de las mujeres participantes, ya que se considera que dicho aumento ocurrió en forma proporcional al tamaño de la ración que recibía la familia la cual también dependía del tamaño de estas familias. El estudio deja inferir que las razones del aumento de peso no pueden ser adjudicadas únicamente a aspectos como la falta de movilidad por parte de las mujeres. Una posible explicación puede ser que la ingesta de raciones redujo la lactancia materna y la lactancia induce la pérdida de peso en el post parto (Leroy et al 2019). Para paliar esta situación se plantea el desarrollo de la adopción de políticas de "dualidad" es decir que no solo mejoren en la ingesta, sino que se enfoquen en el impacto y la ganancia de peso de las madres en forma paralela.

\section{COMEDORES POPULARES “COCINANDO PARA LA SALUD" - PERÚ}

En el Perú desde hace ya varias décadas existen los programas sociales de complementación alimentaria o los llamados "Comedores Populares" que buscan realizar una suplementación de alimentos para el público afectado por la pobreza extrema o diferentes aspectos de vulnerabilidad. Su ejecución se remonta a 1991 con la puesta en marcha de un proyecto llamado "La Mejor Compra" (OPS 2005), que se enfocaba en la provisión de alimentos y productos nutritivos a muy bajo precio para suplementar la alimentación de familias carenciadas en Lima. El programa evolucionó y al presente atiende familias localizadas en zonas urbanas, periurbanas y también en el área rural. Existen alrededor de unos 19,000 comedores populares en los municipios de todo el país, con unos 5,000 localizados en Lima correspondiendo a un $16 \%$ de la totalidad los que a su vez sirven a un millón de personas o un $23 \%$ de beneficiarios de Lima. Estos programas son organizados por los gobiernos locales y consisten en grupos de madres organizadas en cuanto a la compra, preparación y distribución de alimentos. Los menús incluyen comidas preparadas generalmente con carbohidratos, arroz, aceites, carnes, frutas o verduras, pero estas últimas en menor proporción. Los alimentos se distribuyen a los establecimientos donde las madres preparan dichos alimentos en forma diaria los que son ofrecidos al público a un valor muy razonable. Desafortunadamente, no existe en todos los casos un escrutinio de los menús diarios desde el punto de vista nutricional y se ha determinado que los mismos presentan muy pocas opciones de alimentos frescos (frutas y verduras). Programas semejantes en países como Chile y también México (Corvalán et al 2008) han arrojado resultados preocupantes debido al aumento de peso incremental y la tendencia al sobrepeso y la obesidad que presentan un gran porcentaje de usuarios asiduos de estos servicios de alimentación. También en el Perú un estudio de evaluación de los servicios de alimentación accesibles en los comedores populares, arrojo resultados preocupantes que determinaron un elevado incremento de peso en aquellas personas que utilizaban estos servicios con notable frecuencia, principalmente las mu- 
jeres (Carrillo Larco et al 2016). En los últimos cinco años se ha determinado que de cada cuatro hogares en situación de pobreza al menos un miembro de cada familia es beneficiario de estos programas alimentarios con una frecuencia del $43 \%$ and área rurales y $19 \%$ en zonas urbanas (INEI 2015; Diez-Canseco et al 2017).

Los comedores populares han sido en oportunidades objeto del desarrollo de programas de alimentación con miras a proveer suplementos y en algunos casos alimentos altos en hierro y otros nutrientes, aunque no existe una consistencia en la implementación de estos suplementos en todo el país. A partir del año 2012 y por un período de dos años, el Centro de Excelencia en Enfermedades Crónicas (CEEC) realizó un estudio que se llamó "Cocinando para la Salud" que fue un seguimiento en tres etapas para estudiar la organización, el funcionamiento y la implementación de los menús corrientes a modo de cuantificar el impacto en la salud de quienes utilizan estos comedores populares. Durante la tercera etapa de estudio, en 2014, se desarrolló un modelo de ofertas variadas de productos frescos principalmente ensaladas y frutas, también carnes y sopas y se entrenó al personal que cocinaba estos productos en aspectos básicos de nutrición. Luego de un seguimiento y de la realización de encuestas para averiguar la preferencia de los menús por parte del público, se determinó que los usuarios por lo general se fijan más que nada en el precio de los alimentos ofrecidos, pero en todos los casos los usuarios expresaron que estaban dispuestos a pagar un mayor precio por alimentos frescos. El valor de una porción de alimentos se estima en Soles 1.5.(US\$0.50) pero también existe un subsidio de apoyo que reduce el costo de las raciones a Soles 0.25 (US\$ 0.07 ) siendo esta modalidad adoptada en 1800 comedores principalmente en Lima.

La selección de los programas citados con anterioridad en nueve países de la región presentó algunas opciones innovadoras en cuanto a asociación, cobertura y modalidades de implementación. La mayoría de ellos se centra en poblaciones vulnerables con un rango de edades muy amplio, es decir desde la niñez a la tercera edad. Es interesante realizar un análisis comparativo dado que casi todos los citados programas se enfocan en la provisión de alimentos de una u otra forma: ya sea entrega de producto, compra a precios descontados o por medio de transferencias, pero aun así son pocos aquellos que especifican acciones concretas en referencia a la prevención del sobrepeso y la obesidad de la población atendida. Se hacen referencias a este análisis en la sección de conclusiones. 


\section{PROGRAMAS DE ALIMENTACION ESCOLAR}

Otra importante modalidad de programas de protección social de apoyo a la población de bajos recursos y con carencias alimentarias se centra en la oferta directa de alimentos nutritivos a través de programas de alimentación escolar vehiculizados por los llamados comedores escolares que son ofrecidos desde la temprana edad hasta la adolescencia siguiendo el ciclo educativo. De acuerdo con el Programa Mundial de la Alimentación, las medidas "sensibles a la nutrición" y en particular los programas de alimentación escolar son un componente crítico para hacer frente a la malnutrición en sus variadas formas. El informe Nutrir al Futuro (WFP 2017) con un análisis de los programas de alimentación escolar en 16 países de la región establece que el adecuado diseño de estos se transforma en una herramienta indispensable para paliar la desnutrición infantil de la franja de niños/as y jóvenes de la región de los cuales más del 92\% se encuentran matriculados en la educación primaria. Aun así, existe un porcentaje que no es cubierto por estos programas de protección social.

Al igual que con la adopción de los PTC, los programas de alimentación escolar cuentan con un período de implementación prolongado en la región, aun los programas más recientes como el de Paraguay (1995) llevan ya más de dos décadas de ejecución y algunos aún más como en el caso de Colombia (1945) y El Salvador (1984). Los programas cubren las necesidades de alimentación con un buen nivel nutricional para atender aproximadamente al $11.6 \%$ de las niñas y niños en la región que son afectados por la malnutrición crónica. Según el Banco Mundial:

"Los programas de alimentación escolar son la red de protección social más prevalente a nivel mundial. Hoy en día, más de 85 millones de escolares en la región reciben comidas en la escuela, con recursos procedentes principalmente de presupuestos nacionales. ${ }^{72}$

Las meriendas o almuerzos escolares se han convertido en una estrategia exitosa para asistir a niños y niñas desde la temprana edad cuyas familias se hallan bajo niveles de pobreza. Los diversos programas de alimentación escolar incluyen dietas sanas y nutritivas, por lo general su diseño está a cargo de nutricionistas que desarrollan estos programas en base a los perfiles poblacionales teniendo en cuenta las necesidades específicas de estos grupos. Otra ventaja de los programas es que además incentivan la participación de los niños y niñas a permanecer en los programas educativos en forma regular. Un aspecto de interés es que los programas de alimentación escolar pueden ser combinados con otras estrategias de provisión de alimentos

\footnotetext{
72 WFP. Nutrir el Futuro Programas de Alimentación Escolar Sensibles a la Nutrición en América Latina y el Caribe Un Estudio de 16 Países. (2017) pp.10 https://docs.wfp.org/api/documents/WFP. $\underline{0000071367 / \text { download/? ga=2.92193818.1462672604.1527517334-307212363.1525721785 }}$
} 
como parte de la previsión de canastas de alimentos y las compras públicas cuando los productos ofrecidos en las escuelas provienen de compras a productores locales, de este modo se determina además un apoyo y una importante movilización de la economía local.

A continuación, se describen los programas de alimentación escolar desarrollados e implementados actualmente en varios de los países de América latina y el Caribe. La información presentada, se basa en las descripciones y las cifras publicadas en la base de datos de la Plataforma de Seguridad Alimentaria y Nutricional (PSAN) de la Comunidad de Estados Latinoamericanos y Caribeños, (CELAC), la base de datos NOURISHING Framework ${ }^{73}$ y también mediante la revisión documental de los programas detallados en los correspondientes sitios web de los gobiernos de los respectivos países cuando estos estuvieran vigentes.

${ }^{73}$ NOURISHING framework: http://www.wcrf.org/int/policy/nourishing-framework 


\section{Cuadro 9. PROGRAMAS DE COMPLEMENTACION ALIMENTARIA ESCOLAR EN PAISES SELECCIONADOS DE} AMERICA LATINA.

Bolivia $^{74}$ Ley $N^{\circ} 622$ de Alimentación Escolar en e Marco de la Soberanía Alimentaria y la Economía Plural

Brasil

El Programa Nacional de Alimentos Escolares (PNAE)

Con la Ley $\mathrm{N}^{\circ} 11.947$, del 16 de Junio de 2009
Contribuir al crecimiento y desarrollo bio-psicosocial, el aprendizaje, rendimiento escolar y a la formación de hábitos alimentarios saludables de los estudiantes, a través de acciones de educación alimentaria y nutricional y el su-

ministro de alimentos para cubrir

1.Garantizar progresivamente la vas del Sistema Educativo Plurinacional, con alimentos proveel marco del desa para el Vivir Bien

2.Contribuir al rendimiento escolar y promover la permanencia de las y los estudiantes de las unidacativo Plurinacional, a través de la alimentación sana, oportuna y culturalmente apropiada.

3.Fomentar la compra de productos destinados a la Alimentación Complementaria Escolar, incentivando y priorizando el consumo la producción local de alimentos. Alimentación Complementaria nientes de la producción local en

\section{La producción y provisión de Nivel Nacional} alimentos para la Alimentación Complementaria Escolar de las/los estudiantes de las unidades educativas del Sistema Educativo Plurinacional, se sustenta en la complementariedad de acciones de los diferentes niveles de gobierno, los proveedores y/o productores locales y nacionales de alimentos.

Se proveen alimentos en forma permanente: Las entidades territoriales autónomas responsables de proveer Alimentación Escolar, asistirán en forma permanente durante toda la gestión educativa, con alimentos sanos, inocuos, de calidad, nutritivos y culturalmente apropiados, provenientes de la producción local y nacional.

\section{Educación Alimentaria}

y Nutricional recibe alimentos de la Agricultura familiar (AF) productos obtenidos de

proyectos y huertos escolares Con la Ley $\mathrm{N}{ }^{\circ} 11.947$, el

$30 \%$ del monto transferido por el Programa Nacional de
Nivel Nacional: 5,564 Municipalidades;

Alumnos atendidos por e

PNAE 45 millones al día/

200 días al año

Escuelas 190.000

Este programa cubre 200

días escolares de febrero
Ministerio de

Desarrollo Productivo y Economía

Plural

Ministerio de Desarrollo Rural y

Tierras

El Gobierno Federal le transfiere montos financieros a los estados, municipios y escuelas federales

\footnotetext{
74 Plataforma CELAC. Ley N 622 de alimentación escolar en el marco de la soberanía alimentaria y la economía plural. Bolivia. https://plataformacelac.org/ley/90
} 
sus necesidades nutricionales durante el año escolar. ${ }^{75}$
Alimentación Escolar - PNAE debe invertirse en la compra directa de productos de la agricultura familiar, una medida que estimula el desarrollo económico y sostenible de las comunidades. ${ }^{76}$

Mejorar la asistencia a clases y retener a los estudiantes en el sistema educacional, a través de la entrega de un servicio de alimentación escolar saludable, variado y nutritivo, que les permita un desarrollo físico y mental que favorezca y estimule la concentración y aprendizaje necesarios para su éxito académico. ción Escola

Ley № $15.720 / 1964$
Se entrega una ración diaria de alimentación por estudiante, complementaria y diferenciada, compuesta por: desayuno, almuerzo y/u once además en hogares se entrega desayuno, almuerzo once y cena. Cubre alrededor de un tercio de las necesidades nutricionales del día de los escolares de enseñanza básica y media y entre un 45 y un $50 \%$ de los requerimientos de los preescolares y en el caso de los hogares el

$100 \%$ del requerimiento diario de los alumnos y alumnas beneficiarias. noviembre. En el 2012, al-

canzo a más de 250000 ins-

titutos educativos..$^{77} \mathrm{En}$

2014, PNAE benefició a 42.2

millones de estudiantes y

además los recursos utilizados para la adquisición de alimentos de los pequeños agricultores alcanzaron más de (Reales) R\$711millones. ${ }^{78}$

Cobertura Nacional: Alumnos de familias que pertenecen al $60 \%$ más vulnerable o Becas con mayor desventaja socioeconómica según registro social de hogares, que asisten a establecimientos educacionales municipales y particulares subvencionados del país (adscritos al PAE) en los niveles de educación prebásica, básica, media y adultos.

\section{Junta Nacional de}

-


Colombia $^{80} \quad$ Programa de Alimentación Escolar

\section{Documento Consejo} Nacional de Política Económica y Social 113, 2008: Política Nacional de Seguridad Alimentaria y Nutricional. escolar de las niñas, niños

Costa Rica ${ }^{83}$ Programa de alimentación y nutrición del escolar y del adolescente $^{84}$

Constitución Política (1949). Artículo 21 títu $4^{\circ}$ Derechos y Garantías Individuales, artículo 50 del título quinto sobre "Derechos y Garantías Sociales" -Decreto No 30256 Etiquetado Nutricional de los Alimentos
Contribuir al acceso con permay adolescentes en edad escolar,

omplemento alimentario a las niñas, niños y adolescentes en edad escofomentando estilos de vida saludables y mejorando su capacidad de aprendizaje, a través del suministro de un complemento alimentario.

Grupo meta: gía, maquerimientos de energía, macronutrientes (carbohidratos, proteínas y grasas) y micronutrientes (hierro, y calcio), en los porcentajes que se definan para cada modalidad durante la jornada escolar.

Ofrecer una alimentación comple- El menú debe ser adecuado mentaria a la población estudiantil y promover hábitos alimentarios saludables, hábitos de higiene y comportamientos adecuados en torno a la alimentación diaria. para la edad, suficiente para la energía necesaria, y culturalmente apropiado. El gobierno tiene una descripción completa del menú de desayunos y almuerzos ${ }^{85}$ Se incluyen leguminosas, frutas, verduras, pastas, sopas, vegetales con carne, carnes semimagras, verduras, picadillos, arroces compuestos para 14 ciudades y 45,34
Colegios en áreas rurales,

que atiendan comunidades

étnicas, víctimas del conflicto armado, o con alta concentración de población con puntajes de SISBEN ${ }^{81} 48,49$

Consejo Nacional de Política Económica y Socia (CONPES) para resto urbano, de acuerdo con la nueva metodología del SISBEN III.

Nacional; Actualmente el Programa de Nutrición y Alimentación del Escolar y el Adolescente (PANEA) del

Ministerio de Educación Pública cubre el $96.1 \%$ del total de centros educativos, asegurando alimentación al

$88.3 \%$ de la población estudiantil costarricense inscrita en el sistema de educación pública.
Ministerio de Edu-

cación Pública

Ministerio de Educación ${ }^{82}$

80 Plataforma CELAC. Programa de Alimentación Escolar. Colombia. https://plataformacelac.org/programa/366

${ }^{81}$ EI SISBEN: EI Sisbén es la principal herramienta con que cuenta el Gobierno de Colombia para la focalización del gasto social que garantice que los programas sociales lleguen a las personas que viven la pobreza en sus diferentes formas. http://www.sdp.gov.co/gestion-estudios-estrategicos/sisben/metodologia-4

82 Mineducación, Ministerio de Educación Nacional - República de Colombia PAE http://www.mineducacion.gov.co/1621/w3-article-327088.html

${ }^{83}$ Plataforma CELAC. Programa de Alimentación y nutrición del escolar y del adolescente. Costa Rica. https://plataformacelac.org/programa/301

${ }^{84}$ Programa de Alimentación y Nutrición del Escolar y del Adolescente (PANEA). Gobierno de Costa Rica. http://www.mep.go.cr/programas-y-proyectos/programa-de-alimentacion-ynutricion

${ }^{85}$ Manual de Menú para Comedores Estudiantiles de primaria https://www.mep.go.cr/sites/default/files/page/adjuntos/manual-primaria.pdf 
Ecuador ${ }^{86} \quad$ Programa de Alimentación Escolar

Ley Orgánica del Régimen de la Soberanía

Alimentaria

Decreto № 696 uir al mejoramiento de la calidad y eficiencia de la educación básica mediante la entrega de un complemento alimenticio, principalmente en zonas con mayor incidencia de la pobreza.
El Salvador ${ }^{87}$ Programa de Alimentación y Salud Escolar

Programa de Desayunos Escolares
Contribuir con la mejora del estado nutricional del estudiantado para propiciar mejores condiciones de aprendizaje.

Entregar una refacción escolar todos los niños y niñas del país en las modalidades de preescolar y primaria.
Desayuno: Compuesto de una colada fortificada de sabores y galleta rellena o tradicional; barra de cereal, y granola. Refrigerio consiste en $200 \mathrm{ml}$ en envase tetra brik de leche de sabores y entera. Almuerzo: El almuerzo escolar es entregado listo para el consumo en las Instituciones Educativas, su elaboración se efectúa en base a requeri-

mientos nutricionales de los escolares de acuerdo con el grupo de edad, y su preparación es realizada con productos frescos de la zona, propiciando la compra local y directa a pequeños productores.

Como parte de este Programa se entrega frijol, arroz, azúcar, aceite, bebida fortificada y leche en polvo, ésta última para aquellos centros escolares que aún no reciben leche líquida.

el año escolar 2017

2018 , se alcanzaron a

$1,168,837$ estudiantes de

5,102 centros educativos

220 centros de Atención Ini-

cial del Instituto Salvadoreño para el Desarrollo Integral de la Niñez y Adolescencia y 42 centros rurales de nutrición del Ministerio de Salud.

Entrega de desayunos escoares compuestos por un ato elaborado de Incaparina y cinco menús elaborados con
Zonas Rurales y Urbanas 24.840 escolares reciben el desayuno anualmente.
Ministerio de Educación e Instituto de Provisión de Alimentos

Ministerio de Educación

Ministerio de Educación

${ }^{86}$ Plataforma CELAC. Programa de Alimentación Escolar. Ecuador. https://plataformacelac.org/programa/41

${ }^{87}$ Plataforma CELAC. Programa de Alimentación y salud Escolar. El Salvador. https://plataformacelac.org/programa/132

${ }^{88}$ Plataforma CELAC. Programa de Desayunos Escolares. Guatemala. https://plataformacelac.org/programa/159 


\section{Honduras $^{89}$ \\ Programa Escuelas Sa- ludables \\ -Decreto Ejecutivo No. PCM-0001-2000 De- creto $N^{\circ}$ 54-2010, -Ley del vaso de Leche para el fortalecimiento de la Merienda Escolar \\ Reglamento General de la Ley Del Vaso de Le- che para fortalecimiento a la Merienda Escolar}

Jamaica $^{90}$

Jardín Escolar Nacio nal/National School Garden

Constitución Política de 1962 Derecho a la Alimentación en Jamaica

México $^{91}$

Programa de Desayunos Escolares
El Programa busca la reducción de los índices de desnutrición deserción y repitencia escolar; aumentando la asistencia y el rendimiento académico de los es colares en ambientes y entorno favorables para la vida con la instituciones. participación activa de los padres y madres de familia, comunidad e

Protemás entre otros alimentos preparados por las madres de los alumnos.

Merienda escolar urbana y ru ral; Implementación de huertos escolares.

Entrega de micronutrientes, desparasitantes, vacunas y realiza capacitaciones. Vitamina $A$ : se proporciona una (1) cápsula de 200,000 U.I. a los mayores de seis años, dos veces al año (marzo y septiembre).

Hierro: de preferencia amino quelado y complementado con ácido fólico (este se absorbe en un $90 \%$ comparado con $60 \%$ del sulfato ferroso, siendo las molestias gástricas mínimas), una tableta de 30 mg o sulfato ferroso de 300 mg semanalmente

Equipar a todos los establecimientos educacionales públicos de jardines escolares, dirigidos a proveer, a los jóvenes, de habilidades y conocimiento necesa-

rios, para desarrollar la agricul-

tura y promover el emprendi-

miento en el campo.

Contribuir a la seguridad alimentaria de la población escolar, su-
El programa otorga los materiales para la construcción de los jardines escolares. También construye y mantiene los jardines escolares y genera las instancias pedagógicas para que los jóvenes interactúen e intervengan en los jardines.

El desayuno o comida escolar caliente se compone de:
Todos los niños y niñas del país en las modalidades de preescolar y primaria.

La población escolar de los centros educativos rurales y urbanos- marginales, de los municipios con más alta vulnerabilidad del país.

Secretaría de Desarrollo e Inclusión Social

Secretaría de Edu cación

Presidencia de la República de Honduras

Cobertura urbano-rural, jóve- Autoridad de nes en etapa escolar primaria, secundaria y terciaria.

Desarrollo Agricultural Rural
Niñas, niños y adolescentes en condiciones de riesgo y vulnerabilidad, que asisten a
Sistema Nacional para el Desarrollo

${ }^{89}$ Plataforma CELAC. Programa Escuelas Saludables. Honduras. https://plataformacelac.org/programa/211

${ }^{90}$ Plataforma CELAC. Jardín Escolar Nacional. Jamaica. https://plataformacelac.org/programa/254

${ }^{91}$ Plataforma CELAC. Programa de Desayunos Escolares. México. https://plataformacelac.org/programa/116 
jeta de asistencia social, mediante la entrega de desayunos calientes, desayunos fríos, diseñados con base en los Criterios de Calidad Nutricia, y acompañados de acciones de orientación alimentaria, aseguramiento de la calidad alimentaria y producción de alimentos.

Mejorar el nivel nutricional y el acceso a la educación, promoviendo la asistencia y retención escolar, de niños y niñas, con la participación de la comunidad y una estrecha coordinación interinstitucional en municipios con muy alta y alta inseguridad alimentaria y extrema pobreza.

$\begin{array}{ll}\text { Panamá }^{94} & \text { Merienda Escolar } \\ & \text { Educación Alimentaria } \\ & \text { Nutricional }\end{array}$

El programa se enfoca en los niños y niñas que diariamente acuden a establecimientos escolares, ofreciendo productos nutricionales de alta calidad que además de contribuir con su aporte de energía (de 320 a $330 \mathrm{kcal}$ por modalidad) equivalente al de una merienda ligera, cumplen tam-

bién con una serie de nutrientes
1. Leche descremada $y / 0$ agua natural.

2. Un platillo fuerte que incluya verduras, un cereal integral, una leguminosa y/o un alimento de origen animal.

\section{Fruta.} nas, rurales y urbano-margi-

El programa provee una Merienda a estudiantes de nivel preescolar y primario de todas las escuelas públicas de los alumnos de municipios en ria. situación nutricionalmente más críticas.

El programa entrega una merienda escolar compuesta por galletas nutricionalmente mejoradas, bebida láctea y crema nutritiva enriquecida, conformada por un paquete de 34 gramos de galletas, 8 onzas de bebida láctea u 8 onzas de crema nutritiva. planteles oficiales del Sistema Educativo Nacional, ubicados en zonas indígenadas, preferentemente. El

Programa distribuye 6 millones 92 mil 103 raciones alimentarias diarias en 80 mil 746 escuelas de nivel preescolar, primaria y secundaria, de las cuales, $50 \%$ se otorgan en su modalidad caliente a través de las casi 40 mil cocinas escolares instaladas en los 32 estados del país. ${ }^{92}$

Integral de la Familia

Alcance Nacional Niños -Niñas entre 3 y 12 años escolarizados (2012)

Cobertura 1.020 .447 n prima-

Cobertura público urbano. El Ministerio de EduMinisterio de Educación, ga- cación rantiza la entrega de productos altamente nutritivos a cerca de $\underline{500.000 \text { niños y ni- }}$ ñas que acuden diariamente a los más de 3.500 centros de educativos a nivel nacional.

\footnotetext{
${ }_{92}$ Gobierno de México. Desayunos escolares Calientes. https://www.gob.mx/difnacional/acciones-y-programas/desayunos-escolares-calientes

${ }^{93}$ Plataforma CELAC. Programa Integral de Nutrición Escolar. Nicaragua. https://plataformacelac.org/programa/1 y https://www.mined.gob.ni/

${ }^{94}$ Plataforma CELAC. Merienda Escolar. Panamá. https://plataformacelac.org/programa/330
} 
(macro y micronutrientes) indispensables para el adecuado crecimiento y desarrollo de los escolares.

Mejorar el estado nutricional de los niños-niñas más pobres a través de la entrega de leche para

Perú

Vaso de Leche ${ }^{95}$

Programa social creado mediante la Ley № 24059 y complementada con la Ley $\mathrm{N}$ 27470,

Perú
Proyecto Qali Warma
$\begin{aligned} & \text { Ley General de Salud. } 10 \text { regula el dere- } \\ & \text { cho a una alimentación } \\ & \text { sana y suficiente }\end{aligned}$

los desayunos. Ofrece una ración diaria de alimentos a la población vulnerable, con el propósito de ayudarla a superar la inseguridad alimentaria

Los principales beneficiarios son los niños de 0 a 6 años $(61,2 \%)$ seguido por los niños de 7 a 13 años (18,1\%), adultos mayores y pacientes con tuberculosis.

Mejorar la alimentación de los niños desde los 3 años, matriculados en instituciones educativas públicas. ${ }^{97}$ Garantizar una ali-

mentación diaria, variada, balanceada, de calidad y adecuada a los requerimientos nutricionales, a través de un menú contextualizado, en congruencia con los parámetros socioculturales y económicos del entorno, así como la disponibilidad de los productos e insumos alimenticios característicos de las regiones.
Ofrece una ración diaria de 250 mil de leche un alimento equivalente. Las raciones se entregan semanal o mensualmente a los 1834 municipios del país, entre provinciales y distritales. comendaciones del Centro Nacional de Alimentación y Nutrición (CENAN) y con la asistencia técnica del Programa Mundial de Alimentos (PMA) ha establecido el aporte de energía y nutriente que debe comprender el servicio alimentario

os miembros de la comunidad deciden los ingredientes que se utilizarán en el menú de las escuelas de determinada zona y se encargan de comprarlos. El sector privado cubre otro vacío importante,
Cobertura nacional: Existen unos 3 millones de beneficiarios que están asociados a los más de 66000 Comités de Vaso de Leche. El Departamento de Cajamarca cuenta con el mayor número de comités y beneficiarios (7,2 y 6,2\%), seguido por Piura $(6,7$ y $5,4 \%)$ y Puno $(5,9 \text { y } 5,2 \%)^{96}$

Qali Warma atendió a más de 4 millones de niños en 64 mil instituciones públicas en el 2019,99 entre las que se incluyen las de comunidades indígenas de la región amazónica peruana.

Productos ofrecidos: Pan

con granos andinos, pasas y leche, pan con aceituna, pan con cebada, avena o amaranto y mantequilla.

Pan con derivado lácteo:

Pan con Queso y leche.

Pan dulce: Chancay de huevo, Pan de yema. Pan
Gobiernos Locales. Las municipalidades son responsables de la ejecución del Programa, en coordinación con la Organización del "Vaso de Leche."
Ministerio de Desarrollo e Inclusión Social (MIDIS)

\footnotetext{
${ }^{95}$ Diez-Canseco F, Saavedra-García L. Programas sociales y reducción de la obesidad en el Perú: reflexiones desde la investigación. Rev. Perú; Med Exp Salud Publica. 2017; 34(1):105-12. Doi: 10.17843/rpmesp.2017.341.2772

96 Ibid. Diez-Canseco, Saavedra-García L.

${ }^{97}$ Ibid., Diez-Canseco F, Saavedra-García L.

99 Info Qali Warma. https://www.qaliwarma.gob.pe/ y http://qaliwarma.gob.pe/InfoQaliwarma/\#/indicadores/prestacion-alimentaria ; CELAC https://plataformacelac.org/programa/185
} 
pues garantiza que la dieta de los niños sea variada y cumpla con parámetros nutricionales $^{98}$. Estos son planeados según región (mayor

mente cereales y productos de origen animal). Los desayunos cubren el $20-25 \%$ de los requerimientos energéticos diarios; los almuerzos aportan 35\% -40\% de requerimientos energéticos diarios

República Do- Programa de Alimentaminicana ${ }^{100}$
Garantizar una alimentación diaria, variada, balanceada, de calidad y adecuada a los requerimientos nutricionales, a través de un menú contextualizado, en congruencia con los parámetros so cioculturales y económicos del entorno, así como la disponibilidad de los productos e insumos alimenticios característicos de las regiones. Además, promover una acción pedagógica o cultural que permita una formación de hábito alimentarios en la población escolar atendida por el sistema educativo.
El Programa ofrece: 1- desayunos cuya modalidad depende de la ubicación geográfica de los centros educativos; 2- almuerzos listos (contratación de empresas suplidoras), o cocinado en el propio centro. 3- Merienda de jugo o preparado lácteo. En esta modalidad de implementa un menú que se coresponde con cuatro semanas cíclicas, que permiten la elaboración de alimentos variados, conforme los requerimientos nutricionales de los niños desde el Nivel Inicial hasta el Nivel Medio. Los centros reciben semanalmente este tipo de alimentos, zanahorias, tomates y bacalao. regional: Pan de Plátano,

Pan integral.

Galletas: Galleta con amaranto, galleta con quinua, galleta con cereales, galleta integral, galleta con maca, entre otros.

Queque con granos andinos. Snack Saludable: Maní con o sin pasas.

Cobertura Nacional rural y urbana; Actualmente cubre cerca de 1.4 millones de estudiantes en unos 1.600 centros educativos.

Existen 3 modalidades:

-PAE de Jornada Escolar Extendida

-PAE Fronterizo se implementa en las comunidades del suroeste y el noroeste, $3.2 \%$ de los establecimientos reciben: habichuelas, guandules, sardinas y salchichas.

-PAE REAL Ración Escolar con alimentos locales: plátanos verdes o maduros, salamis, huevos, harina de maíz pan, queso, arroz, preparado lácteo, zanahoria, tomate, bacalao.

-PAE Urbano: leche blanca y saborizada, jugos, néctares y una ración sólida de pan y
Instituto Nacional de Bienestar Estudiantil

Ministerio de Educación https://blogs.worldbank.org/es/education/alimentaci-n-escolar-una-herramienta-para-la-inclusi-n-social

100 Plataforma CELAC. Programa de Alimentación Escolar. República Dominicana. https://plataformacelac.org/programa/244 
galleta nutritiva. Esta modalidad cubre alrededor del 92\% de los centros educativos públicos existentes.

\begin{tabular}{|c|c|c|c|c|c|}
\hline Uruguay ${ }^{101}$ & $\begin{array}{l}\text { Programa de Alimenta- } \\
\text { ción Escolar }\end{array}$ & $\begin{array}{l}\text { Complementar la alimentación } \\
\text { brindada en el hogar, favore- } \\
\text { ciendo la capacidad de aprendi- } \\
\text { zaje, mejorando el nivel de aten- } \\
\text { ción en el aula y el rendimiento } \\
\text { escolar de los niños y niñas que } \\
\text { asisten a los comedores de las } \\
\text { escuelas públicas del país. }\end{array}$ & $\begin{array}{l}\text { Distribución de menús al } \\
\text { desayuno, almuerzo y me- } \\
\text { rienda, y distribución de leche } \\
\text { fortificada. Además, vigilancia } \\
\text { del estado nutricional de los } \\
\text { niños en las escuelas públi- } \\
\text { cas de todo el país, le hace } \\
\text { control de calidad e higiene } \\
\text { de los servicios en los come- } \\
\text { dores escolares y lleva a } \\
\text { cabo capacitación sobre Con- } \\
\text { trol de Calidad e Higiene de } \\
\text { los Alimentos. }\end{array}$ & $\begin{array}{l}\text { Alcance nacional, cobertura } \\
\text { nacional rural y urbana, el } \\
\text { PAE brinda diariamente ali- } \\
\text { mentación a } 248.590 \text { escola- } \\
\text { res de escuelas públicas de } \\
\text { todo el país. } \\
67 \% \text { de niños matriculados } \\
\text { en escuelas públicas. El } \\
90 \% \text { de las escuelas reciben } \\
\text { alguna prestación alimenta- } \\
\text { ria. } \\
\text { Asistencia alimentaria por } \\
\text { categoría de servicio: } \\
71 \% \text { - Almuerzo; } 16 \% \text { - } \\
\text { Desayuno o merienda. } \\
7 \% \text { - Desayuno, almuerzo y } \\
\text { merienda. } \\
5 \% \text { - Almuerzo y desayuno o } \\
\text { merienda. } \\
1 \% \text { - Desayuno, almuerzo, } \\
\text { merienda y cena. }\end{array}$ & $\begin{array}{l}\text { Consejo de Edu- } \\
\text { cación Inicial y Pri- } \\
\text { maria }\end{array}$ \\
\hline
\end{tabular}

101 Plataforma CELAC. Programa de Alimentación Escolar. Uruguay. https://plataformacelac.org/pais/ury y http://www.cep.edu.uy/inicio-pae 


\section{REFLEXIONES SOBRE PROGRAMAS DE PROTECCIÓN SOCIAL Y LA OFERTA DE ALIMENTOS SANOS Y VARIADOS EN LAC REGIÓN}

El presente documento revisó tres modalidades concretas de protección social con componentes de alimentación saludable más comúnmente adoptadas por los países de la región. Estas son: los programas de transferencia condicionada (PTC), los programas alimentarios desarrollados en los países y los programas de alimentación escolar. La revisión bibliográfica incluyó 13 PTCs en ejecución en 7 países de la región; 10 programas de alimentación en 9 países y los programas de alimentación escolar en marcha en 16 países de América Latina, Centroamérica y el Caribe. Es importante considerar que estos programas son parte de la red de estrategias que ponen en marcha todos los gobiernos de la región para atender a las poblaciones más vulnerables.

Esta revisión se centró en los programas de protección social vigentes, los cuales adoptan y conforman una compleja red de servicios que tienden a proporcionar alimentos, acceso a salud y trabajo a las poblaciones bajo el nivel de pobreza. Las modalidades analizadas incluyen algún aspecto relacionado con la nutrición, la provisión de alimentos y el acceso a productos o suplementos alimentarios de distinto tipo y origen.

Todos los programas detallados en esta revisión presentan una serie de estrategias para hacer frente al hambre y mejorar la nutrición de los usuarios, aun así, no todas las estrategias de implementación llegan a establecer canales para asegurar la provisión de productos sanos y frescos como una prioridad del programa. La posibilidad de acceder a una alimentación de calidad se torna en un elemento crucial y hace una llamada de atención en particular a la creciente tendencia que se observa en cuando al incremento de los patrones de sobrepeso y obesidad prevalentes en toda la región que afecta no solo a los adultos sino también a grandes sectores de la niñez. La generalidad de los programas propone la adopción de una alimentación sana, pero son pocos los que canalizan estas estrategias en guías concretas para evitar el incremento del sobrepeso y la obesidad lo cual induce al desarrollo de las enfermedades no transmisibles como la diabetes, la enfermedad coronaria y ciertos canceres. El enfoque de muchos de estos programas está centrado en la provisión de bonos, váuchers, transferencias de dinero y también de alimentos, pero por lo general, la provisión y el acceso a los alimentos frescos y de calidad no es tan asequible ya sea por el costo de estos o por la falta de opciones de mercado.

En tal sentido, el enfoque de una mejor alimentación y probablemente más balanceada es observable en forma más plausible en los programas de alimentación escolar dado por su ajustada implementación, asiduidad (diariamente) y también a que dichos programas son diseñados por nutricionistas y personal de la salud, estableciendo el objetivo estratégico de contribuir a una dieta sana. Aun así, estos programas de alimentación escolar por lo general solo cubren el desayuno y el almuerzo, además que funcionan durante el año escolar (9 meses) dejando un vacío de varios meses hasta el comienzo del siguiente año escolar. Entre los programas de país analizados se mencionó el programa "Elije Vivir Sano" en Chile y Qali Warma de alimentación escolar en el Perú los cuales pueden ser tomados como ejemplo por el enfoque holístico y multidisciplinario que presentan y al mismo tiempo por la adopción de estrategias para reducir el sobrepeso y la obesidad. En el caso de Qali Warma esto se materializa 
mediante un menú variado y congruente con aspectos socioculturales y económicos del entorno, así como la disponibilidad de los productos e insumos alimenticios autóctonos de las regiones. Los citados programas además de la provisión de alimentos incluyen componentes vitales como el ejercicio, la educación y un énfasis en los entornos alimentarios locales. Asimismo, es interesante destacar la evaluación del programa PROCOMIDA en Guatemala, llevada a cabo por el IFPRI, que determinó un aumento no-intencional de peso por parte de las madres enroladas en el programa lo cual sirve como precedente para hacer un escrutinio del diseño e implementación de este tipo de programa a futuro. También el programa "Cocinando para la Salud" en Perú cuya evaluación por medio de encuestas determinó que el público usuario favorecía y adoptaba la oferta de alimentos frescos a pesar de un costo incremental de los mismos ofrecidos en los comedores comunitarios de Lima.

Se quiere resaltar, dentro de las modalidades innovativas y que rescatan aspectos de agroecología o soberanía alimentaria, el caso de las "canastas o cajas" de Ecuador y Honduras. Estos modelos ofrecen opciones de movilización local que facilitan las compras y aumentan la participación de varios sectores de la producción y transformación de alimentos con acceso a productos frescos en circuitos cortos. Un aspecto para tener en cuenta con respecto a las canastas es que se trata de una coordinación entre grupos (familias o grupos de base) que adquieren productos y otros que se comprometen a proveer dichos productos, es decir que existe un compromiso preestablecido y además en ciertas oportunidades son apoyados también por los gobiernos locales. Otra de las modalidades innovativas es el caso del programa "Sabores andantes" de Uruguay ya que el mismo plantea la educación nutricional desde una temprana edad acompañada por la inclusión de alimentos nativos y recetas locales presentadas en escuelas y centros comunitarios.

Como se expresó al inicio, esta revisión de la literatura sobre programas de protección social no pretende ser exhaustiva, pero rescata modalidades concretas que pueden ser replicadas en los países para hacer frente a una estrategia cambiante en cuanto a la necesidad de incorporar elementos que faciliten dar un mayor énfasis al consumo de productos frescos y nutritivos y la creación de hábitos saludables para reducir los alarmantes patrones de sobrepeso y obesidad que presenta la región.

A modo de cierre se ofrecen una serie de consideraciones para optimizar las modalidades más relevantes de cobertura en los programas y en los países con respecto a la adopción de las dietas sanas y variadas para mejorar la nutrición y prevenir desnutrición de todo tipo.

- Se debe tener en cuenta que si bien los programas detallados hacen referencias a "dietas sanas" ya sean los PTC u otros programas de asistencia social que incluyen acceso a alimentos, no hay necesariamente una definición especifica o una guía de la composición de dichas dietas en la gran mayoría de los casos. Una excepción es la tarjeta AlimentAR de Argentina y el Programa Elije Vivir Sano de Chile.

- Con respecto a la operacionalización de los programas, en general los mecanismos de operación no son concretos para asegurar el acceso y la adopción a las dietas sanas; y además la gran mayoría de los programas no presenta mecanismos de monitoreo y evaluación los cuales debería ser incorporados como parte del esquema de implementación de los programas.

- Es importante enfocarse en la inter-institucionalidad de las leyes de Seguridad Alimentaria y Nutricional (SAN) como marco, considerando también los frentes regionales como el Frente Parlamentario contra el Hambre en América Latina y el Caribe y el Observatorio por el Derecho Alimentación. Asimismo, se debe hacer énfasis a la puesta en marcha de alianzas con diversas organizaciones del sector privado, los sectores de la producción y el estado a nivel local y nacional. 
- Es necesario establecer una visión de "sistema" y una estrategia "compartida" con los sectores a cargo de la implementación de estos programas, dado que la segmentación de los actores del estado y la poca inclusión del sector privado son quizás las principales barreras para garantizar el éxito de estos programas.

- Es importante destacar la necesidad de elaborar y diseñar menús adecuados en los programas de alimentación escolar, teniendo en cuenta productos culturalmente aceptables y evitar que los alimentos ofrecidos presenten elevados porcentajes de carbohidratos, aceites y azúcares en los jugos y meriendas. Si bien muchos países están analizando la oferta de alimentos, es menester también dar impulso y realizar campañas de concientización y educación para quienes implementan estos programas incluyendo sus beneficiarios (madres y padres de familia) y también quienes tienen a su cargo la preparación de los alimentos en comedores escolares o comunitarios.

- Son muy pocos los programas que hacen referencia a la importancia de la ingesta de micronutrientes y la necesidad de acceder a alimentos biofortificados ${ }^{102}$. Esta es un área estratégica que puede facilitar la adopción desde el sector productivo de cultivos como, frijoles ricos en hierro, yuca amarilla/batata rica en vitamina A; mijo perla con hierro y zinc, arroz con hierro y zinc, y arroz con "provitamina A".

- Se debe dar prioridad a las compras de la agricultura familiar como importante forma de movilizar la producción local, de evitar las pérdidas por transporte y extender la viabilidad del producto (caducidad) y también los circuitos cortos que proveen productos frescos y de mejor calidad a comedores comunitarios y escolares.

- Es aconsejable desarrollar y fortalecer las capacidades para la ejecución de políticas locales, considerando como eje principal a quienes desarrollan estos programas como ser gerentes y administradores, técnicos y nutricionistas, docentes y coordinadores locales o regionales de educación, entre otros. Además, es deseable incluir componentes de evaluación y acompañamiento, para monitorear y evaluar las actividades programadas.

- Con respecto a los PTC y los programas de alimentación escolar es aconsejable promover innovaciones que faciliten obtener mejores resultados mediante la combinación de transferencias monetarias con la entrega de alimentos, teniendo en cuenta los "entornos alimentarios" ya sean urbanos o rurales. Ambas modalidades, PTCs y alimentación escolar, presentan además limitada participación del sector privado y de no ser por las compras a la agricultura familiar estos vínculos están completamente ausentes.

- Otro aspecto de importancia y consideración inmediata tanto desde los PTCs como en los programas de alimentación comunitaria se refiere a las estrategias de los gobiernos para hacer frente a las crecientes necesidades de un alto porcentaje de la población de la tercera edad y cuyas necesidades de alimentación y salud son criticas además de su elevado costo de mantención dentro del sistema social de salud.

- Es aconsejable impulsar el empleo de tecnologías para la recolección y análisis de la gestión de datos, la planificación y el seguimiento de los programas alimentarios de mediana y gran escala sobre todo en referencia a establecer sistemas de alertas y control para detectar patrones que demuestran un aumento de peso por alimentación y el impacto en la salud de quienes son beneficiarios de estos programas.

\footnotetext{
${ }^{102}$ Cultivos Biofortificados, Harvest Plus. http://lac.harvestplus.org/fact tabs/cultivos-biofortificados/
} 
Estas son algunas de las sugerencias de mejora inmediata para inducir a un cambio en los programas existentes, desde el diseño y las políticas para dar oportunidad a posicionar los mismos como fuentes de alimentación variada y sana con una visión estratégica que incluya sectores rezagados en un enfoque de sistema y no solo como una intervención puntual. La creciente brecha en los ingresos, el aumento de la pobreza y malnutrición (por falta o por exceso) son aspectos que afectan hoy a la región en forma global. De allí que el rol de la asistencia social retome un importante énfasis y se llame la atención a los factores y a la propuesta de adoptar patrones de alimentación adecuados y un enfoque de vida sana que logre alcanzar el resultado esperado de los programas de asistencia alimentaria de actual vigencia en la región. 


\section{ANEXO I. TARJETA ALIMENTAR - ARGENTINA}

\section{Ministerio de Desarrollo Social, Argentina contra el hambre}

Recomendaciones para las compras con la Tarjeta Alimentar ${ }^{103}$ (Información Tomada de la Pagina Web del Programa Argentina Contra el Hambre)

Una alimentación saludable debe incluir alimentos variados y de todos los grupos, que nos aporten los nutrientes y energía necesarios. Cuando elegimos alimentos frescos y mínimamente procesados, evitamos el exceso de sal, azúcares y grasas. Evitar comprar gaseosas, jugos, aguas saborizadas. embutidos, snacks y golosinas.

\section{Alimentos recomendados:}

- Leche, yogur y quesos

- Frutas y verduras

- Carnes y huevos

- Legumbres, cereales, papas, pan y pastas

- Panes

- Aceites, frutas secas y semillas

- Alimentos de consumo opcional

- Infusiones

- Leche, yogur y quesos

- Leche líquida o en polvo

- Yogur

- Quesos

Nos ayudan a crecer y mantener huesos y dientes fuertes, ya que aportan el calcio y proteínas que necesitamos durante toda la vida. Preferí siempre quesos blandos (tipo fresco o untables) que contienen menos grasa y sal.

Las leches en polvo deben conservarse en un lugar fresco, seco y en su envase original (siempre bien cerrado). Si elegís leche larga vida, una vez abierta, debe ir a la heladera.

\section{Frutas y verduras}

- Frutas y verduras frescas: todas.

- Frutas deshidratadas: pasas de uva, ciruelas, duraznos, manzanas, bananas, dátiles. Es importante aumentar su consumo diario y para toda la familia. Aportan fibras, vitaminas, minerales y agua, lo que nos ayuda a prevenir enfermedades. Recordá lavarlas siempre con agua segura. Es bueno elegir las de tu región y variarlas según las estaciones del año.

\section{En primavera}

- Frutas: ananá, frutilla, banana, manzana, durazno, damasco, pera.

- Verduras: alcaucil, coliflor, repollo, radicheta, zapallito verde, espinaca, puerro, tomate.

\footnotetext{
${ }^{103}$ Recomendaciones para las compras con la Tarjeta AlimentAR 


\section{En verano}

- Frutas: ananá, cereza, ciruela, durazno, damasco, pelón, higos, uvas, sandía, melón.

- Verduras: berenjena, calabaza, morrón, pepino, tomate, chaucha, zapallo, acelga, lechuga, choclo.

\section{En otoño/invierno}

- Frutas: limón, mandarina, naranja, pomelo, pera, kiwi, manzana.

- Verduras: berenjena, brócoli, cebolla, repollo, zapallo, papa, radicheta, chaucha, acelga, remolacha, puerro.

\section{Todo el año}

- Frutas: manzana, naranja, banana.

- Verduras: zapallo, zanahoria, acelga, espinaca, lechuga, rabanito, remolacha, rúcula.

\section{Carnes y huevos}

- Vaca

- Pollo

- Pescado

- Cerdo

- Vísceras y otras

- Huevos

Son importantes para la formación y reparación de todos los tejidos del cuerpo. Contienen hierro, que es bueno para el funcionamiento del cerebro, mejora el rendimiento físico y ayuda a prevenir la anemia.

Las carnes son fuente de proteínas, hierro, zinc, fósforo y vitaminas del complejo B, principalmente B12.

Se recomienda variar entre los distintos tipos de carnes rojas, blancas y pescado. Elegir cortes con poca grasa y quitar la piel del pollo al cocinarlo. Cuidar que no queden partes rojas o rosadas en el interior de las carnes luego de la cocción.

Los huevos contienen proteínas, vitaminas, minerales y grasas; son nutritivos, económicos y hay en todo el país. Incluir hasta un huevo por día, especialmente si no se consume la cantidad de carne recomendada. Lavarlos bien antes de cocinar y conservarlos en la heladera.

- Legumbres, cereales, papas, pan y pastas

- Legumbres secas, sus harinas o en lata: lentejas, porotos, soja, garbanzo y arvejas.

- Arroz, fideos secos, pastas, sémola, trigo, salvado, maíz, avena y harina de trigo.

- Papa, batata y mandioca.

- Panes

- Preferir los integrales.

- Aceites, frutas secas y semillas

- Aceites: girasol, maíz, oliva, soja y mezcla.

- Semillas: chía, girasol, sésamo, lino, zapallo. 
- Frutas secas: maní, nueces, almendras, castañas.

\section{Alimentos de consumo opcional}

- Dulces regionales

- Mermeladas

- Dulce de membrillo y batata.

Infusiones

- Mate cocido

- Té

- Yerba

- Café

- Cacao 


\section{ANEXO II. PROGRAMA DE CIUDADANÍA PORTEÑA (2005 - )}

El programa de la Ciudadanía Porteña circunscribe su implementación a la Ciudad Autónoma de Buenos Aires (CABA) únicamente y no es parte de un programa de cobertura nacional, el mismo está en vigencia desde 2005. El organismo responsable de este Programa es el Ministerio de Desarrollo Social y el organismo ejecutor la Dirección General de Ciudadanía Porteña siendo financiado por el Gobierno de la Ciudad Autónoma de Buenos Aires. Su institucionalidad está dada por la Ley 1878 de la legislatura de la Ciudad Autónoma de Buenos Aires.

Este programa consta de cuatro componentes básicos importantes: a- Ciudadanía Porteña Con todo Derecho, b-Estudiar es Trabajar, c- Red Primeros Meses y d-Ticket social.

\section{Ciudadanía Porteña Con todo Derecho}

Los destinatarios de este programa son los hogares con al menos 2 años de residencia en la Ciudad Autónoma de Buenos Aires en situación de pobreza, su énfasis es la cobertura del área urbana enfatizando su accionar en los de mayor vulnerabilidad. Para acceder a este beneficio se considera la situación socioeconómica del hogar y no el número de integrantes o la edad. El programa prioriza la cobertura de hogares indigentes los que reciben el equivalente al $75 \%$ de una canasta básica de alimentos y los hogares pobres un 50\%. La modalidad de transferencia o forma de entrega es una tarjeta magnética (Tarjeta de compra) con una periodicidad de entrega mensual. En general este beneficio es otorgado a las madres preferentemente con el gozo de una transferencia por hogar. Los requisitos de este programa incluyen corresponsabilidades de educación y alimentación incluyendo la admisión de los niños y niñas de 3 y 4 años en guarderías; los de más de 5 años en programas preescolares (jardín de infantes); y los chicos entre 6 y 18 años ya sea a la escuela primaria y o secundaria. Quienes acceden al programa, es decir en el caso de ser receptor del Program de la Asignación Universal por Hijo o de Ticket Social, no es posible su inscripción en la "Ciudadanía Porteña". El programa también incluye aspectos de salud con controles mensuales durante el embarazo, parto y post parto; enfocándose además en el control y el desarrollo nutricional de los niños y niñas para asegurar su desarrollo adecuado. Estos controles y exigencias se adaptan a la edad de beneficiarios además de asegurarse de que estos siguen y cumplen con un calendario de vacunación obligatorio. Este programa ofrece la posibilidad de acceder a la compra de productos alimenticios nutritivos y de primera necesidad como así también productos de limpieza o de higiene personal; combustibles para la preparación de los alimentos y otros como ser útiles escolares. No se describen aspectos referidos al control y acceso a las dietas sanas ni tampoco si existen sistemas de monitoreo para dar seguimiento a estas opciones de alimentación. 
Cuadro 10. PROGRAMA DE CIUDADANIA PORTEÑA (2005-)

\begin{tabular}{|rr}
\hline Características & \\
\hline Presupuesto & 2018 \\
\hline ARS\$ $\$$ USD\$ & 2.108 .015 .142 \\
\hline \%PIB / GDP & 75.031 .706 \\
\hline Cobertura personas & $0,01 \%$ \\
\hline Efectiva & 97.633 \\
\hline \% Población & $0,22 \%$ \\
\hline Hombres & 54.813 \\
\hline Mujeres & 42.821 \\
\hline El \% del PBI y de las personas corresponde al total nacional & \\
\hline
\end{tabular}

Fuente CEPAL ${ }^{104}$; Elaboración de la autora

\section{Estudiar es Trabajar}

Este Programa está destinado a ofrecer apoyo mediante el otorgamiento de una tarjeta de débito, por lo que se da acceso monetario directo a Jóvenes entre 18 y 40 años integrantes de hogares beneficiarios, que estudian en cualquier nivel del sistema educacional formal. Las transferencias son individuales y el dinero puede utilizarse solamente para la compra de alimentos, productos de higiene personal y limpieza, como así también combustible para cocinar y también útiles escolares en la red de comercios adheridos al programa. Este beneficio es de periodicidad o entrega mensual. No existen indicaciones con respecto a cómo se controla la compra de alimentos sanos o criterios de selección de estos.

En referencia a las corresponsabilidades de este programa de apoyo a la educación, quienes acceden al mismo deben estar inscriptos en cualquier nivel del sistema educativo formal con reconocimiento oficial (primario, secundario, terciario universitario/no universitario). Quienes están en el nivel primario o secundario deben asistir a la escuela y promover los estudios anualmente; los que se encuentran en el nivel terciario o universitario deben aprobar al menos dos materias en el año.

\section{Red Primeros Meses}

El Programa Red Primeros Meses tiene como destinatarios a las mujeres embarazadas y niños y niñas de 0 a 1 años integrantes de hogares beneficiarios del Programa Ciudadanía Porteña. Esta es una transferencia de carácter individual con el empleo de una tarjeta magnética o de débito. La modalidad y la periodicidad de entrega incluye en primer lugar a las mujeres embarazadas a quienes se les

\footnotetext{
104 https://dds.cepal.org/bpsnc/ptc
} 
otorga tres pagos correspondiendo al ciclo de gestación (las semanas 13, 24 y 36 de embarazo) y en segundo lugar a niños y niñas de 0 a 1 año mediante tres pagos correspondientes a los meses 1,6 y 12 después del nacimiento. Para mantener ese beneficio de participación directa, en el caso de las mujeres embarazadas, ellas deben realizar 5 controles médicos de gestación previos al parto. La cantidad de controles puede ser aún mayor según la indicación médica, además quienes prestan servicios médicos deben también ser acreditados por el programa. Durante el primer mes de vida de los niños y niñas se deben realizar como mínimo 2 controles pediátricos -uno obligatoriamente entre las 48 horas y 7 días de vida- y el segundo entre los 15 y 30 días de vida. A los 6 meses deben presentar 5 controles (uno por mes), y a los 12 meses 3 controles bimestrales. Este programa presenta otro apoyo mediante el refuerzo de un acompañamiento familiar llamado el acceso a los Trabajadores Sociales de Referencia tanto para dar seguimiento a las mujeres que estén cursando un embarazo o para los niños y niñas que estén transitando el primer año de vida. La finalidad de este programa es construir una conciencia del cuidado prenatal y de los niños por parte de la madre y su entorno familiar, garantizando los controles médicos necesarios que favorezcan el desarrollo de un embarazo y el crecimiento saludable de los niños y niñas.

\section{Ticket Social}

Este programa se centra en proveer a los hogares que se encuentren en situación de inseguridad alimentaria o vulnerabilidad social la opción de acceder a una transferencia o tarjeta de compra que es emitida y recargada en forma cíclica por el Banco de la Ciudad de Buenos Aires. La periodicidad de entrega es mensual con beneficiarios directos para utilizar la tarjeta en la red de comercios de alimentos (si bien no se especifican en profundidad que tipo de alimentos son los sugeridos) y también en cadenas de supermercados adheridos al programa. Esta tarjeta solo puede ser utilizada para la compra de alimentos saludables y productos de higiene y limpieza; quedando absolutamente prohibido -como en todos los casos anteriores- la compra de bebidas alcohólicas, lo cual puede provocar la perdida inmediata de este beneficio. Si bien se detalla claramente los productos que no deben ser adquiridos con la tarjeta, no hay una guía de seguimiento que haga referencia sobre aquellos alimentos o dietas sugeridas que pueden adquirirse con la tarjeta. Como se explicó con anterioridad para evitar superposiciones, quienes acceden al beneficio del "Ticket Social" no puede reclamar la Asignación Universal por Hijo (AUH) o la Ciudadanía Porteña ${ }^{105}$.

En referencia a los controles y operacionalización de sus componentes, el Gobierno de la Ciudad Autónoma de Buenos Aires hace referencia al cumplimiento de obligaciones para formar parte del programa y permanecer en el mismo bajo el título de "compromisos"106.

"Para ingresar y permanecer en el programa y para mantener el subsidio, Ciudadanía Porteña Con Todo Derecho solicita que sus beneficiarios se comprometan a cumplir con obligaciones en materia de salud materno-infanto-juvenil, educación obligatoria, documentación e información. Además, los hogares deben comprometerse a: Gestionar el DNI argentino a todos los integrantes del hogar.

\footnotetext{
${ }^{105}$ Fuente: Base de datos de programas de protección social no contributiva en América Latina y el Caribe. CEPAL https://dds.cepal.org/bpsnc/ptc

${ }^{106}$ Fuente: Ciudadanía Porteña con Todo Derecho: Compromisos y condiciones que las familias deben cumplir para ser parte y permanecer en el programa. https://www.buenosaires.gob.ar/desarrollohumanoyhabitat/ciudadaniaportena/compromisos-ciudadania-portena
} 
Brindar información verdadera sobre la composición y las condiciones socioeconómicas del hogar y de cada uno de sus integrantes (cantidad de integrantes, sexo, estado de salud, edad, domicilio, ingresos etc.), así como de las modificaciones que puedan ocurrir desde el ingreso al Programa (fallecimientos, nacimientos, salida de uno o más de los miembros de la unidad de convivencia, etc.).

Brindar información fidedigna respecto de los ingresos del hogar y de posibles modificaciones (por ejemplo, nuevos ingresos laborales). No omitir ni falsear información que solicite el Programa."

Como en el caso de otros programas el incumplimiento de los "compromisos" citados puede causar la suspensión, reducción o la pérdida del subsidio. 


\section{ANEXO III. DIMENSIONES Y LOGROS BÁSICOS DE LA RED UNIDOS - COLOMBIA}

La Estrategia UNIDOS cuenta con 9 Dimensiones y 45 logros, mediante los cuales se da una mirada multidimensional de la pobreza, contemplando las Dimensiones como aspectos de bienestar que tiene como objetivo contrarrestar la pobreza de las familias más vulnerables. Los Logros Básicos (LB), en que se encuentran desagregados de las 9 Dimensiones, constituyen el conjunto de condiciones mínimas deseables que una familia en situación de pobreza extrema debe de alcanzar para considerar como realizada cada una de estas dimensiones. Es a partir de este enfoque, que la Red estructura el acompañamiento familiar y comunitario, y gestiona la oferta de programas y servicios sociales hacia las familias beneficiarias.

Logros básicos en 9 dimensiones ${ }^{107}$ :

- La Estrategia UNIDOS cuenta con 9 Dimensiones y 45 logros, mediante los cuales se da una mirada multidimensional de la pobreza, contemplando las Dimensiones como aspectos de bienestar que tiene como objetivo contrarrestar la pobreza de las familias más vulnerables. Los Logros Básicos (LB), en que se encuentran desagregados de las 9 Dimensiones, constituyen el conjunto de condiciones mínimas deseables que una familia en situación de pobreza extrema debe de alcanzar para considerar como realizada cada una de estas dimensiones. Es a partir de este enfoque, que la Red estructura el acompañamiento familiar y comunitario, y gestiona la oferta de programas y servicios sociales hacia las familias beneficiarias.

\section{IDENTIFICACION}

Los miembros de la familia cuentan con los documentos especiales que los identifican como ciudadanos colombianos y demuestran el cumplimiento de requisitos establecidos por la ley, esta dimensión comprende 3 logros:

1. Los menores entre 0 y 7 años tienen registro civil, los niños entre 7 y 18 años tienen tarjeta de identidad, y las personas mayores de 18 años tienen cédula de ciudadanía.

2. Los hombres entre 18 años y 50 años de edad tienen libreta militar.

3. La familia incluida en el SISBEN tiene registrada la información personal de cada uno de sus miembros, exactamente igual a como aparecen los documentos de identidad vigentes a sus rangos de edad.

107 https://www.ucn.edu.co/unidos/Paginas/dimensiones-y-logros-basicos.aspx (Católica del Norte Fundación Universitaria, Colombia) 


\section{INGRESOS Y TRABAJO}

La familia accede a ingresos (monetarios o en especie) a través de diferentes medios de sustento, contemplando en esta dimensión 4 logros:

1. Todos los adultos mayores de 60 años poseen alguna fuente de ingreso y/o tienen un mecanismo de sustento económico al interior del hogar.

2. Al menos un miembro de la familia mayor de 15 años tiene una ocupación remunerada o está vinculado a una fuente de ingresos autónoma.

3. Todas las personas del hogar en edad de trabajar alcanzan un nivel de capacidades que facilita su vinculación a una ocupación remunerada o mejora las condiciones de la actividad que ya desarroIla.

4. El hogar alcanza un nivel de activos que facilita su vinculación a una ocupación remunerada o mejora las condiciones de la actividad que ya desarrolla.

\section{EDUCACION Y CAPACITACION}

Los niños, jóvenes y adultos acumulan capital humano y acceden al conocimiento que les permite su desarrollo integral, en esta dimensión se comprenden 5 logros:

1. Los niños y niñas menores de 5 años están vinculados a algún programa de atención integral en cuidado, nutrición y educación inicial.

2. Los menores en edad escolar (desde los 5 hasta los 17 años), que no hayan terminado el ciclo básico (hasta $9^{\circ}$ grado), están siendo atendidos por el servicio educativo formal o un sistema alternativo, que les permita el desarrollo de sus competencias.

3. Los adultos entre 18 y 65 años (incluidos aquellos en situación de discapacidad) están alfabetizados.

4. Las personas que lo deseen, una vez concluido el ciclo básico, se vinculan a la educación media, técnica, tecnológica o acceden a programas de formación para el trabajo.

5. Los niños y las niñas menores de 15 años no están vinculados a actividades laborales. 


\section{SALUD}

Mediante la vinculación efectiva al sistema de salud, todas las personas reciben los servicios de atención y participan en los programas de promoción y prevención. Así, la familia reduce la mortalidad evitable y la morbilidad, en esta fase se comprenden los siguientes logros:

1. Los integrantes de las familias están afiliados al Sistema General de Seguridad Social en Salud SGSS.

2. La familia accede a intervenciones de promoción de la salud a las cuales tienen derecho en el marco del SGSS en salud.

3. Los adolescentes y adultos, de ambos sexos, conocen los métodos de planificación familiar.

4. Los niños y niñas de la familia a los 12 meses de edad tienen tres dosis de vacuna pentavalente (DPT, HB y Hib), los niños y niñas entre 1 y 2 años tienen una dosis de vacuna SRP (sarampión, rubiola y paperas)

5. Las gestantes de la familia están adscritas y asisten a controles prenatales, o reciben atención institucional del parto.

6. Los menores de 10 años de la familia están inscritos y asisten a consultas para la detección temprana de alteraciones de crecimiento y desarrollo.

7. Las mujeres de la familia asisten a los programas de tamizaje de cáncer de cuello uterino y seno, y conocen los resultados.

8. Las personas con discapacidad tienen acceso a los programas de rehabilitación (en particular aquellos basados en la comunidad) y a las ayudas técnicas necesarias para su autonomía.

\section{NUTRICION}

Todos los miembros de la familia cuentan con una alimentación adecuada y tienen buenos hábitos en el manejo de alimentos, en esta dimensión se comprenden 3 logros:

1. La familia practica hábitos saludables en la manipulación y preparación de alimentos.

2. La familia consume alimentos variados y de manera saludable.

3. Los adolescentes y adultos, de ambos sexos, conocen los métodos de planificación familiar.

4. Los niños menores de seis meses reciben al menos cuatro de los seis meses recomendados de lactancia materna exclusiva. 


\section{HABILIDAD}

La familia cuenta con condiciones de habitabilidad segura, acordes con su contexto cultural, en esta dimensión se contemplan 10 logros:

1. La vivienda cuenta con abastecimiento de agua potable y un sistema de desagües.

2. La familia dispone o transforma la basura.

3. La vivienda cuenta con dotación de un sistema de energía convencional o alternativa.

4. La vivienda cuenta con espacios diferenciados de baño, cocina, lavadero y dormitorios.

5. En la vivienda no viven más de tres personas en cada cuarto, y los niños duermen separados de los adultos.

6. La vivienda no tiene pisos de tierra.

7. Los miembros de la familia cuentan con implementos para dormir y alimentarse.

8. La familia cuenta con acceso a un sistema de comunicaciones.

9. La vivienda posee materiales adecuados que posibilitan la seguridad en la infraestructura física y mayor bienestar para la familia en términos de salud.

10. La vivienda cuenta con iluminación, ventilación natural y privacidad.

\section{DINAMICA FAMILIAR}

1. La familia cuenta con un tejido familiar fortalecido y mecanismos saludables de convivencia y de expresión de afecto. Además, reconoce la importancia de las relaciones entre sus integrantes, para su propio desarrollo, en esta fase se comprenden 6 logros:

2. La familia elabora y hace seguimiento a su Plan Familiar.

3. La familia accede a la conformación y servicios de detección temprana, atención y recuperación de las víctimas del violencia intrafamiliar y sexual.

4. Los miembros de la familia conocen los espacios y oportunidades para acceder a programas y servicios disponibles en su localidad (organizaciones comunitarias, espacios de recreación y cultura, clubes deportivos, centros de recreación para niños, jóvenes y para adultos mayores, asociaciones de padres de familia, centros de educación, ludotecas, etc.) y participan en algunos de ellos.

5. La familia con menores de 6 años conoce y aplica pautas de crianza humanizada.

6. La familia genera espacios de diálogo y aplica normas de convivencia familiar y resolución de conflictos.

7. 6. La familia participa en conjunto en el cuidado e integración social de la persona con discapacidad 


\section{8 - BANCARIZACION Y AHORRO}

La familia está interesada en el sistema financiero como medio de acceso a oportunidades de trabajo, ingresos y seguridad familiar. Adicionalmente, crea una cultura de ahorro para lograr metas propuestas por sí misma, en este se contemplan 3 logros:

1. La familia ahorra a través del sistema financiero o de mecanismos no formales.

2. La familia conoce las características de al menos uno de los siguientes servicios financieros: ahorro, crédito y seguros.

3. Las familias que lo requieren han obtenido un crédito a través de un mecanismo financiero o formal o a través de grupos de ahorro y crédito.

\section{ACCESO A LA JUSTICIA}

La familia beneficiaria tiene acceso a los servicios de la justicia formal y no formal para la solución de sus conflictos, conocimiento de sus derechos, fomento de los valores y fortalecimiento de la convivencia de manera oportuna y eficaz, contemplando en esta fase 3 logros:

1. La familia conoce sus necesidades jurídicas, aprende a identificar la ruta institucional apropiada para la resolución de conflictos entre las alterativas que ofrece el sistema de justicia, y conoce sus derechos y deberes ciudadanos.

2. La familia con necesidades jurídicas recibe atención pronta y oportuna de los operadores de justicia y accede a los Mecanismos Alternativos de Solución de Conflictos - MASC.

3. La familia en situación de desplazamiento recibe acompañamiento para apoyar el seguimiento a los indicadores de goce efectivo de derechos. 


\section{BIBLIOGRAFÍA}

Acción Social. 2011. Informe de Gestión 2010. Bogotá, Colombia. http://www.dps.gov.co/documentos/5705 Informe de Gestión 2010 ACCIÓN SOCIAL.pdf.

Adato, Michelle and John Hoddinott, eds. Conditional Cash Transfers in Latin America. Baltimore: Johns Hopkins University Press, 2010. Pp. xviii+385.

Adolio Cascante, Rosa. Manual de menú para comedores estudiantiles de primaria - San José, Costa Rica. Ministerio de Educación Pública; Dirección de Programas de Equidad, 2017. ISBN: 978-9977-60-299-8 Manual https://www.mep.go.cr/sites/default/files/page/adjuntos/manual-primaria.pdf

Alcázar, Lorena. 2007. Por qué no funcionan los programas alimentarios y nutricionales en el Perú?: riesgos y oportunidades para su reforma Titulo - En: Investigación, políticas y desarrollo en el Perú. Lima: GRADE. ISBN 978-9972-615-42-9; pp 197

Bastagli, F., Hagen-Zanker, J., Hartman, L., Barca, V., Sturge, G., \& Schmidt, T. 2019. The Impact of Cash Transfers: A Review of the Evidence from Low- and Middle-income Countries. Journal of Social Policy, 48(3), 569-594. doi:10.1017/S0047279418000715

Cárdenas, Angeline, Eduardo Conrado, Gabriela Guato. 2014. Evaluación y Expansión del Proyecto Canastas Solidarias del Gobierno Autónomo descentralizado de la Provincia de Pichincha (GAPP) en la Parroquia de Chillogallo. Tesis de Grado. Quito. Ecuador. pp.18

Carrillo-Larco RM, Miranda JJ, Bernabe-Ortiz, A. Impact of food assistance programs on obesity in mothers and children: a prospective cohort study in Peru. Am J Public Health. 2016; 106(7):1301-7. doi: 10.2105/AJPH.2016.303191

Cecchini, Simone, 2013, - Transferências Condicionadas na América Latina e Caribe: Da Inovação à Consolidacao, Programa Bolsa Família: uma década de inclusão e cidadania, T. Campello y M.Côrtes Neri (eds.), Brasilia, Instituto de Investigación Económica Aplicada (IPEA).

2013. Social Transfers: Incentives and Disincentives to Labour Insertion and Income Generation, One Pager 236, International Policy Centre for Inclusive Growth.

Cecchini, S.; Atuesta, Bernardo 2017. Programas de transferencias condicionadas en América Latina y el Caribe: tendencias de cobertura e inversión. CEPAL, Serie Políticas Sociales

Cecchini, S.; R. Martínez. 2011. Protección social inclusiva en América Latina: una mirada integral, un enfoque de derechos, Libros de la CEPAL, No. 111 (LC/G.2488-P CEPAL), Santiago de Chile, Comisión Económica para América Latina y el Caribe (CEPAL)

CEPAL. Base de datos de programas de protección social no contributiva en América Latina y el Caribe. https://dds.CEPAL.org/bpsnc/ptc

Collin Harguindeguy, Laura, Economía solidaria: local y diversa, El Colegio de Tlaxcala, A. C., Tlaxcala, México. 2014

Corvalán C, Uauy R, Flores R, Kleinbaum D, Martorell R. Reductions in the energy content of meals served in the Chilean National Nursery School Council Program did not consistently decrease obesity among beneficiaries. Journal of Nutrition. 2008; 138 (11): 2237-43.

Diez-Canseco F, Saavedra-García L. Programas sociales y reducción de la obesidad en el Perú: reflexiones desde la investigación. 2017.Rev Peru Med Exp Salud Publica; 34(1):105-12. doi: 10.17843/rpmesp.2017.341.2772

ECLAC n.d. "Food Productive Programme (Programa Productivo Alimentario)". Economic Commission for Latin America and the Caribbean, Non-contributory Social Protection Programmes Database website.

https://dds.CEPAL.org/bpsnc/programme?id=76>. Accessed 23 January 2019.

FAO, 2008. Constitución de Ecuador. FAOLEX Data base. Right to Food. http://www.fao.org/faolex/results/details/en/c/LEXFAOC127389/ 
FAO, 2013a. "Las Cajas Urbanas: Una experiencia de financiación comunitaria liderada por mujeres". Cristina Rentería Garita, Karla Andino y Alberto Pantoja. Proyecto piloto para el fortalecimiento de la agricultura urbana y periurbana (APU) y de la seguridad alimentaria en el Distrito Central (Tegucigalpa, Comayagüela y alrededores), Honduras. FAO, Santiago, Chile, 2013, pp 4. http://www.fao.org/3/i3286s/i3286s.pdf

FAO. 2013b. Alimentación Escolar y las Posibilidades de Compra Directa de la Agricultura Familiar Estudio de Caso en ocho Países, Cooperación Brasil-FAO, Fortalecimiento de Programas de Alimentación Escolar en el Marco de la, Iniciativa América Latina y Caribe Sin Hambre 2025, Proyecto GCP/RLA/180/BRA, http://www.rlc.fao.org/es/programabrasilfao

FAO, IFAD, UNICEF, WFP and WHO. 2019. The State of Food Security and Nutrition in the World. Safeguarding against economic slowdowns and downturns. Rome, FAO. http://www.fao.org/3/ca5162en/ca5162en.pdf

FAO-OPS. 2018. Políticas y programas alimentarios para prevenir el Sobrepeso y la Obesidad. Lecciones aprendidas. Número de documento: OPS/NMH/17-040; 18156ES/1/01.18 http://www.fao.org/3/i8156es//8156ES.pdf

FAO, OPS, WFP y UNICEF. 2018. Panorama de la seguridad alimentaria y nutricional en América Latina y el Caribe 2018. Santiago. Número de páginas (133). Licencia: CC BY-NC-SA 3.0 IGO. FAO. PANORAMA.2018 pp. 11: http://www.fao.org/3/CA2127ES/CA2127ES.pdf

FAO - WFP. 2019. Fortaleciendo los Programas de Alimentación Escolar: El trabajo conjunto de FAO y WFP en América Latina y el Caribe. Ciudad de Panamá. 44 pp.

Fernald LC, Gertler PJ, Neufeld LM. Role of cash in conditional cash transfer programs for child health, growth, and development: an analysis of Mexico's Oportunidades. Lancet. 2008; 371(9615):828-37. doi:10.1016/S0140-6736(08) 60382-7

Garcés, Sandra y Emma Kirwan (2009) Las canastas comunitarias en Ecuador: una apuesta por la salud, la economía y la solidaridad. FLACSO- Ecuador.

Gobierno de Uruguay. 2019. Sabores Andantes. Encuentros de Cocina Núcleo Interdisciplinario "Alimentación y Bienestar" Espacio Interdisciplinario | Udelar Comisión Sectorial de Investigación Científica | Udelar Instituto Nacional de Alimentación | Mides: https://www.gub.uy/ministerio-desarrollo-social/comunicacion/publicaciones/sabores-andantes-encuentroscocina

Hidalgo, Francisco, Pierril Lacroix y Paola Román. 2013. Comercialización y soberanía alimentaria. Sistema de Investigación sobre la Problemática Agraria en el Ecuador - SIPAE, Quito, Ecuador

Hidrobo, Melisa, John Hoddinott, Amber Peterman, Amy Margolies, Vanessa Moreira, Cash, food, or vouchers? Evidence from a randomized experiment in northern Ecuador, Journal of Development Economics, Volume 107, 2014, Pages 144156, ISSN 0304-3878, https://doi.org/10.1016/j.jdeveco.2013.11.009.

Howe, Caitlin. Las Canastas Solidarias: Construyendo una comercialización directa con los productores. Primavera 2008. Pomona College. https://digitalcollections.sit.edu/cgi/viewcontent.cgi?article=1015\&context=isp collection

International Labour Organization - ILO. 2017. Cash transfer programmes, poverty reduction and women's economic empowerment: Experience from Mexico. Geneva.

Instituto Nacional de Estadística e Informática. INEI. 2015. Encuesta Nacional de Hogares 2014. Lima: Perú.

Kirwan, Emma. Building a rural-urban platform for Food Security. LEISA Magazine 24.3. September,2008. Quito. Ecuador.

Lara Guerrero, Jenny Mariela (2018) Propuesta de planificación estratégica para el Proyecto Canasta Solidaria del Gobierno Provincial de Pichincha Quito UISRAEL, Maestría en Administración Pública. Quito: Universidad Israel 2018, 99p. PhD. Diego José Donoso Vargas UISRAEL-EC-MASTER-ADMP-378-242-2018-003

Leroy, Jef L.; Olney, Deanna K.; and Ruel, Marie T. 2019. PROCOMIDA, a food-assisted maternal and child health and nutrition program, contributes to postpartum weight retention in Guatemala: A cluster-randomized controlled intervention trial. Journal of Nutrition 149(12): 2219-2227. https://doi.org/10.1093/jn/nxz175

Levy, S. y E. Rodríguez (2005), Sin herencia de pobreza. El programa Progresa-Oportunidades de México, Planeta - Banco Interamericano de Desarrollo (BID), Editorial Planeta, México DF. 
Medellín, Nadim y Fernando Sánchez Prada. How does Más Familias en Acción work?: best practices in the implementation of conditional cash transfer programs in Latin America and the Caribbean. Nov. 2015. (IDB Tecnical Note; 884)

Ministerio de Agricultura Familiar y Comunitaria. Nicaragua. 2017. Bono Productivo Alimentario: https://www.economiafamiliar.gob.ni/bono-productivo-alimentario/

Ministerio Secretaria General de Gobierno, Chile. Nueva Agenda Social. Programa Elige Vivir Sano;https://msgg.gob.cl/wp/2018/05/09/conoce-en-que-consiste-el-nuevo-sistema-elige-vivir-sano/

OPS/OMS Indicadores Básicos. Situación de la Salud en las Américas. 2018. http://iris.paho.org/xmlui/bitstream/handle/123456789/49511/IndicadoresBasicos2018 spa.pdf?sequence=2\&isAllowed $=y \& u a=1$

OPS. Organización Panamericana de la Salud. Nutrition and an active life: from knowledge to action. Freire WB. Editor. Washington, D.C.: OPS; 2005.

Programa Mundial de la Alimentación. PMA. 2014. Manual sobre transferencias de efectivo y cupones. SEGUNDA EDICIÓN. Roma. Italia. https://docs.wfp.org/api/documents/WFP-0000015440/download/

PROSPERA.2016. Reglas de Operación de PROSPERA Programa de Inclusión Social, para el ejercicio fiscal 2017. http://www.gob.mx/cms/uploads/attachment/file/177672/Reglas de Operaci n 2017.pdf

Rodríguez Aguilar, Laura. 2017. "Análisis relacional de la economía solidaria con los derechos humanos para la transformación social. Experiencia Canastas Solidarias". Tesis de Grado, Universidad Autónoma de San Luis Potosí, SLP, México

Salazar, Angulo; Carlos Roberto, Yadira Díaz Cuervo, and Renata Pardo Pinzón. 2011. Índice de Pobreza Multidimensional para Colombia (IPM-Colombia) 1997-2010. 382. Archivos de Economía. Bogotá, Colombia

Stampini, Marco \& Leopoldo Tornarolli, 2012. The Growth of Conditional Cash Transfers in Latin America and the Caribbean: Did They Go Too Far? Inter-American Development Bank

Social Protection. Programa Productivo Alimentario, Nicaragua. Social Protection.org. https://www.socialprotection.org/discover/programmes/programa-productivo-alimentario-food-productive-programme

Teruel, Graciela, Erika Arenas y Karla Renata Flores. Coordinación Nacional de PROSPERA. Programa de Inclusión Social y la Universidad Iberoamericana, A.C. México. 2014. www.gob.mx/PROSPERA

UNSCN. 2017. Schools as a System to Improve Nutrition. https://www.unscn.org/uploads/web/news/document/School-PaperEN-WEB.pdf

Vásquez Russi, Catalina María y Mónica, Uribe Gómez. Los estudios sobre los programas de transferencias monetarias condicionadas en América Latina: trayectorias, enfoques y perspectivas sobre la pobreza (June 18, 2019). OPERA No. 25, Julio-Diciembre, 2019. Accesible SSRN: https://ssrn.com/abstract=3406091

WFP. Nutrir el Futuro: Programas de Alimentación Escolar Sensibles a la Nutrición en América Latina y el Caribe Un Estudio de 16 Países. (2017) pp.10

The Word Bank. Andy Chi Tembon, Linda Brooke Schultz, Erick Fernandez. Alimentación escolar: Una herramienta para la inclusión social. Octubre 2015. https://blogs.worldbank.org/es/education/alimentaci-n-escolar-una-herramienta-para-lainclusi-n-social

Yuriko Takahashi, 2017. "Varieties of Conditional Cash Transfers in Latin America," Working Papers 1619, Waseda University, Faculty of Political Science and Economics. Tokyo, Japan.

\section{SOBRE LA AUTORA}

Patricia Biermayr-Jenzano es una científica social, especialista en estudios de género y seguridad alimentaria. Tiene un Doctorado en Agricultura y Antropología Social, un Máster (MS) en Extensión Agrícola de la Universidad de Cornell en Nueva York y un título de Ingeniería Agrónoma de Buenos Aires, 
Argentina. Su trabajo tiene profundas raíces en la investigación participativa, además de incorporar la perspectiva de género en la agricultura y los esfuerzos para la conservación del ambiente. Se ha desempeñado como líder del programa de Género en el Centro Internacional de Agricultura Tropical (CIAT) en Cali, Colombia y como consultora del Banco Mundial, la organización de las Naciones Unidas para la Agricultura (FAO), el Fondo de Inversiones para el Desarrollo Agrícola (FIDA), el Centro Internacional de Investigaciones para el Desarrollo (IDRC) y el Instituto Internacional de Políticas de la Alimentación (IFPRI). Actualmente es profesora adjunta del Programa de Estudios de Género y Mujer y del Centro de Estudios Latinoamericanos de la Universidad de Georgetown en Washington DC.

\section{AGRADECIMIENTOS}

Este documento es parte de un proyecto sobre sistemas alimentarios y obesidad, realizado en colaboración con FAO-LAC. El documento se enriqueció con los comentarios de Eugenio Díaz-Bonilla y Florencia Paz (IFPRI), Ricardo Rapallo (FAO); Maria Eugenia Herrera Vegas (Fundación Alimentaris) y Virginia Biermayr (Hospital General de Niños Dr. Ricardo Gutiérrez), Buenos Aires, Argentina y Grace Valdevitt (Universidad de Georgetown). Este artículo refleja la opinión del autor y no del IFPRI o de las instituciones mencionadas.

Este documento de trabajo es parte de un proyecto más amplio sobre sistemas alimentarios y obesidad, en colaboración y financiamiento de FAO-LAC. No ha sido revisado por pares de forma independiente.

\section{INTERNATIONAL FOOD POLICY RESEARCH INSTITUTE}

